This item was submitted to Loughborough's Research Repository by the author.

Items in Figshare are protected by copyright, with all rights reserved, unless otherwise indicated.

\title{
A review of the behavioural change challenges facing a proposed solar and battery electric cooking concept
}

PLEASE CITE THE PUBLISHED VERSION

http://dx.doi.org/10.12774/eod_cr.browneetal

\section{PUBLISHER}

Climate, Environment, Infrastructure and Livelihoods Professional Evidence and Applied Knowledge Services (CEIL PEAKS) programme, jointly managed by DAI (which incorporates HTSPE Limited) and IMC Worldwide Limited. (C) Crown copyright

\section{VERSION}

VoR (Version of Record)

\section{LICENCE}

CC BY-NC-ND 4.0

\section{REPOSITORY RECORD}

Brown, Edward D., and Jon Sumanik-Leary. 2019. "A Review of the Behavioural Change Challenges Facing a Proposed Solar and Battery Electric Cooking Concept". figshare. https://hdl.handle.net/2134/20915. 
This report has been produced by Loughborough University Department of Geography for Evidence on Demand with the assistance of the UK Department for International Development (DFID) contracted through the Climate, Environment, Infrastructure and Livelihoods Professional Evidence and Applied Knowledge Services (CEIL PEAKS) programme, jointly managed by DAI (which incorporates HTSPE Limited) and IMC Worldwide Limited.

The views expressed in the report are entirely those of the author and do not necessarily represent DFID's own views or policies, or those of Evidence on Demand. Comments and discussion on items related to content and opinion should be addressed to the author, via enquiries@evidenceondemand.org

Your feedback helps us ensure the quality and usefulness of all knowledge products. Please email enquiries@evidenceondemand.org and let us know whether or not you have found this material useful; in what ways it has helped build your knowledge base and informed your work; or how it could be improved.

DOI:http://dx.doi.org/10.12774/eod_cr.browneetal 


\section{Contents}

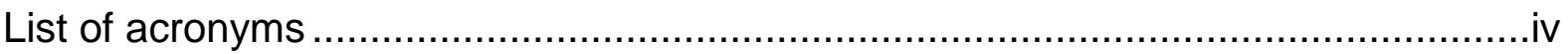

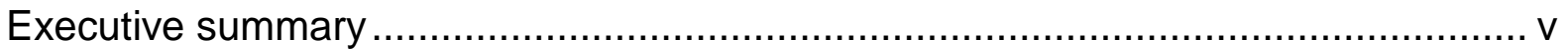

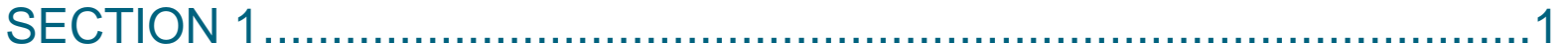

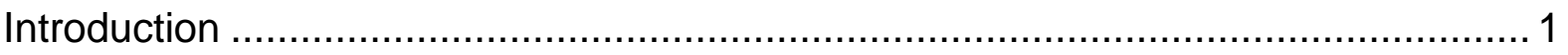

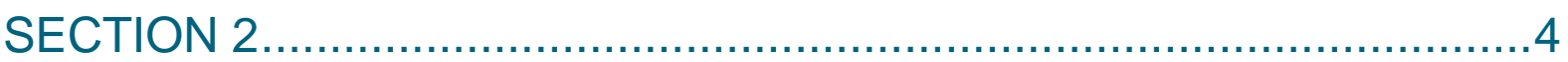

Household transitions to cleaner cooking and electricity ................................ 4

2.1 Clean cooking transitions................................................ 4

2.1.1 Electric cooking in South Africa....................................... 4

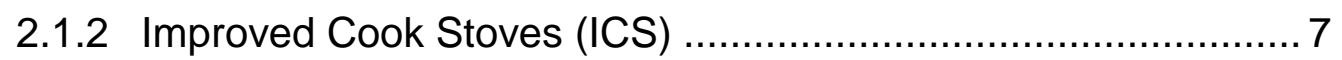

2.1 .3 Conclusion ............................................................. 11

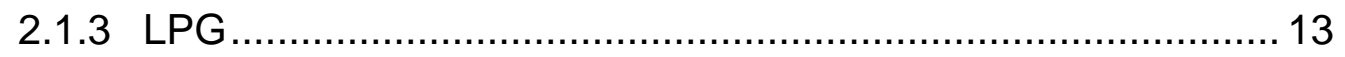

2.1 .4 Conclusion ......................................................... 15

2.2 The transition to Solar Home Systems (SHS) for lighting \& other low power applications .............................................................. 15

2.2.1 The importance of locally applicable solutions .................... 16

2.2.2 Financial models ........................................................ 17

2.2 .3 Perception of SHS.................................................... 18

2.2 .4 Adaptability ........................................................... 19

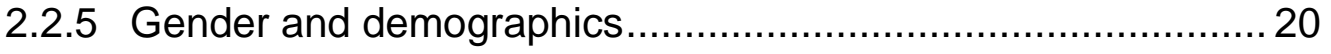

2.2.6 Consumer awareness .............................................. 21

2.2.7 Maintenance ........................................................ 21

2.2 .8 Conclusion ............................................................. 22

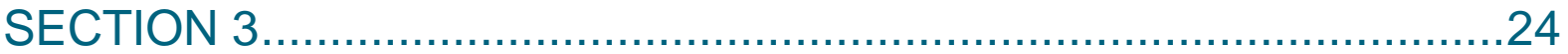

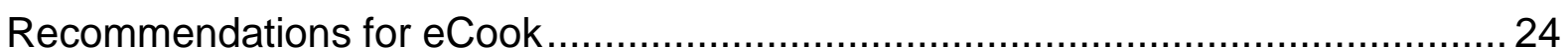

3.1 Market segmentation according to the key factors affecting household

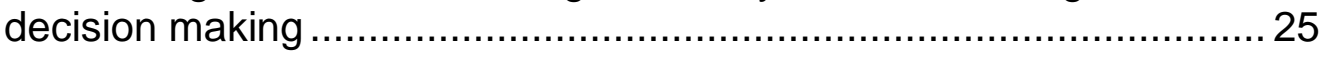

3.1.1 Comparison of eCook with other clean cooking interventions.. 25

3.1.2 Existing access to energy and socio-economic status ............ 28

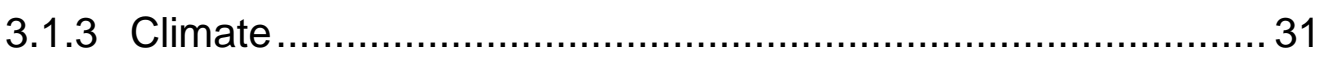

3.1.4 Local cooking practices.......................................... 31

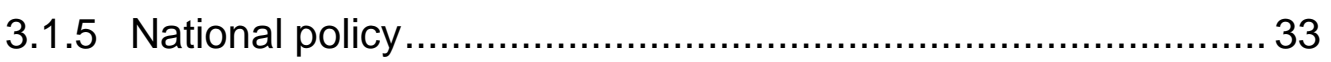

3.1.6 Electricity generating infrastructure ................................ 34

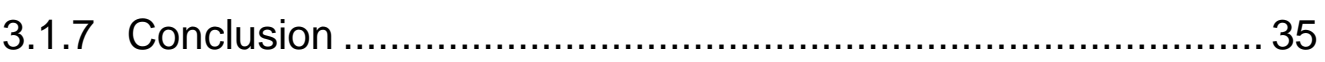




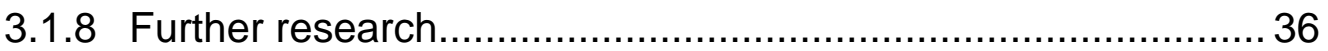

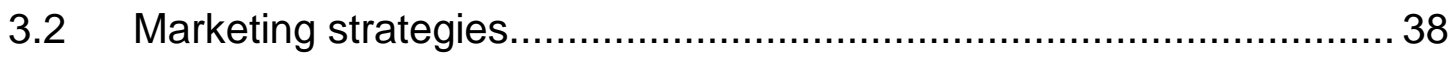

3.2.1 Innovative financing mechanisms ………….............................. 38

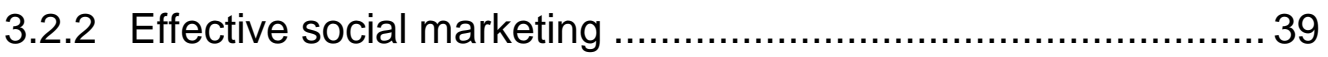

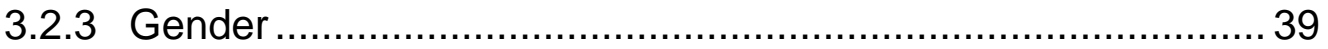

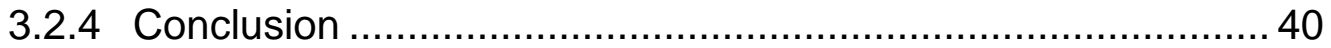

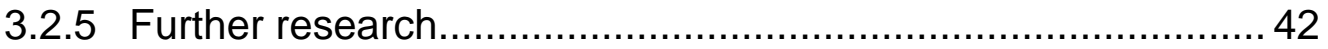

3.3 User-focussed system design .................................................... 42

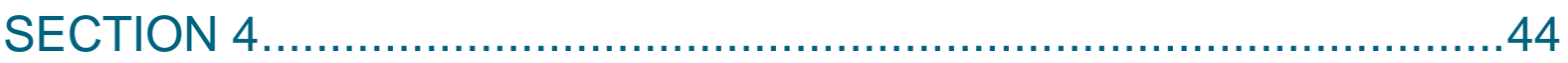

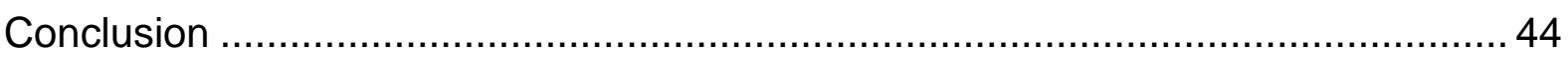

4.1 Where is this transition likely to take place first? ................................ 44

4.2 How can this transition be supported? ................................................. 44

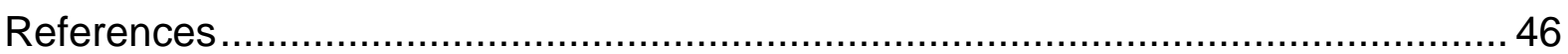

\section{List of Figures}

Figure 1 Main fuel used by households for cooking (IEA 2014) ............................................. 4

Figure 2 Residential electricity tariffs in selected African countries 2014, in USD cents per

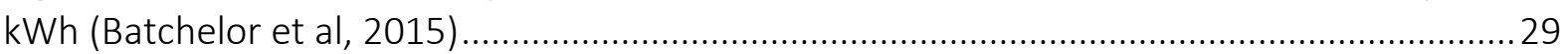

Figure 3 Estimated energy requirements for traditional dishes from a range of African countries (Batchelor, 2015b) .................................................................................... 32

Figure 4 Main energy source used for cooking, by living standard level and quintiles of per capita monthly income (percent using) (Republic of South Africa, 2012)

\section{List of Tables}

Table 1 Key barriers preventing the transition to electric cooking in South Africa and (where applicable) the enablers that overcame them ………………..............................................

Table 2 The key drivers for the transition to electric cooking in South Africa............................ 7

Table 3 Key barriers preventing the transition to ICS in the Global South and (where applicable) the enablers that overcame them. ……………………................................... 13

Table 4 The key drivers for the transition to ICS in the Global South......................................13

Table 5 Key barriers preventing the transition to LPG in the Global South and (where

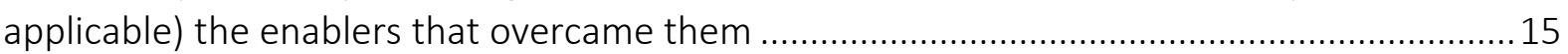

Table 6 The key drivers for the transition to LPG in the Global South....................................15

Table 7 Key barriers preventing the transition to SHS in the Global South and (where

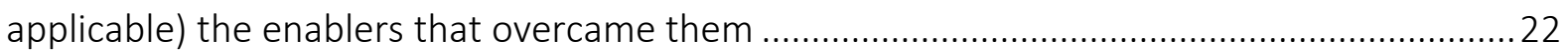

Table 8 The key drivers for the transition to SHS in the Global South .....................................23 Table 9 Comparison of the key factors affecting the initial adoption of the eCook concept with the most common clean cooking interventions...................................................................26 Table 10 Comparison of the additional key factors affecting the sustained use of the eCook concept with the most common clean cooking interventions 
Table 11 Comparison of the benefits of the sustained use of the eCook concept with the most

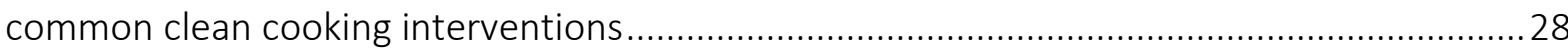

Table 12 Categorisation of potential eCook adopters according to existing levels of energy

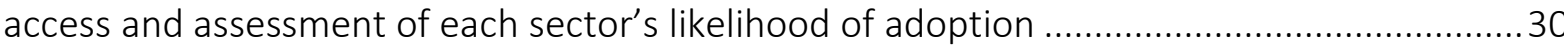
Table 13 Effect of power and energy requirements for preparing local foods on the viability of the eCook concept

Table 14 Classification of different power generation grids according to their compatibility with the eCook concept.

Table 15 Key market segmentation recommendations for eCook ............................................36

Table 16 Key marketing strategy recommendations for eCook ................................................. 41

Table 17 Key recommendations for the eCook concept relating to user-focused design ........43

Table 18 Electricity access and population relying on traditional biomass in sub-Saharan Africa in 2012 (Hancock, 2015).

Table 19 Main energy source used for cooking by electrification status (cell percent, multiple response table) (Republic of South Africa, 2012)

Table 20 Main energy source used for cooking, by socioeconomic characteristics (cell percent, multiple response table) (Republic of South Africa, 2012)

Table 21 Energy Choice for cooking, by electrification status and living standard (column percent) (Republic of South Africa, 2012)

Table 22 Measured energy costs for four different meal types and four different fuels (Cowan 2008)

\section{List of Appendices}

Appendix A Electricity access and population relying on traditional biomass in sub-Saharan Africa 51

Appendix B Statistics from South African electric cooking transition

Appendix C Cooking energy cost comparison for a range of typical South African meals using a

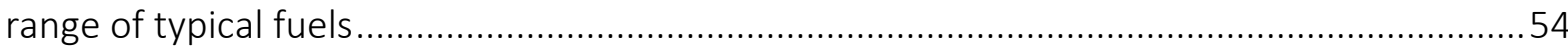

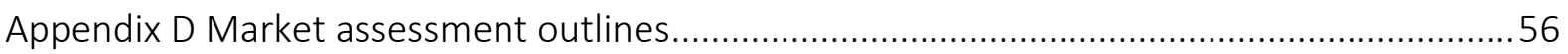

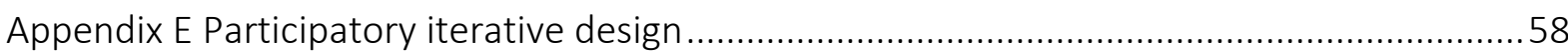




\section{List of acronyms}

$\begin{array}{ll}\text { DECC } & \text { UK Department of Energy and Climate Change } \\ \text { DFID } & \text { UK Department for International Development } \\ \text { EPSRC } & \text { UK Engineering and Physical Sciences Research Council } \\ \text { FBE } & \text { The South African government's Free Basic Electricity programme } \\ \text { GACC } & \text { Global Alliance for Clean Cookstoves } \\ \text { GIRA } & \text { Grupo Interdisciplinario de technologia Rural Apropiada (Mexico) } \\ \text { ICS } & \text { Improved CookStove } \\ \text { ISO } & \text { International Organisation for Standardisation } \\ \text { KCJ } & \text { Kenyan Ceramic Jiko } \\ \text { LCA } & \text { Life Cycle Assessment } \\ \text { LPG } & \text { Liquid Petroleum Gas } \\ \text { PNG } & \text { Papua New Guinea } \\ \text { SE4All } & \text { The UN's Sustainable Energy for All initiative } \\ \text { SHS } & \text { Solar Home System } \\ \text { SSA } & \text { Sub-Saharan Africa } \\ \text { WHO } & \text { World Health Organisation }\end{array}$




\section{Executive summary}

This paper evaluates the behaviour change aspects likely to affect the uptake of a proposed electric cooking concept (Batchelor 2015a), which consists of a simple battery and 500W electric hob. The battery storage enables households with unreliable electricity supplies to cook at a time that is convenient to them. The concept has initially been proposed in two forms:

a) packaged with solar PV panels in a similar format to the popular Solar Home Systems (SHS) and referred to here as PV-eCook; and

b) packaged with a battery charger for grid or mini-/micro-/nano-grid connections, referred to in this document as B-eCook.

This work has been commissioned by the UK Department for International Development (DfID) alongside two further studies, which are being undertaken in parallel, addressing specific aspects of the technical and economic feasibility of the eCook concept. As a result, although the technical, social and economic dimensions are clearly intertwined, this study is conducted on the assumption that the eCook concept will be both technically and economically feasible and instead focuses on the social/behavioural implications that need to be considered in its development by specifically addressing the following two research questions posed by DfID:

1. "What are the possible intra and inter household dynamics among African households (including the very poor) that may affect the uptake of [the proposed eCook concept]?"

2. "What are the behavioural change challenges that should be understood and investigated through longer term research that may affect the outworking of the concept?"

Our specific focus in the paper is on the potential uptake of the eCook concept within the Sub-Saharan African (SSA) context, although where appropriate we draw upon relevant examples from other parts of the Global South (and beyond) and also make some commentary upon the potential prospects for electric cooking within these contexts. The paper is organised into two main sections. The first comprises a literature review focusing on a range of related energy transitions, with the aim of drawing out the key lessons learned and highlighting their relevance to the assumptions underlying the proposed eCook concept. We have focused this discussion on four specific transitions chosen for their particular relevance to eCook within the SSA context. These comprise:

a) Experiences with electric cooking in South Africa, the only SSA country which has had considerable take-up of electric cooking to date.

b) Ongoing attempts to accelerate the uptake of improved cookstoves.

c) The take-up and promotion of LPG as a cleaner alternative to traditional biomass stoves, which is comparable to electric cooking from an end-user perspective.

d) The spread of Solar Home Systems (SHS) that has taken root to differing degrees across the Global South. This is of particular relevance, as the PV-eCook concept is fundamentally a higher capacity SHS designed to replace solid fuel burning for cooking instead of kerosene/candles for lighting.

The second section draws on the review of experiences presented in the first section to make recommendations for how the eCook concept might be taken forward in ways that make transition more likely. This section is divided into three sub-sections. 

identify those market segments that appear most likely to embrace the proposed eCook concept. It begins by comparing eCook to other clean cooking technologies, before exploring how it might relate to existing energy access dynamics and socioeconomic status, variations in climatic conditions, differing national policy contexts, local cooking practices and other key factors.

b) A discussion of alternative marketing strategies for eCook, which explores questions of intra-household dynamics, community engagement, participation and household decision-making processes.

c) Consideration of how taking a user-focussed, locally-framed approach to the design of the eCook concept could increase its uptake.

Clearly, given time and resource constraints, all that we have been able to do in conducting this study is to scratch the surface of the major behavioural change challenges that may affect the outworking of the eCook concept. At the end of each of the three sub-sections outlined above, we therefore outline some of the knowledge gaps that could be addressed by further programmes of detailed research.

\section{Main Findings:}

The eCook concept offers significant potential for a transition towards emission free cooking, with time/money saving for adopters and broader environmental benefits from reductions in fuelwood collection/purchase of charcoal/wood. The high upfront cost is predicted to be the most significant barrier that will affect household uptake, however recent developments in micro-loans and fee-for-service business models (particularly when combined with mobile phones) have the potential to overcome this. In contrast to other technologies such as solar cookers, where the adaptation of cooking practices has been a substantial barrier, the behaviour change required to use an electric hob is relatively minimal.

\section{Where is this transition likely to take place first?}

Uptake of the eCook concept is predicted to be most rapid in hot climates, where there is no need for heating from a traditional stove; contexts where fuelwood/charcoal is purchased and prices are increasing most rapidly; cultures where low energy diets (fewer meals that require lower thermal input during the cooking process per meal) and low power cooking devices are the standard; and in higher income, better educated, younger households.

The transition to PV-eCook is expected to take place first in rural areas without potential for grid connection in the short- or medium-term, where SHS programmes have already reached scale in a sustainable manner, developing locally appropriate delivery models and paving the way for PV-eCook. Naturally, places with high solar resource throughout the year are seen as especially favourable and relatively higher income rural households in remote areas, some distance from the grid are expected to be the early adopters. B-eCook is expected to spread most rapidly in urban settlements with unreliable grid or mini-grid connections in countries with a low unit cost for electricity and would find favourable political support in countries where load balancing would be beneficial to national grid infrastructure. $\mathrm{B}$-eCook is potentially a synergistic precursor to PV-eCook, as the urban market could be used to set up local service networks and create awareness before reaching out to the harder rural markets. Of course, the relative price points of other cooking fuels are also a critical factor, which vary both geographically and temporally.

Countries with strong policy support for electrification (and/or SHS for PV-eCook) are likely to provide more favourable enabling environments for eCook initiatives and the value that load balancing (and if appropriate, also peak load reduction) can offer to the national electricity generation network is expected to be crucial for obtaining high level support for the concept. 
How can this transition be supported?

To ensure that appropriate after-sales service is available and feedback is collected from end users and delivered to relevant stakeholders, a suitable service network should already be in place when eCook is launched. Ideally this should be achieved by adapting existing networks, e.g. by strengthening the existing SHS infrastructure in rural areas to accommodate PV-eCook. In many contexts, training programmes may be most effective if focussed on women, as they are likely to be the primary beneficiaries and will therefore have the greatest motivation to see the technology succeed. Bundling eCook with locally appropriate appliances can maximise the value of the embedded electrical infrastructure offered to households. This is particularly important in cultural contexts where men make major household decisions, as it can offer an incentive both to purchase and keep up with repayments. Productive appliances that match with the availability of the solar resource such as irrigation pumps are particularly appropriate for PV-eCook uptake in rural areas where few opportunities for paid work exist that could take advantage of the time saved on food preparation and/or fuel collection. Due to the high value of the eCook equipment (and therefore longer investment horizon for poor households), a utility business model is seen as the most attractive for poor households, as the utility would take on the financial risk of owning the system.

Awareness raising campaigns on the benefits of clean cooking that are tailored to the local market (matching messages to context-specific purchasing triggers/barriers, brand awareness of locally available high quality and affordable products, credible partners and cost-effective campaign delivery mechanisms) should pave the way for eCook in new places by beginning with a surge of social marketing activities. However, in order to ensure maximum impact throughout society, longer term awareness raising campaigns should be targeted at older, less well educated and poorer households who are less likely to be amongst early adopters. Finally, in order to overcome the potential perception of PV as an inferior technology that communities can be 'locked-in' to, PV-eCook should be designed to enable quick and easy conversion to B-eCook if/when the grid arrives.

\section{What further research needs conducting?}

In order to better understand the behavioural change challenges that may affect the outworking of the concept, the following longer term research is proposed. A global market assessment to identify actual places that most closely resemble the ideal context described above should be undertaken. In each of the places identified with high potential, a more detailed local market assessment can determine in what form eCook should be delivered in order to achieve maximum impact for the poorest members of society. If the results of the local market assessment are favourable, a participatory process should ensue, whereby local people can determine how eCook can best evolve to meet their needs, engaging local leaders, particularly women, as champions. The potential for local manufacture should be given thorough consideration in each place, as supply chains, manufacturing capacities and enabling policies vary greatly.

There is no substitute for empirical data and as a result, field trials in locations identified above are the logical next step. eCook should be trialled in a significant number of households, collecting valuable data on actual energy consumption, consumer satisfaction and suggestions for further design modifications to both the generic and local variant of the concept. The dynamics of fuel stacking should be given particular attention, as understanding the degree to which any eCook device is able to replace pre-existing stoves will determine to what degree the benefits can be obtained.

Thinking more broadly, developing strong relationships with the Global Alliance for Clean Cookstoves (GACC), the World Health Organisation (WHO) and other international organisations concerned with clean cooking, as well as local stakeholders in each new 
context, will also be important. Finally, investigating the dynamics of the $2 \%$ of South Africans already reportedly cooking on solar electric systems (e.g. system design, target market segments, end-user feedback, drivers of uptake) could provide valuable further learning opportunities for eCook. 


\section{SECTION 1 \\ Introduction}

This paper seeks to evaluate the behaviour change challenges and opportunities associated with the uptake and utilization of a proposed electric cooking concept (hereafter referred to as eCook). The original concept (Batchelor, 2013) suggested that, due to reductions of price in both solar PV systems and batteries, stand-alone household solar systems for cooking (based around a 500W hob and a battery) could begin substituting charcoal and wood for cooking across Africa by 2020. It argued that by that date the lifetime cost of such a system would be economically viable with monthly payments estimated at around $\$ 10$ a month - a level of expenditure that is already being reached on charcoal and wood costs by 1.6 billion people across the continent. More recently, the concept has been expanded to suggest that "a large proportion of current biomass users who are already connected to a grid could (also) transition towards electric cooking" (Batchelor 2015a:1).

The reasons why few grid-connected households currently use electricity for cooking relate to the perceived cost, difficulties of using unreliable and unstable grid electricity and fears over accentuating the over-loading of already stretched systems at peak times when most people want to cook (Howells et al. 2006). The solution offered by the eCook concept is the trickle-charging of a battery during off-peak hours which means that cooking can take place at peak times without accentuating pressure on overloaded systems and through which problems of unstable and inadequate supply can also be assuaged.

We refer to the original solar electric cooking concept as PV-eCook and the grid-based trickle-charging battery electric cooking concept as B-eCook; in what follows we explore the behavioural challenges associated with the take-up of both concepts.

This work has been commissioned by the UK Department for International Development (DfID) in order to:

a) validate the behaviour change aspect of the work conducted to date on the eCook concept by Dr Batchelor and Dr Scott of Gamos Ltd ${ }^{1}$; and

b) further explore the behavioural change challenges that are likely to affect the uptake of the eCook concept.

Two further studies are being undertaken in parallel, addressing specific aspects of the technical and economic feasibility of the eCook concept. As a result, although the technical, social and economic dimensions are clearly intertwined, this study is conducted on the assumption that the eCook concept will be both technically and economically feasible (although it is also intended that it will provide learning that might be of utility in improving the technical design and economic potential of the initiative) and instead focuses on the social/behavioural aspect by specifically addressing the following two research questions posed by DfID:

$1 \quad$ Batchelor 2013; Batchelor 2015b; Batchelor 2015a; Batchelor \& Scott 2013; Batchelor 2014; Gamos 2015 
1. "What are the possible intra and inter household dynamics among African households (including the very poor) that may affect the uptake of [the proposed eCook concept]?"

2. "What are the behavioural change challenges that should be understood and investigated through longer term research that may affect the outworking of the concept?"

The "intra and inter household dynamics" mentioned in the first research question have been interpreted as follows:

- $\quad$ "intra" = differences within households, where we have placed particular but not exclusive emphasis upon gender based differences.

- $\quad$ "inter" = differences between households at a range scales, such as inter-community, inter-regional and international. For example, income levels, the rural/urban divide, power relationships within a community etc.

Our focus in the paper is on the potential uptake of the eCook concept within the SubSaharan African context, although where appropriate we draw upon relevant examples from other parts of the Global South (and beyond) and also make some commentary upon the potential prospects for electric cooking within these contexts. The decision to focus on the African context reflects the emphasis suggested from the first research question but also because it is where we believe both the challenges and the potential benefits are likely to be greatest.

Over recent years the international community has gradually begun to recognise the importance of addressing the tremendously limited access to modern energy services amongst large swathes of the global population. Nowhere is this more evident than in the case of Sub-Saharan Africa (SSA). Overall, biomass continues to constitute more than $80 \%$ of overall energy demand in SSA and most rural Africans continue to utilise three stone fires or traditional cookstoves for their cooking and heating (Hancock 2015) - see Appendix A for a breakdown of biomass dependence for individual SSA states. This indicates that levels fluctuate from less than 40\% dependence on biomass in countries like Botswana, Cape Verde, Gabon and South Africa to over 95\% in nations such as Mozambique, Rwanda, Niger, Sierra Leone, Tanzania, Uganda and Burundi. These differences indicate the influence of such factors as: different levels of urbanization, the level of development of infrastructures supplying alternative fuels and cooking technologies and a range of other nationally specific contextual factors.

A burgeoning literature (reviewed by The World Bank, 2015) details the significant human costs that high levels of dependence upon traditional cooking methods bring for households across the continent. These include the enormous health toll of the smoke from cooking fires (as well as the impacts of burns and firewood collection on health), the economic costs of high fuel expenditure and the time lost in gathering fuel, as well as the environmental implications of GreenHouse Gas (GHG) emissions, forest degradation and deforestation from unsustainable practices. The international community has not been inactive in the face of these challenges and over the past decades there have been a succession of interventions and initiatives which have sought to promote the uptake of improved cookstoves and modern cooking fuels. Nevertheless, by 2015 the uptake of clean cooking solutions (transition to all modern fuels (except kerosene), renewable fuels or improved efficiency biomass cookstoves) remains as low as 10\% in Sub-Saharan Africa (compared with $27 \%$ in South Asia, 41\% in Southeast Asia, 51\% in East Asia and 80\% in Latin America: World Bank, 2015).

At the same time, however, the challenges facing the development of electric cooking solutions are also particularly evident in the SSA context. It remains the region of the world 
where electrification rates are lowest, as demonstrated in Appendix A, which indicates that electrification rates for SSA remained at 32\% overall in 2012 (levels were 59\% for urban areas and as low as $16 \%$ for rural areas). National rates range from nearly $100 \%$ in Mauritius and Cape Verde, $85 \%$ in South Africa and $72 \%$ in Ghana to levels as low as $20 \%$ in Kenya, $16 \%$ in Burkina Faso, 14\% in Niger, 9\% in both Malawi and the Democratic Republic of Congo and 4\% in Chad (Hancock, 2015). Over the past few years, however, the Sustainable Energy for All (SE4All) initiative finally appears to be giving some momentum to grid extension initiatives (such as the recently announced last half mile scheme in Kenya) and there is considerable international interest in the potential for green solar mini-grids (IED 2012) to deliver significant progress in off-grid electrification. At the same time, there have also been some substantial successes with the uptake of small-scale household solar technologies (from solar lanterns to solar home systems of different capacities) in specific national contexts (Bhattacharyya 2012).

In the next section, a literature review focusing on related energy transitions is presented, with the aim of drawing out the key lessons learned and highlighting their relevance to the assumptions underlying the proposed eCook concept. Given the limited budget and time available, we have focused this discussion on four key transitions chosen for their relevance to the eCook concept within the SSA context. First, we explore the experiences with electric cooking in South Africa. Second, we consider the lessons to be learnt from attempts to accelerate the uptake of improved cookstoves. Third, we explore existing transitions to LPG for cooking and then finally we consider the lessons from the differential spread of solar home systems within different national contexts.

Following this, recommendations for eCook are drawn out from the literature under three broad themes:

1. Market segmentation - a very high level market analysis is conducted using the findings from the literature review with the goal of identifying the market segments who are most likely to embrace the transition to the proposed eCook concept.

2. Marketing strategies - recommendations for facilitating uptake in the target market segments identified above.

3. User-focussed system design - how the technical design of the eCook system could be modified to improve uptake.

At the end of each of these three sections, recommendations are made for longer-term research that would enable a deeper understanding of both the generic and place specific challenges that will affect the uptake of the eCook concept. 


\section{SECTION 2 \\ Household transitions to cleaner cooking and electricity}

As explained above, this first major section of the paper reviews historical experiences from a range of energy transitions, with the intention of drawing out relevant lessons and experiences in order to determine where the eCook concept is most likely to be adopted and how this process can be best facilitated. For each transition, the key barriers and drivers, together with the most important enablers that the literature suggest have recently accelerated that transition are discussed in the context of the proposed eCook concept.

\subsection{Clean cooking transitions}

\subsubsection{Electric cooking in South Africa}

South Africa is one of the few places in Africa where a significant number of people already cook using electricity (see Figure 1, for other studies see Beute 2012; Dinkelman 2011; Howells et al. 2006; Republic of South Africa 2012). There are a few other instances where there is evidence of smaller-scale transitions to electric cooking across the continent but none have been anywhere near as widespread as the South African example (for example, see Alem et al. (2013) on attempts to promote the electric Mitad stove for preparing injera in Ethiopia). Whilst the South African transition has been achieved without the use of a household battery (in contrast to the eCook concept), studying this transition provides useful insight into the factors that may affect the uptake of eCook, especially cultural aspects that are specific to SSA (although there is of course a huge amount of cultural diversity across the region so any comparisons must be made with care).

Figure 1 Main fuel used by households for cooking (IEA 2014)

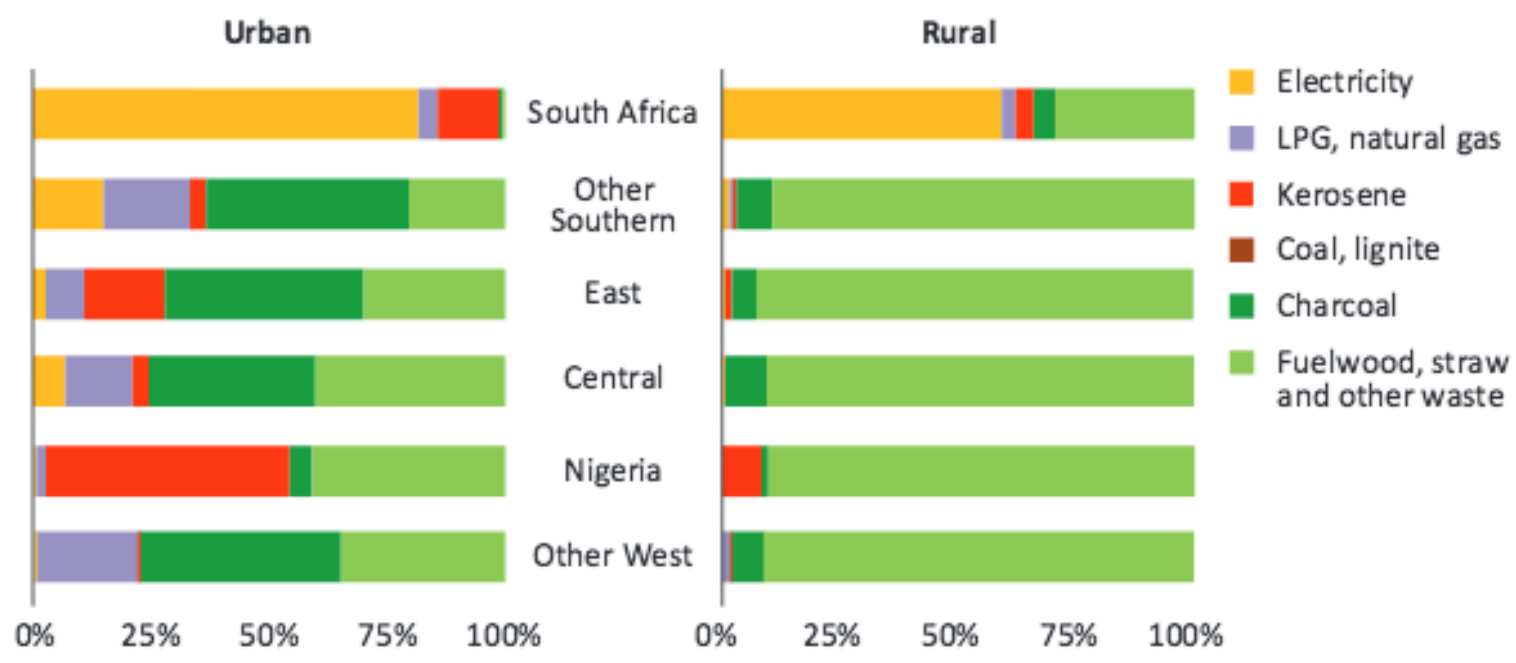

The precursor for electric cooking without a household battery is of course, a reliable grid connection. South African energy policy has focussed heavily on the expansion of electricity access in recent years (Bekker et al. 2008; Beute 2012), meaning that although just one 
third of the population had access to electricity before 1990 (Bekker et al. 2008), this figure has now grown substantially to above $80 \%$ (Republic of South Africa 2012). This has involved both bringing electricity to areas formerly unconnected to the grid but also bringing access to urban communities previously unserved even though the grid passed nearby. The use of paraffin/kerosene stoves is particularly problematic in urban settings, as if knocked over, they can cause a rapidly spreading fire that can quickly engulf a house before moving onto nearby buildings. In order to incentivise transition away from paraffin and other hazardous fuels commonly used for lighting and cooking amongst the poor, the government launched the Free Basic Electricity (FBE) policy in 2003, which entitled poorer households to $50 \mathrm{kWh}$ per month free of charge (Lemaire 2011; Bekker et al. 2008). Although this has been one factor encouraging the transition to electric cooking described above (Bekker et al. 2008), electric cooking is in reality more prominent amongst higher income level households (Republic of South Africa 2012).

In 2012, Republic of South Africa (2012) carried out an energy survey of 3000 households, stratified to represent the diversity within South African society (i.e. reflecting such factors as: urban/rural, informal/formal housing, high/low income, high/low level of education and a range of ethnicities). $84 \%$ of respondents stated that they had an electricity connection and $76 \%$ indicated that they used electricity as their main source of energy for cooking, which would imply a total of around 40 million households throughout South Africa. Plunging deeper into the dataset (see Appendix B) offers the ability to discover how far this transition has reached through different social sectors. The survey shows that households with a low standard of living are most likely to rely on firewood (44\%) or paraffin (31\%) as their main cooking energy source, whilst for medium/high living standards, it is overwhelmingly electricity ( $77 \%$ and $93 \%$ respectively). Again, correlated with income level, there is a steady increase in electric cooking from 55\% amongst the poorest quintile up to $90 \%$ for the richest. Republic of South Africa (2012:25) state that even the electrified low income households are more likely to rely on firewood than electricity, which "suggests the existence of barriers or practices amongst poorer households that inhibit a fuller transition." Sebitosi \& Pillay (2005), Bekker et al. (2008) and Cowan (2008) all suggest that cultural resistance to change and the perceived high cost of electricity play a significant part.

Interestingly, Howells et al. (2006) criticised the FBE's focus on electricity as a replacement for basic cooking fuels, on the grounds that demand for electricity for cooking was likely to be highest in the evening, when electricity demand for other applications was also highest. They suggested that this was likely to put additional strain on South Africa's already overloaded power grid and instead advocated for exchangeable credits that could be used to purchase LPG for cooking. Whilst such concerns bear the imprint of the generation crises which hit South Africa over the course of the late 2000s, it is true to say that South Africa's coal-driven grid electricity system remains precarious despite the introduction of additional capacity, although the potential implications of accelerated transitions to electric cooking would appear to be relatively low on policy makers' agendas in terms of the major challenges facing South Africa's grid in the years to come (Krupa \& Burch 2011; Baker et al. 2014).

As would be expected, due to its greater abundance and the lower rates of electrification in rural areas, the use of firewood for cooking is much greater in rural areas (36\% in rural traditional authority areas and $18 \%$ on farms). Paraffin is most widely used in informal urban settlements (27\%), whilst a few households use LPG or coal. Interestingly, 1\% of informal urban households cook using electricity from a generator and $2 \%$ reportedly cook on a solarpowered electric system, i.e. PV-eCook.

The survey showed that around half of all South African households rely on just a single energy source for cooking, but also captured the dynamics of 'fuel stacking'. Treiber et al. (2015) explain that households regularly use various energy carriers and technologies in 
order to ensure a continuous supply of cooking energy in the most convenient and appropriate form for the task at hand. Also, the same person may cook different meals with different appliances. Tomei et al. (2014) note that even within each carrier, users will frequently employ multiple appliances for different tasks. Interestingly, despite this, $42 \%$ of households indicated that they rely on just electricity for cooking, indicating that grid connections for this sector of society must be sufficiently reliable. Electricity is also paired with firewood, paraffin and LPG for around a third of the population (around 10\% each). Households with a low standard of living tend to pair paraffin and firewood. There is a strong urban/rural divide, with formal urban areas relying mainly on electricity alone (60\%), whilst multiple energy use (i.e. fuel stacking) is the norm in rural areas (approximately $70 \%$ ). In informal urban areas, $16 \%$ of households supplement electricity with paraffin, most probably due to the inferior reliability of their grid connections and the perception that cooking with electricity in South Africa is expensive, particularly given the increases in electricity prices which had occurred immediately prior to the survey (Cowan 2008; Republic of South Africa 2012). Bekker et al. (2008:3135) argue that despite the FBE allowance, "it is unlikely that poor households will abandon multiple fuel use even in the long term," because of the small size of the allowance and the balance of relative fuel costs.

Cowan (2008)'s seminal work in the EU-funded APPLES (Alleviation of Poverty through the Provision of Local Energy Services) project, focussed on the informal settlement of Imizamo Yethu on the outskirts of Cape Town and offers valuable insight into some of these trends. $\mathrm{He}$ explains that in many informal communities, whilst formal electrification may have occurred for some residents, there is considerable informal illegal connection and power outages are frequent, ironically often due to fires caused by paraffin stoves. Electric stoves are widely available but are generally more expensive than paraffin stoves, although less expensive than LPG stoves. Double spiral hot plate stoves are most common, however the quality of different models varies significantly and does not necessarily correlate with cost. Electric kettles are also used for water heating for hot drinks, washing and bathing.

Cowan combined participatory field methods with laboratory testing in order to evaluate the energy requirements for the preparation of local meals using the most common energy sources: electricity, LPG, ethanol gel and paraffin. Local community volunteers were asked to collect recipes for popular local dishes, which were then broken down into the cooking operations they contained (frying, boiling, simmering, baking/roasting, and grilling). Both laboratory and field measurements were made on the energy consumption of locally available cooking appliances when performing these operations. An estimated total energy consumption and associated cost was calculated for each recipe, which was then calibrated against field measurements from the actual cook process of that dish in order to ensure that real user practices were accurately reflected in the final figures. Four categories of dish were defined (see Appendix C) and the results clearly show that other than collected fuelwood (which is assumed to be free), electricity is by far the cheapest option for all types of dish. Ethanol gel was found to be the most expensive fuel, with LPG approximately $15 \%$ cheaper, paraffin $35 \%$ and electricity $70 \%$.

Cowan (2008) also researched simple energy saving measures which could make cooking with electricity even cheaper and more convenient (these are outlined in Appendix C). Cowan and his team applied two strategies for disseminating these techniques that also functioned as opportunities for data collection:

1. The Imizamo Yethu Energy Cookbook documented each of the local recipes used during the analysis, presenting the energy, time and financial costs of preparing each meal with the electricity, paraffin, ethanol gel or LPG.

2. Public cooking competitions were held in Imizamo Yethu, with the multiple objectives of collecting user feedback on electric stove design, raising awareness of the 
convenience and cost of cooking with electricity and taking further measurements of actual energy use during the preparation of local dishes.

Unfortunately it was not possible to obtain details of any evaluative studies on either of these two methods.

\subsubsection{Conclusion}

From the literature review provided above, Table 1 and Table 2 summarise the key drivers, barriers and enablers in the transition to electric cooking in South Africa.

\begin{tabular}{|l|l|l|}
\hline Barrier & Enabler & Sources \\
\hline $\begin{array}{l}\text { Cooking with electricity perceived as } \\
\text { expensive (and stove cost more expensive } \\
\text { than paraffin alternatives). }\end{array}$ & $\begin{array}{l}\text { FBE (Free Basic Electricity) } \\
50 \mathrm{kWh} / \mathrm{month} \text { for poor } \\
\text { households }\end{array}$ & $\begin{array}{l}\text { (Cowan 2008; } \\
\text { Bekker et al. } \\
2008)\end{array}$ \\
\hline $\begin{array}{l}\text { Collected firewood still more attractive for } \\
\text { many grid connected low income rural homes } \\
\text { due to lack of cost. }\end{array}$ & & $\begin{array}{l}\text { (Cowan 2008; } \\
\text { Republic of } \\
\text { South Africa } \\
2012 ; \text { Bekker } \\
\text { et al. 2008) }\end{array}$ \\
\hline $\begin{array}{l}\text { Lack of grid connection in rural and informal } \\
\text { urban areas. }\end{array}$ & $\begin{array}{l}\text { Increasing number of } \\
\text { relatively reliable grid } \\
\text { connections, due to national } \\
\text { policy focus on grid } \\
\text { expansion }\end{array}$ & $\begin{array}{l}\text { (Bekker et al. } \\
2008 ; \text { Republic } \\
\text { of South Africa } \\
2012)\end{array}$ \\
\hline Poor quality equipment (hob). & & Cowan 2008) \\
\hline $\begin{array}{l}\text { Additional peak demand placed on South } \\
\text { Africa's already strained generating capacity. }\end{array}$ & & $\begin{array}{l}\text { (Howells et al. } \\
2006)\end{array}$ \\
\hline
\end{tabular}

Table 1 Key barriers preventing the transition to electric cooking in South Africa and (where applicable) the enablers that overcame them

\begin{tabular}{|l|l|}
\hline \multicolumn{1}{|c|}{ Driver } & \multicolumn{1}{c|}{ Sources } \\
\hline Electric stove purchase price lower than LPG stove. & (Cowan 2008) \\
\hline $\begin{array}{l}\text { High fire risk of paraffin stoves in informal urban settlements } \\
\text { leading to government favouring safer electric cooking in national } \\
\text { policy. }\end{array}$ & $\begin{array}{l}\text { (Cowan 2008; Bekker et } \\
\text { al. 2008) }\end{array}$ \\
\hline $\begin{array}{l}\text { Low unit cost (kWh) makes electricity significantly cheaper per } \\
\text { meal than LPG, paraffin and ethanol gel. }\end{array}$ & (Cowan 2008) \\
\hline
\end{tabular}

Table 2 The key drivers for the transition to electric cooking in South Africa

\subsubsection{Improved Cook Stoves (ICS)}

Another key area identified for relevant lesson learning is the massive international effort that has been exerted over recent decades into designing and distributing Improved CookStoves (ICS), with the aims of encouraging more efficient use of fuelwood/charcoal (reducing the pressure on local forestry resources and reducing the time spent collecting it and/or money spent buying it) and reducing the damaging health impacts of high levels of indoor air pollution. The burgeoning literature on this global intent to enable/hasten the transition to ICS can offer valuable insight into the factors affecting cooking behaviour change. This can be of significant value for our attempts to evaluate the potential issues affecting the uptake of the eCook concept. The following sub-section has benefitted greatly from the materials produced by (and discussions with) the team leading an ongoing EPSRC-DECC-DfID funded research project at the University of Nottingham (the 'Barriers' project), which aims to identify and explore these barriers to ICS adoption in conjunction with a series of Southern 
and Northern partners (Ray et al. 2015; Ray et al. 2014). The discussion is divided into two sections: firstly and most importantly, overcoming the main barrier of persuading people to purchase new cooking technology; and secondly, ensuring that people use that technology effectively/optimally.

\subsubsection{Initial adoption}

\subsection{Participation and social marketing}

Pampallona \& Bollini (2014) describe the limitations of a major Indian ICS programme that distributed over 32 million stoves over three decades beginning in the 1980s. The programme offered significant subsidies for the stoves, which amongst other factors resulted in a low sense of ownership of the technology and low levels of sustained uptake. Coupled with the poor quality of the stoves and poor after sales support, they describe how most units were used for little more than two years. This programme is typical of an early subsidybased approach, however more recent initiatives have tended to adopt market-based models, some of which have seen considerable success (Practical Action 2014). Bailis et al. (2009) present two excellent examples of such initiatives: KCJ in Kenya and GIRA in Mexico. However, market-led approaches are not without their perils. Sesan et al. (2013) caution against the conflicting interests in some of these initiatives between the development of stoves by profit-driven corporations and the needs of the poor; whilst Lewis \& Pattanayak (2012) highlight the fact that even seemingly 'efficient' ICS can often fail to find favour in households with traditional stoves, due to their incompatibility with local customs, poor distribution channels or ineffective marketing. Interestingly, Pampallona and Bollini (2014) go on to suggest that the more recent National Biomass Cookstoves Initiative (2009) for India features a much stronger role for private enterprises, innovative financing mechanisms and technology that is adapted to local cooking practices.

Goodwin et al. (2014) state the importance of delivering clear messages to households on the social benefit of clean cooking technologies, which often are not as salient as would be presumed. The Shell Foundation (2013) describe the key learning experiences from their social marketing campaign, Room to Breathe (RtB), which was designed to raise awareness of the multiple benefits of ICS amongst traditional biomass stove users in Karnataka, India. The programme included a wide range of activities, from village demonstrations and street theatre to static wall painting and local influencers (household activists). Results were mixed, but their greatest success was in pairing proven stove promotion activities with stove purchase loans in partnership with an established microfinance institution (Grameen Koota). They highlight the following key lessons:

1. Understand the local market by identifying the aspirations, knowledge, attitudes and practices of the target population, identifying the triggers and barriers for ICS purchase.

2. Match the key marketing messages to these triggers and barriers and refine through iterative smaller scale trials.

3. Get the mix of quality/affordable ICS, brand awareness, credible partners, costeffective campaign deliver mechanisms and local availability of products/spare parts right.

4. Begin with a surge of (most likely donor funded) social marketing in each new place. Early adopters may not be the poorest, but will be a foot in the door that will allow word of mouth to reach much deeper (Shell Foundation 2013).

Goodwin et al. (2014) add that empowering change agents and arranging cooking demonstrations can offer additional potential for reaching scale and that effective social marketing strategies should operate across the individual, interpersonal, community and national scales. As Pampallona and Bollini suggest 
"Too much emphasis has gone on technology and talking to the people at the top and too little on consulting the women who actually do the cooking." (Pampallona \& Bollini 2014:17)

They go on to describe how a more 'participative approach' to ICS design and development can address some of the limitations of previous donor-lead strategies. They refer to an example where two rural Indian communities (60 households) have themselves developed, tested and adopted an ICS ${ }^{2}$. Whilst this is still small in terms of scale and merely shows initial adoption as opposed to sustained use, there are still important lessons to be learned in terms of the value of participation in finding locally appropriate solutions. Ray et al. (2014)'s research in Kenya also highlights the need to adapt ICS designs to locally available skills and resources, as well as local customs when they discovered that the clay required for certain ICS designs was only found in specific parts of the country.

\subsection{Local manufacture}

Another major debate that came out of the ICS literature concerns the tensions between models that prioritise the local manufacture of easily constructed ICS and programmes that rely on the mass-production of much higher quality stoves (which meet more stringent international standards on fuel efficiency and particulate emissions and hence will generate more carbon credits per stove). Whilst the former offers local job creation, capacity building and economic benefits, the availability of poor quality ICS has on a number of occasions significantly undermined the reputation of the technology as a whole, as consumers often find it difficult to distinguish between poor quality imitation and genuine ICS (Ray et al. 2014).

\subsection{Gender}

In most Southern countries, women are responsible for providing and using household energy sources (Hart \& Smith 2014; Jeuland \& Pattanayak 2012; Gill et al. 2015). As a result, if fuel must be collected, it is they who must spend their time doing so. Often, this can involve long and/or dangerous journeys, for example leaving a refugee camp to gather fuel often exposes women to both physical and sexual violence (Hart \& Smith 2014). The utilization of traditional energy also carries with it its own hazards, with the burning of solid fuel exposing women (and their children who often accompany them in the kitchen) to burns and dangerously high levels of indoor air pollution (Hart \& Smith 2014; Jeuland \& Pattanayak 2012).

Hart \& Smith (2014:20) present a literature review, applied research and a series of case studies in order to put forward the argument that in order to increase sustainable adoption of ICS, women should be "encouraged to lead efforts that seek to develop effective, culturally appropriate and sustainable solutions." For example, Hart \& Smith (2014:22) describe how:

$2 \quad$ This participatory experiment began when a popular ICS design (the rocket stove) was brought to a community meeting. Various cultural modifications were discussed, with a consensus obtained on adapting the geometry to make it usable in the traditional squatted position and adding an adjustable metal skirt to cater for different sizes and shapes of pots. A local artisan then produced a prototype that included these modifications and this was taken home by different households for testing. Each household then fed back to the artisan and a series of this second of prototype was produced and distributed as a set to each household. Feedback was again received from both the users and the manufacturers and the third prototype will utilise locally available brick working skills by replacing the metal parts with brick. The design will continue to evolve, as two diffusion teams consisting primarily of women have been presenting the work to surrounding communities, who have been so impressed that 15 further villages (around 4,500 individuals) have expressed an interest in participating. Village leaders also played a crucial role in the process by building consensus during the feedback process and promoting the technology. Although it was not an issue in this case as everyone in these villages was of the same caste, this was highlighted as a potential barrier to this type of participatory development in other regions. 
"Solar Sister is tapping into the skills, knowledge, and networks of women to distribute solar energy products and clean cookstoves. They currently have over 400 female sales agents in Sub-Saharan Africa who serve to build and extend a supply chain for household clean energy products. Likewise, Sakhi Unique Rural Enterprise (SURE) in India engages rural women in the supply chain to distribute clean energy products to last mile consumers and to provide after- sales service. SURE works with over 400 women entrepreneurs who have sold over 86,000 cookstoves in the past four years."

The Barefoot College's solar training school for poor rural women in India (Sharma 2007) is another example of a successful strategy that has since been replicated. As the main users of ICS, women's input from the very beginning of the design process is absolutely essential in order to ensure that the product meets their needs (Gill et al. 2015). What is more, by engaging women in the marketing of the product, their local knowledge and access can generate demand in new market segments, allowing distribution at scale. However, the design of gender-based interventions should be preceded by an informed gender analysis of each specific context; and consider how both genders can be appropriately and effectively engaged. By taking this gendered perspective, energy access interventions can encompass and leverage the different roles of women and men at both the inter- and intra-household scales (Goodwin et al. 2014).

Miller \& Mobarak (2013) constructed a model of inter-household decision making and executed an experimental study on the marketing of ICS with 799 households in 16 villages in Bangladesh. They offered the ICS at randomly varying prices to both husbands and wives (separately) in order to assess willingness to pay as a function of a series of key variables. They noted that other research has shown that women have greater tendencies to choose products that improve welfare (Hanna et al. 2012). In line with this, they found that women in this area had a stronger preference for lower emission stoves, however, they frequently lack the authority to make purchases. Male financial decision makers did not take into account the costs and benefits of this new technology to their wives. What is more, even women did not see indoor air pollution as an important health hazard (compared to other hazards they faced). As a result, (Miller \& Mobarak 2013) suggested that public policy aimed at exploiting gender differences by highlighting the health benefits to women is therefore likely to be ineffective in Bangladesh and potentially elsewhere. Consequently, they recommend building in additional energy services, which may broaden appeal, including for men, as a strategy for increasing uptake in market based systems. They specifically highlight the Biolite stove in this context, which has a USB port for charging mobile phones.

\subsection{Shifting climate}

Political support for energy technologies in Africa, particularly in Southern Africa, has historically tended to favour electrification over clean cooking interventions such as ICS (Ray et al. 2014). Combined with the fact that firewood is often collected for free in rural settings (Preston 2012), this means that poor rural households who would benefit most from the technology are often unable to because the market price for stoves available in their local area is higher than they are willing/able to pay. However, Lewis and Pat argue that there are a number of enabling factors that can make adoption of ICS more likely:

- Innovative financing models, such as micro-credit, are being linked to new financing sources such as climate funds, lowering the barrier of upfront cost, with some programmes distributing stoves for free, e.g. Delagua's current programme in Rwanda (Barstow et al. 2014), although this returns us to the questions of ownership and sustained use discussed above). At the same time, with the increased focus on market based approaches, international funding is also being directed at offering much needed capital for business development of key market actors (Ray et al. 2014). 
Evidence from Ghana, Kenya, Tanzania and Uganda all agrees that the price of charcoal is increasing rapidly (at least $20 \%$ per year in all four countries during the most recently surveyed year). This is due to both increasing demand (growing with population, price of competing fuels such as kerosene and LPG and household incomes) and decreasing supply (dwindling forest reserves and poor quality transportation links between charcoal production and major demand centres and national policy changes) (Ghana Energy Commission 2014; EEP 2013). The World Bank (2015) state that this is a general trend throughout the continent, with charcoal prices across Africa tripling in the last decade. They add that LPG prices are also rising and that although poorly documented, fuelwood scarcity appears to also be increasing.

- $\quad$ The formation of the Global Alliance for Clean Cookstoves (GACC), which aims to have 60 million households adopt ICS by 2020 is working to strengthen the sector by coordinating efforts to procure investment, drive innovation and grow the market for clean cookstoves.

\subsubsection{Sustained use}

\subsection{Efficiency, efficiency, efficiency}

Whilst the literature on ICS is vast, most focuses on maximising the efficiency of biomass use (Jeuland \& Pattanayak 2012), with surprisingly few studies focussing on the allimportant (in our opinion) behavioural change aspect (Goodwin et al. 2014; Shell Foundation 2013). In fact, the way in which these stoves are used in practice often gives very different results to laboratory testing, as certain behaviour (e.g. specific fire-tending techniques or lack of maintenance) actually results in net increases in time spent cooking or preparing fuel (Jeuland \& Pattanayak 2012) and in some cases, even increased fuel wood consumption (George 2002). Even when fuel consumption is reduced, this does not necessarily translate into reduced time collecting the fuel (Burwen \& Levine 2012). What is more, Jeuland \& Pattanayak (2012) note that not all foods can be prepared in a simple pot, certain foods such as Mexican tortillas or Ethiopian injera require specialist cooking equipment. Even foods that can be prepared in a standard pot require a variety of different operations - frying, boiling, simmering, pot-roasting, etc. (Cowan 2008) - whereas many ICS are optimised for just one of these. Consequently, Treiber et al. (2015) argue that a wide range of stoves is essential for the success of any ICS market, in order to cater for differing social and cultural traditions and the selection of the best stove for the particular tasks that each user deems most important.

Jeuland \& Pattanayak (2012) also point out that the health benefits of ICS are related to the way in which the stove is used, with convenience often taking preference over indoor smoke reduction, as the health benefits are not as immediate as time saved on either cooking or fuel collection (or cost if fuel is purchased). This agrees with Lewis \& Pattanayak (2012)'s broader findings that households often do not choose to invest in environmental health technologies.

\subsubsection{Conclusion}

Based on the discussion above, Table 3 and Table 4 summarise the key drivers, barriers and enablers in the transition to ICS in the Global South. 


\begin{tabular}{|c|c|c|}
\hline Barrier & Enabler & Sources \\
\hline Poor quality imitation ICS. & $\begin{array}{l}\text { Development and enforcement } \\
\text { of international/national } \\
\text { standards }\end{array}$ & $\begin{array}{l}\text { (Pampallona \& Bollini } \\
\text { 2014; Ray et al. } \\
\text { 2014) }\end{array}$ \\
\hline $\begin{array}{l}\text { Financing: } \\
\text { - Upfront cost of the stove. } \\
\text { - Poorly designed subsidies } \\
\text { undermining end-user ownership. } \\
\text { Lack of capital for business } \\
\text { growth. } \\
\text { Firewood in rural areas usually } \\
\text { collected for free. }\end{array}$ & $\begin{array}{l}\text { Innovative financing } \\
\text { mechanisms: } \\
\text { - } \text { Micro-credit. } \\
\text { - International carbon } \\
\text { funding. } \\
\text { - Financing support for key } \\
\text { sector actors and } \\
\text { development of } \\
\text { entrepreneurialism. }\end{array}$ & $\begin{array}{l}\text { (Pampallona \& Bollini } \\
\text { 2014; Ray et al. } \\
\text { 2014; Miller \& } \\
\text { Mobarak 2013; Bailis } \\
\text { et al. 2009; Lewis \& } \\
\text { Pattanayak 2012; } \\
\text { World Bank 2015) }\end{array}$ \\
\hline $\begin{array}{l}\text { In many cultures, ICS benefits are } \\
\text { mainly for women, whilst men make } \\
\text { purchasing decisions. }\end{array}$ & & $\begin{array}{l}\text { (Ray et al. 2014; } \\
\text { Miller \& Mobarak } \\
\text { 2013; Hart \& Smith } \\
\text { 2014) }\end{array}$ \\
\hline $\begin{array}{l}\text { User practices often different to } \\
\text { laboratory test conditions used by } \\
\text { stove designers \& still only a partial } \\
\text { solution: } \\
\text { - Even the best ICS still produce } \\
\text { harmful emissions, particularly } \\
\text { when not used as designed. } \\
\text { - Can be incompatible with local } \\
\text { cooking practices due to lack of } \\
\text { adaptability. } \\
\text { Efficiencies can be lower than } \\
\text { traditional three stone fire if not } \\
\text { utilised appropriately. } \\
\text { Ongoing need } \\
\text { firewood/charcoal. } \\
\text { Small reductions in fuelwood use } \\
\text { don't always translate into } \\
\text { fuelwood collection time savings. }\end{array}$ & & $\begin{array}{l}\text { (Goodwin et al. 2014; } \\
\text { Ray et al. 2014; } \\
\text { Jeuland \& } \\
\text { Pattanayak 2012; } \\
\text { Ray et al. 2014; } \\
\text { Lewis \& Pattanayak } \\
\text { 2012; Goodwin et al. } \\
\text { 2014; Burwen \& } \\
\text { Levine 2012; Miller \& } \\
\text { Mobarak 2013) }\end{array}$ \\
\hline $\begin{array}{l}\text { Policy focus on electrification, not } \\
\text { biomass means lack of high-level } \\
\text { political buy-in. }\end{array}$ & $\begin{array}{l}\text { Strong global and national } \\
\text { promotional framework } \\
\text { (GACC). }\end{array}$ & (Ray et al. 2014) \\
\hline $\begin{array}{l}\text { Lack of awareness of locally available } \\
\text { ICS products and their benefits. }\end{array}$ & $\begin{array}{l}\text { Well-regulated market based } \\
\text { approaches with effective social } \\
\text { marketing strategies: } \\
\text { - Knowing the market. } \\
\text { - Matching message to } \\
\text { context-specific purchasing } \\
\text { triggers \& barriers. } \\
\text { - Getting the mix right. } \\
\text { - Surge of social marketing } \\
\text { activities is required initially. } \\
\text { - Early adopters who may not } \\
\text { be the poorest facilitate } \\
\text { word of mouth } \\
\text { dissemination in new } \\
\text { places. } \\
\text { Targeted awareness raising } \\
\text { campaigns on benefits of } \\
\text { ICS. }\end{array}$ & $\begin{array}{l}\text { (Venkataraman et al. } \\
\text { 2010; Pampallona \& } \\
\text { Bollini 2014; Shell } \\
\text { Foundation 2013; } \\
\text { Hart \& Smith 2014; } \\
\text { Ray et al. 2014; } \\
\text { Practical Action } \\
\text { 2014; Goodwin et al. } \\
\text { 2014; Gill et al. 2015; } \\
\text { Lewis \& Pattanayak } \\
\text { 2012) }\end{array}$ \\
\hline
\end{tabular}




\begin{tabular}{|c|c|c|}
\hline Barrier & Enabler & Sources \\
\hline & $\begin{array}{l}\text { - Village leaders facilitating } \\
\text { consensus in community } \\
\text { decision making and } \\
\text { promotion of the technology. }\end{array}$ & \\
\hline $\begin{array}{l}\text { Each context different: } \\
\text { - Local availability of skills and } \\
\text { construction } \\
\text { - Effectiveness of particular } \\
\text { marketing messages }\end{array}$ & 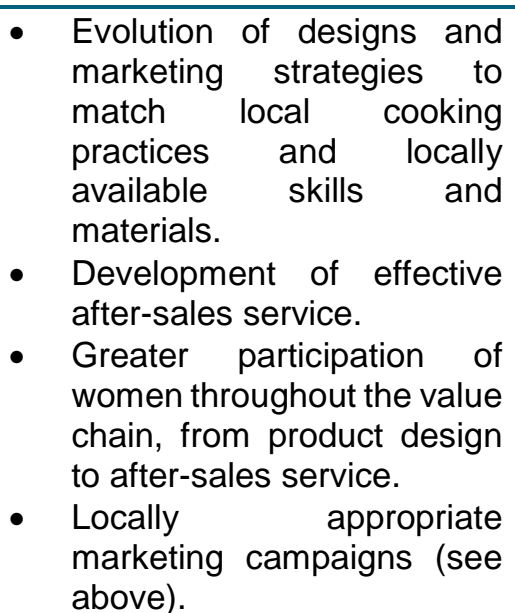 & $\begin{array}{l}\text { (Ray et al. 2014; } \\
\text { Pampallona \& Bollini } \\
\text { 2014) }\end{array}$ \\
\hline
\end{tabular}

Table 3 Key barriers preventing the transition to ICS in the Global South and (where applicable) the enablers that overcame them.

\begin{tabular}{|c|c|}
\hline Driver & Sources \\
\hline $\begin{array}{l}\text { Potential for local manufacture high: } \\
\text { - Ability to offer communities the option to participate in the } \\
\text { design and delivery of locally appropriate stoves. } \\
\text { - Boosting local economy. } \\
\text { - Building capacity for after-sales service. } \\
\text { - Creating local jobs. }\end{array}$ & $\begin{array}{l}\text { (Pampallona \& Bollini } \\
\text { 2014) }\end{array}$ \\
\hline $\begin{array}{l}\text { Negative health effects of traditional cooking methods, } \\
\text { predominantly for women and children: } \\
\text { - Indoor air quality. } \\
\text { - Risk of burns. } \\
\text { - Strong international funding interest. }\end{array}$ & $\begin{array}{l}\text { (Ray et al. 2014; Lewis } \\
\text { \& Pattanayak 2012) }\end{array}$ \\
\hline $\begin{array}{l}\text { Time taken to collect fuelwood (primarily rural areas) and cost of } \\
\text { purchased fuelwood/charcoal, which in many contexts is } \\
\text { increasing. }\end{array}$ & $\begin{array}{l}\text { (Ray et al. 2014; EEP } \\
\text { 2013; Ghana Energy } \\
\text { Commission 2014) }\end{array}$ \\
\hline
\end{tabular}

Table 4 The key drivers for the transition to ICS in the Global South.

\subsubsection{LPG}

The third example drawn from existing cooking transitions literature comes from explorations of the take-up and promotion of LPG as a cleaner alternative to traditional biomass stoves (improved or otherwise). LPG is comparable to electric cooking in terms of the end-user experience and is widely used as an equivalent to natural gas in Northern regions without a mains gas supply. As a result, the literature surrounding the transition to LPG can offer a greater understanding of the factors that influence consumer choice when switching to a modern cooking fuel. 
Heltberg (2004) studied the transition to modern fuels (LPG and kerosene) using comparable household survey data from eight countries (Brazil, Ghana, Guatemala, India, Nepal, Nicaragua, South Africa, and Vietnam). They found that modern fuel use correlates with urban location, high income level, electrification, high level of education and large household size (as larger households are more likely to use multiple fuels due to the individual preference of different people within a household to cook with different appliances.). In rural areas, it was mainly the top income groups who switched to LPG and biomass remained almost universal, as fuel stacking was widespread.

"Energy choice needs to be conceptualized more as a menu in which households simultaneously can choose low- and high-cost options" (Heltberg 2004:886)

Subsidies for modern fuels were not found to be effective, with LPG subsidies often poorly targeted and frequently seen as helping the urban rich instead of the rural poor with kerosene subsidies frequently leading to 'leakage' (as it was often used as a motor vehicle fuel). Heltberg (2004) recommends targeting interventions at those most likely to transition, i.e. the consumers of expensive purchased wood/charcoal.

STEPs (2014) investigated the transition to LPG in Ghana, which was initiated in 1990 by a government programme to replace fuelwood and charcoal with LPG in order to reduce deforestation and improve the standard of living. Initially, all the LPG was sourced from a single national refinery, however, after numerous breakdowns led to severe distribution problems, LPG imports were permitted and the supply chain stabilised. Subsidies and price controls were used in an attempt to make the technology affordable, however almost all LPG consumption was in urban areas, as rural households could not afford the initial purchase costs of the stove, canister and accessories. In fact, in addition to the urban elite (as suggested above by Heltberg), taxi drivers captured much of the benefit from the subsidies as they converted their vehicles to run on LPG. Even a targeted subsidy for rural households proved insufficient to assist them into the transition and when the general subsidy and price controls were removed, many of the urban households switched back to charcoal. At the time of writing, LPG was the primary cooking fuel of just $20 \%$ of urban and $1 \%$ of rural households in Ghana. In 2014, a new subsidy programme for rural users was introduced, which covers the initial purchase costs of the stove, cylinder and accessories. The impact of this remains to be seen. The World Bank (2015) confirm that the price volatility of LPG is an issue throughout Africa and that it has been steadily increasing in price (11\% per year over the past decade).

Nautiyal (2013) looked at the LPG transition in low, mid and high altitude communities in the Indian Himalayas using a questionnaire administered to 60 households. India is the fourth largest global consumer of LPG and has seen considerable growth in uptake over recent years, although levels remain much lower in rural areas. Forest conservation was cited as a major motivation for increased government support for the introduction of LPG in rural areas (introduced in the Indian Himalayas in the 1980s). Nautiyal's survey found that there had been a strong, if differentiated, uptake of LPG in the region and it was found that both the time spent collecting and the quantity of fuelwood collected had reduced in those areas where the LPG distribution systems were most well developed, implying that the shift to LPG use has been encouraged via the time saved from collecting firewood. Household health was also reported to have increased in those households reporting higher LPG usage and lower use of firewood. 


\subsubsection{Conclusion}

Table 5 and Table 6 list the key drivers, barriers and enablers in the transition to LPG in the Global South.

\begin{tabular}{|c|c|c|}
\hline Barrier & Enabler & Sources \\
\hline $\begin{array}{l}\text { High relative cost levels. Subsidies often } \\
\text { poorly targeted, so benefit can fall primarily } \\
\text { on: } \\
\text { - the rich, well-educated urban elite } \\
\text { - motor vehicle owners, especially if cross- } \\
\text { subsidised from petrol }\end{array}$ & $\begin{array}{l}\text { Clear marketing of health } \\
\text { and other benefits, paired } \\
\text { with well-targeted subsidies, } \\
\text { e.g. initial purchase costs } \\
\text { (stove, cylinder, accessories) } \\
\text { for low income rural } \\
\text { households. }\end{array}$ & $\begin{array}{l}\text { (Nautiyal } \\
\text { 2013) } \\
\text { (Heltberg } \\
\text { 2004) (STEPs } \\
\text { 2014) }\end{array}$ \\
\hline $\begin{array}{l}\text { Supply Issues: } \\
\text { - Dependent on imports in countries } \\
\text { without indigenous resources or the } \\
\text { expertise to exploit them. } \\
\text { - Supply chain vulnerabilities can create } \\
\text { price volatility and even cut off supply. }\end{array}$ & $\begin{array}{l}\text { Exploitation of national fossil } \\
\text { fuel reserves where they } \\
\text { exist and opening up to } \\
\text { international suppliers and } \\
\text { introducing effective price } \\
\text { controls to ensure diversity of } \\
\text { supply. }\end{array}$ & $\begin{array}{l}\text { (STEPs 2014; } \\
\text { World Bank } \\
\text { 2015) }\end{array}$ \\
\hline
\end{tabular}

Table 5 Key barriers preventing the transition to LPG in the Global South and (where applicable) the enablers that overcame them

\begin{tabular}{|l|c|}
\hline \multicolumn{1}{|c|}{ Driver } & Sources \\
\hline $\begin{array}{l}\text { Desire for modernisation - strong link between electrification and } \\
\text { uptake of modern fuels. }\end{array}$ & (Heltberg 2004) \\
\hline $\begin{array}{l}\text { Deforestation from excessive fuelwood collection leading to rising } \\
\text { consumer prices of fuelwood/charcoal. }\end{array}$ & $\begin{array}{c}\text { (Heltberg 2004)(STEPs } \\
2014 ; \text { Nautiyal 2013) }\end{array}$ \\
\hline $\begin{array}{l}\text { Health/safety: } \\
\text { Less dangerous than paraffin/kerosene. }\end{array}$ & $\begin{array}{c}\text { (Cowan 2008)(Nautiyal } \\
\text { Reduce indoor air pollution. }\end{array}$ \\
\hline $\begin{array}{l}\text { Potential for local manufacture of stoves, cylinders and even LPG } \\
\text { itself if local gas reserves exist. }\end{array}$ & (STEPs 2014) \\
\hline
\end{tabular}

Table 6 The key drivers for the transition to LPG in the Global South

\subsection{The transition to Solar Home Systems (SHS) for lighting \& other low power applications}

The PV-eCook concept is fundamentally a higher capacity SHS designed to replace solid fuel burning for cooking instead of kerosene/candles for lighting. As a result, understanding the factors underlying the substantial growth in the use of Solar Home Systems (SHS) and smaller solar products for meeting lighting needs across the Global South is of particular relevance to exploring the factors affecting the potential uptake of the PV-eCook concept.

Numerous studies describe the two main uses of SHS:

1. Better quality, safer and healthier lighting for security, studying, social space, evening work (Komatsu et al. 2011) (Mondal \& Klein 2011; Samad et al. 2013); and

2. Mobile phone charging, and powering radio, TV and other 'connective' applications (Jacobson 2007; Komatsu et al. 2011; Mondal \& Klein 2011; Samad et al. 2013). 
Although these types of benefits are highly valued by end users (Prasad 2007; Sovacool \& D'Agostino 2012; Mondal \& Klein 2011) and in many cases are cost neutral in terms of replacing the expenditure previously made on kerosene, phone charging and battery purchases (Samad et al. 2013), studies of user experiences have regularly reported enduser dissatisfaction with the limited range of energy services available, often specifically mentioning the inability to make productive use of the energy (Prasad 2007; Mondal \& Klein 2011; Laufer \& Schäfer 2011) or the ability to cook (Prasad 2007). Whilst some households are able to use SHS for limited agricultural processing (Laufer \& Schäfer 2011) or lighting for businesses such as restaurants or shops (Mondal \& Klein 2011), a recurring theme of evaluations of the 'developmental' impact of SHS programmes is that their income generating potential is limited and as a result, they can in some cases actually increase poverty levels, particularly if the household is required to pay back the original purchase or replacement part cost rather than operating via a fee for service model (Laufer \& Schäfer 2011).

Many sources, especially those published over 10 years ago (Karekezi \& Kithyoma 2002), refer to the limited potential of PV for poverty alleviation, due to the restriction to low power appliances. However, as the price of virtually all system components has now fallen dramatically and significant investment has gone into building local markets, SHS are no longer restricted to low power appliances (see Bond et al. (2012) for a discussion of the relative sizing of SHS over time). SHS first offered solely lighting, then expanded to TV, radio and mobile phone charging and now, higher capacity systems are being offered that allow refrigeration and ventilation (GVEP 2015). Expanding to encompass cooking requirements seems a logical progression:

"SHS owners are happy having electricity for lighting and media but they still have to use other sources such as fuelwood, kerosene or gas for their greatest energy need, cooking." (Prasad 2007:12)

\subsubsection{The importance of locally applicable solutions}

"Institutions like the World Bank or USAID think that if you have a good idea or new energy technology, you are 90 percent there, and implementation takes the remaining 10 percent. Experience here suggests it is really the opposite: 10 percent the idea, and 90 percent the training, the consumer awareness, and the promotion. Getting the technology right is completely secondary to effective promotion in gaining social acceptance."

(Sovacool et al. 2011:1539)

The necessity of finding locally appropriate solutions cannot be understated. Numerous studies warn of the perils of rolling out technology that has worked in another context without properly analysing the intertwined social, cultural, institutional, political and economic factors specific to the target area (Sovacool \& D'Agostino 2012; Solar Energy East Africa 2015). This seems to have been particularly true of solar energy initiatives. To give an example, Sovacool, D'Agostino, \& Jain Bambawale (2011) describe an unsuccessful World Bank funded SHS programme in Papua New Guinea (PNG), where a variety of contextual factors rendered the majority of the installed capacity inoperable. In particular, neglecting the complexities of inter-household dynamics played a major role in the failure of the programme:

- $\quad$ Tribal leaders, politicians or 'big men', were typically responsible for providing for their people, by purchasing and distributing commodities such as kerosene or candles. SHS were provided directly to end-users, which resulted in high levels of theft and vandalism as they were seen as belonging to everyone and therefore no one. 
Rural people in PNG often spend little time at home, choosing instead to spend their time outside under trees or at social gatherings rather than in a "Westernised permanent house" (Sovacool et al. 2011:1540). It was assumed that the concepts of "money, property, time and community" in rural PNG were identical to those in Northern countries (Sovacool et al. 2011:1541).

The argument here is not that these particular barriers should be addressed in future PVeCook initiatives, but instead that each local context presents its own unique challenges (which cannot just be limited to those reflecting orthodox ideas of market differentiation), which must be understood and fed into the design of both the technology and its roll out if it is to be culturally accepted. Consequently, due to the previously mentioned similarities between SHS and PV-eCook, it is recommended that efforts to disseminate PV-eCook might best be focussed in areas where SHS programmes have already achieved success. By 'piggy-backing' on the delivery models that have already been tried and tested by SHS in that particular local context, PV-eCook can short-cut much of the lengthy and costly iterative field testing that was required to adapt the generic solar electricity concept to that particular place. What is more, consumer awareness and technical understanding of solar electricity will also already be much higher, which would enable programme designers to focus on the cultural barriers to changing cooking practices.

"Rural communities... cannot be understood from one's desk, and they cannot be reliably provided energy services according to any simple formula or blueprint. Unfortunately, the implication is that energy development programs, and efforts to distribute SHS and similar technologies, will forever have to be nuanced, targeted, and context specific in order to succeed." (Sovacool et al. 2011:1542)

\section{Madeleine Akrich (1995:167) "the success or failure of innovations frequently depends on their ability to cope with dissimilar users possessing widely different skills and aspirations."}

Sovacool \& D'Agostino (2012) recommend using market analysis tools to inform programme designers about consumer preferences. In the case of PV-eCook, a detailed market assessment should be conducted in each new context, in order to properly evaluate the success of existing SHS programmes and the viability of offering PV-eCook to their existing customers. The discussion below provides learning from contextually-specific examples in order to inform possible approaches to eCook transitions, but it is prefaced by this acknowledgement that the approach taken in any area, country or region must always be founded on appropriate contextual analysis.

\subsubsection{Financial models}

Hansen (2014) states that until recently, most solar PV electrification in Africa has been driven primarily by international donor and government led projects. However, a lack of ownership of the equipment can lead to vandalism, neglect and misuse (Sovacool \& D’Agostino 2012). Market based approaches in countries such as Kenya have shown greater success and as a result, much of the rest of SSA is now following in their footsteps (Hansen 2014). Coupled with stable, but not overpowering regulatory frameworks (Lemaire 2011), new business models have been vital in unlocking market based approaches (Martinot et al. 2001), as the high upfront cost of renewable energy systems puts them out of reach of the vast majority of people living in poverty. In particular, micro-credit (Lemaire 2011) and fee-for-service approaches where customers pay for the service received from the SHS rather than paying towards personal ownership (Ellegård et al. 2004; Hansen 2014; Lemaire 2011; Prasad 2007; Sovacool \& D'Agostino 2012) have shown particular promise. However, the fee-for-service model has been criticised in some contexts particularly where complex service agreements are not understood by end users (Prasad 2007). In both the 
fee-for-service and micro-credit models, there are reported examples of users having had difficulty in making the monthly repayments, especially the poorest of the poor, who tend to have less financial stability (Prasad 2007). Laufer \& Schäfer (2011) recommended flexible repayment plans that are in sync with incomes, such as the sale of agricultural produce at market.

In fact, Jacobson (2007) found that in Kenya it is the emerging rural middle class who benefit most from SHS, as they were spending more on kerosene, disposable batteries etc. that have since become obsolete and have the greatest amount of disposable income with which to supplement the monthly payments. In contrast, the poorest households in Kenya spent least on kerosene, disposable batteries etc., and were faced with a much bigger increase in spending to make the monthly SHS payments, further increasing the strain on their already limited income (Laufer \& Schäfer 2011; Komatsu et al. 2011; Mondal \& Klein, 2011). These issues suggest the need for careful thought in terms of targeting PV-eCook at communities where the costs of current fuels are significant. In a household survey in Bangladesh, Komatsu et al. (2011) found that if SHS price reduced by $10 \%$, over $60 \%$ of households without SHS would purchase. If $30 \%$, demand would shift to larger packages, clearly showing that although there are many other factors, cost is likely to be a key element in household decision making (Samad et al. 2013; Miller \& Mobarak 2013).

The development of mobile payment systems, such as M-Pesa in Kenya, have greatly facilitated the fee-for-service model by simplifying the payment process and enabling households with variable incomes (usually the poorest) to adapt their use according to their income on a daily basis via a pay-as-you-go tariff (Laufer \& Schäfer 2011). This is seen as particularly compatible with the proposed PV-eCook system, as although the control technology required to process the mobile payments required significant development, much of this work would be directly transferable from SHS to PV-eCook.

However, the fee-for-service model is not without its faults. Vandalism, neglect, misuse, theft and even sale of the systems on the black market have been reported in a number of studies, as the systems are owned by the utility as opposed to the user (Prasad 2007; Lemaire 2011). The reliance on imported components means that fluctuations in international exchange rates and inflation create additional costs that must either be absorbed by the small and fragile businesses or the end-users themselves (Lemaire 2011). What is more, government or donor support in the form of subsidies is often, although by no means in all cases, still needed for fee-for-service companies (Lemaire, 2011).

Sovacool \& D'Agostino (2012) and Lemaire (2011) point out that these financing schemes must be appropriate to the local context. As a result, it is predicted that PV-eCook is likely to have greatest success when targeted in areas where locally appropriate innovative financing schemes have already proven successful, such as Azuri's's pay-as-you-go SHS in SSA and Grameen Shakti's micro-credit SHS in Bangladesh (see Pueyo (2013) for a review of various models). In fact, Lemaire (2011) even recommends the extension of the fee-for-service business model successfully employed by a South African SHS concession operator to cover energy for cooking, albeit using LPG, which at the time was the most viable option. What is more, by including the ability to connect low-power devices such as LED lights and mobile phones in the design of the PV-eCook concept and offering an PV-eCook upgrade to households who have already adopted SHS, savings that these households have made on kerosene, disposable batteries etc. can be put alongside savings on cooking fuel purchase (if applicable) and offset against PV-eCook payments.

\subsubsection{Perception of SHS}

Although little work exists that focuses purely on the perception of SHS, anecdotal evidence from a number of studies suggests that opinion is divided as to whether SHS is a technology 
for rich or poor people. In remote rural areas where grid connection is unlikely in the medium to long term, SHS is often seen as the technology of the rich and welcomed accordingly (Prasad 2007; Lemaire 2011). This could be because income levels are generally lower due to the remote location and therefore only the highest income groups can afford SHS or because of the realisation that regardless of income, this is the only technology available in that location that can offer people access to even a small selection of the energy services of the urban elite. In contrast, those who are within reach of the grid may see SHS as a poor person's technology because of the limited range of compatible appliances.

“Solar is good. But I don't use it as my neighbours will think I can't afford to pay for electricity" (Uncle Ben, ICS Salesman in Zambia cited in Ray et al. 2015:8)

Due to the long expected lifetime of PV systems (PV panels themselves usually come with $20+$ years guarantees), communities who take up government sponsored SHS are often taken off the list for grid connection. Studies in South Africa in particular indicate that this has led to community opposition to SHS programmes for fear of becoming 'locked in' to an inferior 'poor person's' technology (Prasad 2007; Lemaire 2011) and have been described as a 'return to apartheid' (Ray et al. 2015). Consequently, political uncertainty regarding grid extension plans can create very unpredictable dynamics with regards to solar uptake (Lemaire 2011).

"They are disappointed that they cannot cook and use heavy electric machinery and consider this a drawback as compared to grid electricity. They still have to pay more for other fuels such as wood, kerosene and gas for their thermal needs such as cooking." (Prasad 2007:12)

Conversely, this may enhance the potential for B-eCook in grid-connected communities where cooking with electricity might be seen as embracing modern aspirational cooking approaches (in contrast to the indifferent attitudes often expressed towards other forms of improved cookstove - see discussions below).

\subsubsection{Adaptability}

Sovacool \& D'Agostino (2012) conducted a comparative analysis of World Bank funded SHS programmes totalling over 400,000 systems and $\$ 300,000$ of investment in China, Laos, Mongolia and Papua New Guinea using a combination of stakeholder interviews and site visits. Nomadic herdsmen, fishermen and teachers were the main beneficiaries and in the three successful programmes, SHS were specifically adapted to provide them with energy services they were really interested in. In China and Mongolia, SHS lighting systems were bundled with TVs and DVD players, whilst in Laos, they came with lanterns for fishing at night. Due to the necessary higher capacity of the proposed PV-eCook systems, building in such incentives would be much simpler, as a much greater range of appliances would be compatible, meaning that it would be much more likely to find one (or more) that fulfils a specific function within each local context, particularly where there are productive uses which correlate to the seasonality of solar resource. Thus, for example, PV-eCook could be promoted along with productive appliances that are mainly used in the season of peak solar resource. For example, a 500W irrigation pump would offer subsistence farmers the potential to grow crops in the dry season (which is also the sunny season) and increase their income in order to pay back the costs of the system. Further research is needed to determine the extent to which (if at all) these alternative applications reduce the energy available for cooking, i.e. when the battery is low, would cooking be prioritised? Sumanik-Leary et al. (2014) note that one of the major contributing factors to the rapid dissemination of PV is due to the fact that the differences between household power generation potentials are minimal on a local, national and international level, as the solar resource is geographically well 
correlated with the location of people living without access to electricity and PV power production is linearly proportional to the solar resource.

Sovacool \& D'Agostino (2012) highlight the fact that each household is a dynamic unit, whose needs, wants, ability to pay and trust in the SHS change over time. They found that over time, once finances allowed, most households gradually transitioned to larger systems once they became familiar with the energy services offered by SHS and the value they could add to their lives. In the household survey of SHS users in Bangladesh referred to above, Komatsu et al. (2011) found that if SHS prices dropped by 30\%, a majority of households indicated that they would shift to a higher capacity system. As a result, it is recommended that either the PV-eCook system is developed in such a way that extra capacity can easily be added on a modular basis (i.e. adding a second electric hob by doubling the amount of PV panels, upgrading the wiring and controller, adding another battery in parallel) or that larger systems (700W, 1kW etc.) are also available on a part-exchange basis.

Sovacool \& D'Agostino (2012) also noted that some users were still using SHS even after grid connection, either for backup if the grid was not reliable or during herding season. This has two important implications for the PV-eCook concept:

1. PV-eCook should be designed in such a way that when the grid arrives, it can easily convert to B-eCook, i.e. by offering a part-exchange on the PV panels for a mains battery charger. This would also offer users the ability to use other energy services (lights, TV etc.) at times of power outages on unreliable grids.

2. If the PV-eCook system could be redesigned with portability in mind, it could open up a new potential market: nomadic or semi-nomadic people, even those with a grid connection in their main home.

\subsubsection{Gender and demographics}

Samad et al. (2013) studied households who had taken up SHS in Bangladesh and found that the health benefits were greatest for women and children. Women's time collecting fuel was reduced and their decision making at home (on certain topics) increased through connection with modern society via 'connective' (Jacobson 2007) applications such as TV, radio and mobile phones.

Urpelainen \& Yoon (2015) surveyed 760 households in India's Uttar Pradesh and found that willingness to pay for SHS increased with income and education levels. Younger households and those who already had a grid connection (and therefore appreciated the benefits of access to electricity) were also found to be more willing to pay. However, female headed households were not found to be any more willing to pay than male headed households, implying that the benefits of SHS are not perceived differently between genders in that context.

To et al. (2012) offer a case study of a PV electrification project in a remote Nepalese village. They note that due to traditional gender roles, electricity is seen as part of the male domain. However, as much of the benefit of the PV systems is captured by women, maintenance is often not carried out on the systems. Most villages put forward male candidates for the technical training for maintenance, primarily because few women met the requirements for the minimum level of education. Both these issues are expected to improve as women's social status and level of education increase, however, this issue could currently be addressed by designing training courses specifically for women. Programmes such as the Barefoot College in India and Solar Sister in Uganda have successfully offered practically focussed solar PV training programmes to women with low levels of education from around the world for many years now (Allen 2012; Baruah 2015; Harris \& Kor 2013; Sharma 2007) and such a model could easily be extended to PV-eCook. 


\subsubsection{Consumer awareness}

Evidence from several countries suggests that awareness of and interest in investing in SHS is generally highest among younger households (Rebane \& Barham 2011; Urpelainen \& Yoon 2015) with higher levels of education and income (Urpelainen \& Yoon 2015; Samad et al. 2013). In the short term, this implies that uptake of PV-eCook is likely be highest in these market segments, however in the longer term, awareness raising campaigns should also be targeted at older, poorer and less well educated households in order to maximise uptake.

Sovacool \& D'Agostino (2012) describe the critical role of locally appropriate awareness raising campaigns in creating demand for and acceptance of SHS. In Mongolia, a 'solar road show' successfully targeted nomadic herdsmen, whilst in China, village demonstrations and in Laos, advertising on the local radio and news was equally successful (other examples include training local promoters - e.g. Solar Sister etc., as discussed above). Again, PVeCook programme developers could save significant time and effort by following in the footsteps of these proven, locally appropriate models.

\subsubsection{Maintenance}

Research suggests that underperforming service networks can significantly undermine ownership of SHS (Sovacool \& D'Agostino 2012; Carvalho Neves et al. 2015) and in a market based system, if households have difficulties in obtaining the necessary after-sales service, news will soon spread to neighbouring households and further uptake of the technology is likely to be significantly reduced. There is now a large and growing literature illustrating the very different forms of effective service networks that have developed serving SHS programmes in different country and regional contexts (some involving standalone developments by individual companies and others involving different levels of collaboration with local/national government actors and/or other intermediaries such as banks), as well as many examples of the problems caused by poor after sales service and customer relations (Friebe et al. 2013; Harish et al. 2013; Kebede et al. 2014). Establishing a relationship of trust between the end-user and the after-sales service provider is of critical importance, as when a failure inevitably occurs, the end-user must feel comfortable asking for assistance or the system will remain out of service indefinitely. Laufer \& Schäfer (2011), for example, criticise an SHS programme in a remote area of Sri Lanka where both the service technicians and loan repayment collectors were travelling out to households independently. In a similar programme in Bangladesh, a single organisation performed both functions, effectively halving their travel time and cost.

Again, as the system components for PV-eCook are virtually identical to SHS, PV-eCook programme designers would be wise to target areas where service networks for SHS are already established, as the development of the social infrastructure required to get the necessary technical knowledge, tools and spare parts to the end-user when they need them takes considerable time, especially in very remote places (Sovacool \& D'Agostino 2012; Sumanik-Leary et al. 2013; Scott \& Batchelor 1999; Laufer \& Schäfer 2011; To et al. 2012). What is more, as SHS have an international supply chain (as will PV-eCook), enabling policies designed to support the spread of SHS (such as VAT and import tax reductions on PV panels and batteries) will clearly have a significant impact on the both initial purchase and replacement part costs for PV-eCook (Hansen 2014). Of course, end-user training is also critically important, especially for more remote households. However, by 'piggy-backing' on successful SHS initiatives, the households will already have access to services for maintaining off-grid electrical systems and training programmes can focus on cooking with electricity. 


\subsubsection{Conclusion}

Table 7 and Table 8 list the key drivers, barriers and enablers in the transition to SHS in the Global South.

\begin{tabular}{|c|c|c|}
\hline Barrier & Enabler & Sources \\
\hline $\begin{array}{l}\text { Limited range of energy services (and therefore } \\
\text { productive uses), so potential for poverty } \\
\text { alleviation limited. Potential for negative } \\
\text { perception of SHS if grid extension also } \\
\text { available. }\end{array}$ & $\begin{array}{l}\text { Growing capacity of } \\
\text { SHS systems. }\end{array}$ & $\begin{array}{l}\text { (Jacobson 2007; } \\
\text { Lemaire 2011) }\end{array}$ \\
\hline Theft of high value components. & & (Lemaire 2011) \\
\hline $\begin{array}{l}\text { Awareness low in older, poorer and less well } \\
\text { educated households }\end{array}$ & $\begin{array}{l}\text { Awareness raising } \\
\text { campaigns targeted at } \\
\text { specific groups of users. }\end{array}$ & $\begin{array}{l}\text { (Urpelainen \& } \\
\text { Yoon 2015; } \\
\text { Samad et al. } \\
\text { 2013; Sovacool } \\
\text { et al. 2011) }\end{array}$ \\
\hline $\begin{array}{l}\text { Maintenance and after sales service: success of } \\
\text { SHS programmes frequently affected by poor } \\
\text { maintenance, low quality products and lack of } \\
\text { after sales service. }\end{array}$ & $\begin{array}{l}\text { Development of } \\
\text { effective service } \\
\text { networks. } \\
\text { Local capacity building } \\
\text { for small businesses } \\
\text { and technicians. } \\
\text { Independent product } \\
\text { testing and standards. }\end{array}$ & $\begin{array}{l}\text { (Carvalho } \\
\text { Neves et al. } \\
\text { 2015; Sovacool } \\
\text { \& D'Agostino } \\
\text { 2012; Laufer \& } \\
\text { Schäfer 2011; } \\
\text { Sumanik-Leary } \\
\text { et al. 2013; } \\
\text { Scott \& } \\
\text { Batchelor 1999; } \\
\text { To et al. 2012) } \\
\end{array}$ \\
\hline $\begin{array}{l}\text { Cost issues: } \\
\text { High initial purchase costs and even monthly } \\
\text { payments make SHS difficult for poor } \\
\text { households to afford. } \\
\text { Productive uses and hence income } \\
\text { enhancement potential limited. } \\
\text { Savings on low kerosene, disposable } \\
\text { batteries etc. expenditure by poor } \\
\text { households often not enough to cover SHS } \\
\text { costs }\end{array}$ & $\begin{array}{ll}\text { - } & \text { Decrease in price of } \\
\text { LEDs and PV } \\
\text { panels } \\
\text { - } \\
\text { Extensive donor } \\
\text { support for PV } \\
\text { - } \text { Enabling national } \\
\text { policies (e.g. VAT \& } \\
\text { import tax } \\
\text { exemption) } \\
\text { - } \text { New business } \\
\text { models } \\
\text { - Fee-for-service with } \\
\text { mobile payments } \\
\text { and/or micro-credit } \\
\end{array}$ & $\begin{array}{l}\text { (Ellegård et al. } \\
\text { 2004; Hansen } \\
\text { 2014; Lemaire } \\
\text { 2011; Laufer \& } \\
\text { Schäfer 2011; } \\
\text { Jacobson 2007) }\end{array}$ \\
\hline $\begin{array}{l}\text { Every local context unique, so significant time } \\
\text { and effort required to find a system that works in } \\
\text { each new place }\end{array}$ & $\begin{array}{l}\text { Market analyses for } \\
\text { each new context to } \\
\text { determine who to target } \\
\text { and how }\end{array}$ & $\begin{array}{l}\text { (Carvalho } \\
\text { Neves et al. } \\
\text { 2015) }\end{array}$ \\
\hline
\end{tabular}

Table 7 Key barriers preventing the transition to SHS in the Global South and (where applicable) the enablers that overcame them 


\begin{tabular}{|l|l|}
\hline \multicolumn{1}{|c|}{ Driver } & \multicolumn{1}{c|}{ Sources } \\
\hline Replacement of other purchased fuels, e.g. kerosene, candles. & $\begin{array}{l}\text { (Komatsu et al. 2011; } \\
\text { Mondal \& Klein 2011; } \\
\text { Samad et al. 2013) }\end{array}$ \\
\hline $\begin{array}{l}\text { Micro-benefits highly valued by users: } \\
\text { Lighting for indoor air quality, safety, studying, social space, } \\
\text { evening work. }\end{array}$ & $\begin{array}{l}\text { (Jacobson 2007; Prasad } \\
\text { 2007; Sovacool \& } \\
\text { D'Agostino 2012; } \\
\text { Mondal \& Klein 2011; } \\
\text { Samile phone charging, TV and other 'connective' applications. }\end{array}$ \\
\hline $\begin{array}{l}\text { Inter-household power generation differences minimal as solar } \\
\text { resource geographically well correlated with people living without } \\
\text { access to electricity and power production linearly proportional to } \\
\text { the solar resource. }\end{array}$ & $\begin{array}{l}\text { (Sumanik-Leary et al. } \\
\text { 2014) }\end{array}$ \\
\hline
\end{tabular}

Table 8 The key drivers for the transition to SHS in the Global South 


\section{SECTION 3}

\section{Recommendations for eCook}

Over the preceding pages we have presented a review of experiences from a variety of transitions to cleaner cooking technologies and other energy services (SHS). In this section we draw upon these experiences to reflect upon the possible intra and inter household dynamics among African households (including the very poor) that may affect the uptake of the proposed eCook concept, in order to identify key potential market segments and make recommendations for how the eCook concept might be taken forward in a way that makes transition more likely. Firstly, a very high level market analysis is conducted using the findings from the literature review with the goal of identifying the market segments who are most likely to embrace the transition to the proposed eCook concept. It begins by comparing eCook to other clean cooking technologies. This is followed by an exploration of the interplay of existing energy access dynamics and socio-economic status in determining the most likely markets for eCook, as well as consideration of the potential influence of variation in climatic conditions, national policy frameworks and local cooking practices. We then move on to a discussion of alternative marketing strategies, which explores questions of intra-household dynamics, community engagement, participation and household decision-making processes. Finally, we consider how taking a user-focussed, locally-framed approach to the design of the eCook concept could increase its uptake.

Clearly, whilst this extremely time-limited desk-based study has been able to explore some of the major behavioural change challenges that may affect the outworking of the concept, significant gaps in terms of both breadth and depth remain. At the end of each of the three sub-sections described above, we outline some of the knowledge gaps that could be addressed by further programmes of detailed research. In particular, field trials of the eCook concept are highly recommended in order to advance thinking in all three areas, as during the course of this study many assumptions have been made about how households will engage with eCook. Detailed research is required into how people actually use the technology in different contexts and this can only be achieved through pilot studies. Specific possible lines of investigation that could ensue from this are highlighted below at the end of each section. Further research in South Africa is also recommended in order to discover whether the $2 \%$ of South Africans reportedly already cooking on solar electric systems by Republic of South Africa (2012) are actually doing so and if so, what can be learned from their experiences.

Finally, detailed programmes of empirical research are proposed to explore unresolved issues identified within the preceding sections of this paper. Of course, any such programme of empirical research would need to be supplemented by a more detailed review of the literature, as this study has only been able to present a very superficial analysis of what is an extremely voluminous sector. These should both delve further into the literatures already explored here but also introduce new foci on, for example: other energy-related transitions; the specifics of other fuel types (e.g. biogas); the social and economic implications of grid extension initiatives (within the context of recently announced extension programmes such as the last half mile scheme in Kenya) and broader topics such as those exploring technological innovation within African (and the broader Global South) contexts and not solely limited to the energy sector (e.g. mobile phones). 


\subsection{Market segmentation according to the key factors affecting household decision making}

This section aims to identify the market segments most likely to transition to eCook. Due to time restrictions, it has not been possible to locate or quantify these market segments, however, it is recognised that this would be an extremely valuable exercise and as such, a series of market assessments, which would provide a structured methodology for doing so, follows this section as the key recommendation for follow-up research.

\subsubsection{Comparison of eCook with other clean cooking interventions}

Although the analysis here draws on the range of literature reviewed in the discussion of household clean cooking transitions presented in the previous section, it draws particularly strongly upon a systematic review conducted by Puzzolo et al. (2013) on behalf of DfID which assessed the current state of our understanding of the factors affecting the uptake of clean cooking technologies. Whilst there is obviously significant overlap between them, Puzzolo et al. (2013) emphasize the need to differentiate between factors affecting the initial adoption of these technologies and those affecting their sustained use. In what follows, we draw comparisons between the key factors affecting the initial adoption, sustained use and resulting benefits of the most commonly employed clean cooking technologies and the eCook concepts. Clearly, all three are interlinked, as for example, the benefits can only be obtained by sustained use, which first requires initial adoption, yet if the benefits can be made clear to potential users through successful social marketing strategies, they can also play a role in initial uptake. It should be noted that whilst the statements made about the most commonly employed clean cooking technologies are based upon years of field experience contained within many evaluative studies, as eCook is still in the conceptual stage, the equivalent statements are predictions and reflections rather than evidence-based learnings. Although not studied in detail during the previous sections on related energy transitions, solar cookers and biogas are included here, as Puzzolo et al. (2013) include them in their review of the most widely adopted clean cooking technologies.

Firstly, Table 9 focusses on the barriers to initial adoption from an end-user perspective. It shows that eCook is likely to sit alongside LPG as an aspirational cooking technology. Its currently prohibitively high upfront cost is expected to fall over time as battery and PV manufacturing capabilities continue to grow (Hansen 2014; Batchelor 2015a), however cost is expected to remain a significant barrier particularly in the case of PV-eCook, necessitating strong accompanying financing schemes that will allow the user to repay the value of the system over time. Significant effort would also need to be put into raising awareness of this new technological option and into training users not only to adapt their cooking practices to electrical appliances, but also in the basics of electrical systems (Sovacool et al. 2011). However, eCook has broad geographical reach, arguably even broader than LPG, as it does not depend on the local availability of specific fuels or feedstocks. The PV-eCook system clearly requires a good solar resource, however the solar resource in most parts of the Global South is high, so this is not predicted to be a major barrier. In contrast, biogas digesters require a warm climate and organic matter for the feedstock, limiting their use to predominantly rural areas whilst an increasing number of studies (e.g. Ghana Energy Commission, 2014) describe the intensifying challenges of supplying charcoal to both traditional stove and ICS users. 


\begin{tabular}{|c|c|c|c|c|c|c|}
\hline & $\begin{array}{c}\text { Three } \\
\text { stone fire }\end{array}$ & $\begin{array}{l}\text { Solar } \\
\text { cookers }\end{array}$ & ICS & Biogas & LPG & eCook \\
\hline Perception & Traditional & Intermediary & Intermediary & $\begin{array}{l}\text { Intermediary/ } \\
\text { aspirational }\end{array}$ & $\begin{array}{c}\text { Aspirationa } \\
\text { I }\end{array}$ & Aspirational \\
\hline Upfront cost & None & Med & Low-Med & High & High & High (falling) \\
\hline Awareness & Universal & Low & Med & Low & Med & None \\
\hline $\begin{array}{l}\text { Land/Livestock } \\
\text { requirement }\end{array}$ & $\begin{array}{l}\text { Forest/ } \\
\text { livestock/ } \\
\text { ag. } \\
\text { residues } \\
\text { for solid } \\
\text { fuel } \\
\end{array}$ & None & $\begin{array}{l}\text { Forest/ } \\
\text { livestock/ag. } \\
\text { residues for } \\
\text { solid fuel }\end{array}$ & $\begin{array}{l}\text { Livestock/ag. } \\
\text { residues for } \\
\text { digestate }\end{array}$ & None & None \\
\hline $\begin{array}{l}\text { Environmental } \\
\text { restrictions }\end{array}$ & None & $\begin{array}{c}\text { Sunny } \\
\text { location }\end{array}$ & None & Warm location & None & $\begin{array}{c}\text { Sunny } \\
\text { location } \\
\text { (PV-eCook) }\end{array}$ \\
\hline $\begin{array}{l}\text { Training } \\
\text { requirements }\end{array}$ & Low & Med & Med & High & Med & $\begin{array}{c}\text { High (PV- } \\
\text { eCook) } \\
\text { Med (B- } \\
\text { eCook) }\end{array}$ \\
\hline
\end{tabular}

Table 9 Comparison of the key factors affecting the initial adoption of the eCook concept with the most common clean cooking interventions

Clearly, the benefits of cleaner cooking technologies can only be attained if the technology remains in sustained use, however, the degree to which each of these benefits is attained is also directly proportional to the percentage of cooking operations that are regularly replaced by the new technology. The factors affecting each technology can be seen in Table 10. Solar cookers have always suffered heavily from the fact that they can only bake during daylight hours and only on sunny days. As a result, even in favourable contexts (sunny places, where baking is common), they are reported to meet just $25-33 \%$ of cooking needs (Puzzolo et al. 2013). The sustained use of some models of ICS has been limited by the fact that designing for optimum combustion efficiency can severely limit the range of compatible pots and pans due the physical size and shape of the burner (and accompanying shroud if applicable). As a result, the range of cooking needs that they are able to meet can be equally limited. In contrast, both gas and electric hobs typically accommodate a much wider range of pots/pans. Higher power models also have the potential to make significant time savings during the cooking process itself.

The ongoing need for fuel purchase has proved to be a major limiting factor in the sustained use of LPG stoves, as poorer households often revert back to cheaper traditional cooking practices when incomes dip, especially in rural areas where firewood is available for free (Heltberg 2004). What is more, the need to purchase fuel leaves households vulnerable to supply chain issues resulting from oil price fluctuations, disruptions in the local transportation system and the withdrawal of government subsidies (Lemaire 2011). In contrast, eCook has no fuel requirements, however poorer households on pay-as-you go financing models are also likely to revert back to cheaper traditional sources of energy (if available), as the fee-forservice business model effectively mimics the purchasing of fuel (Lemaire \& Kerr 2015). What is more, battery management is likely to be a new concept for many households (unless following in the footsteps of a successful SHS initiative, as recommended previously) and cloudy days (PV-eCook) or multi-day power outages (B-eCook) will force users to revert back to traditional methods. Whilst solar cookers, ICS and biogas should be supported by a service network, the technology is relatively simpler (Puzzolo et al. 2013), which would make the provision of maintenance services by community technicians and to some extent even end-users viable. In contrast, LPG and eCook require a much greater level of technical 
knowledge and more specialist parts, making the establishment of a service network essential (STEPs 2014).

\begin{tabular}{|c|c|c|c|c|c|c|}
\hline & $\begin{array}{c}\text { Three } \\
\text { stone fire }\end{array}$ & $\begin{array}{c}\text { Solar } \\
\text { cookers }\end{array}$ & ICS & Biogas & LPG & eCook \\
\hline $\begin{array}{l}\text { Adaptability } \\
\text { to pots/pans } \\
\text { of different } \\
\text { shapes/sizes }\end{array}$ & High & High & $\begin{array}{l}\text { Often } \\
\text { restricted }\end{array}$ & High & High & High \\
\hline $\begin{array}{l}\text { Adaptability } \\
\text { to range of } \\
\text { cooking } \\
\text { practices }\end{array}$ & High & Baking only & $\begin{array}{l}\text { Often } \\
\text { focussed on } \\
\text { single } \\
\text { cooking } \\
\text { operation }\end{array}$ & $\begin{array}{l}\text { Range of gas } \\
\text { appliances } \\
\text { available }\end{array}$ & $\begin{array}{l}\text { Range of } \\
\text { gas } \\
\text { appliances } \\
\text { available }\end{array}$ & $\begin{array}{l}\text { Range of } \\
\text { electric } \\
\text { appliances } \\
\text { available }\end{array}$ \\
\hline $\begin{array}{c}\text { Flexibility of } \\
\text { preparation } \\
\text { time }\end{array}$ & Any time & $\begin{array}{c}\text { Daytime on } \\
\text { sunny days } \\
\text { only }\end{array}$ & Any time & Any time & Any time & Any time \\
\hline Speed & Baseline & Slower & Faster & Much faster & $\begin{array}{l}\text { Much } \\
\text { faster }\end{array}$ & Much faster \\
\hline Operation & $\begin{array}{c}\text { Fuel } \\
\text { collection/ } \\
\text { purchase, } \\
\text { firetending }\end{array}$ & $\begin{array}{l}\text { Orientation } \\
\text { towards sun }\end{array}$ & $\begin{array}{c}\text { Fuel } \\
\text { collection/ } \\
\text { purchase, } \\
\text { firetending }\end{array}$ & $\begin{array}{c}\text { Feedstock } \\
\text { collection \& } \\
\text { digester } \\
\text { management }\end{array}$ & $\begin{array}{c}\text { Fuel } \\
\text { purchase }\end{array}$ & $\begin{array}{c}\text { Battery } \\
\text { management }\end{array}$ \\
\hline Maintenance & Basic & $\begin{array}{l}\text { Moderate - } \\
\text { service } \\
\text { network } \\
\text { desirable }\end{array}$ & $\begin{array}{c}\text { Basic/mode } \\
\text { rate - } \\
\text { service } \\
\text { network } \\
\text { desirable }\end{array}$ & $\begin{array}{c}\text { Moderate - } \\
\text { service } \\
\text { network } \\
\text { desirable }\end{array}$ & $\begin{array}{l}\text { Difficult - } \\
\text { service } \\
\text { network } \\
\text { essential }\end{array}$ & $\begin{array}{l}\text { Difficult - } \\
\text { service } \\
\text { network } \\
\text { essential }\end{array}$ \\
\hline
\end{tabular}

Table 10 Comparison of the additional key factors affecting the sustained use of the eCook concept with the most common clean cooking interventions

Table 11 shows the various benefits that can be achieved if clean cooking technologies can be adopted into everyday cooking practices in a sustainable manner. Whilst in theory, solar cookers could offer significant benefits, in practice, their limited ability to replace solid fuels due to their lack of adaptability to different cooking practices severely limits the extent to which these benefits are obtained. It could also be argued that some variants of ICS suffer from the same challenges and more generally that they lack the transformative potential of some of the other modern cooking technologies since they only improve the efficiency of solid fuel burning, rather than replace it. Biogas, LPG and eCook all offer the highest potential to achieve the broadest transformations in cooking practices, as they are capable of completely replacing traditional cooking, although this also suggests the scale of the challenge involved in promoting such transitions and some of the potential resistances to it. It is also worth noting, however, that, eCook offers the ability to connect changes in cooking technology to upgrading a household's access to other energy services through the embedding of electrical infrastructure. Whilst this is clearly not comparable to a grid connection, as power and energy (and therefore the range of compatible energy services and the duration of their operation) are limited, it offers significant advantages over a typical SHS in terms of capacity and over an unreliable grid connection in terms of dependability. 


\begin{tabular}{|c|c|c|c|c|c|c|}
\hline & $\begin{array}{c}\text { Three } \\
\text { stone } \\
\text { fire }\end{array}$ & $\begin{array}{c}\text { Solar } \\
\text { cookers }\end{array}$ & ICS & Biogas & LPG & eCook \\
\hline $\begin{array}{l}\text { Air quality of } \\
\text { kitchen }\end{array}$ & Smoky & Moderate $^{3}$ & Moderate & Clean & Clean & Clean \\
\hline $\begin{array}{l}\text { Health } \\
\text { impact } \\
\end{array}$ & Baseline & Low $^{3}$ & Moderate & High & High & High \\
\hline Time savings & Baseline & $\begin{array}{l}\text { Low } \% \text { of } \\
\text { fuel } \\
\text { collection } \\
\text { extra time } \\
\text { cooking }\end{array}$ & $\begin{array}{c}\text { Moderate \% } \\
\text { of fuel } \\
\text { collection }\end{array}$ & $\begin{array}{l}\text { High } \% \text { of } \\
\text { fuel } \\
\text { collection \& } \\
\text { prep time }\end{array}$ & $\begin{array}{l}\text { High } \% \text { of } \\
\text { fuel } \\
\text { collection \& } \\
\text { prep time }\end{array}$ & $\begin{array}{l}\text { High } \% \text { of } \\
\text { fuel } \\
\text { collection \& } \\
\text { prep time }\end{array}$ \\
\hline $\begin{array}{c}\text { Money } \\
\text { savings }\end{array}$ & Baseline & $\begin{array}{c}\text { Low } \% \text { of } \\
\text { fuel costs }\end{array}$ & $\begin{array}{l}\text { Moderate \% } \\
\text { of fuel costs }\end{array}$ & $\begin{array}{l}\text { High \% of } \\
\text { fuel costs }\end{array}$ & $\begin{array}{l}\text { High } \% \text { of } \\
\text { fuel costs }\end{array}$ & $\begin{array}{l}\text { High \% of } \\
\text { fuel costs }\end{array}$ \\
\hline $\begin{array}{c}\text { Embedded } \\
\text { infrastructure }\end{array}$ & Baseline & None & $\begin{array}{l}\text { Occasionally } \\
\text { USB port }\end{array}$ & $\begin{array}{c}\text { Gas for } \\
\text { lighting/ } \\
\text { heating }\end{array}$ & $\begin{array}{l}\text { Fuel for } \\
\text { lighting/ } \\
\text { heating }\end{array}$ & $\begin{array}{l}\text { Electricity } \\
\text { for wide } \\
\text { range of } \\
\text { energy } \\
\text { services }\end{array}$ \\
\hline $\begin{array}{c}\text { Positive } \\
\text { environmental } \\
\text { impact }\end{array}$ & Baseline & Minimal $^{3}$ & Moderate & High & High & High \\
\hline
\end{tabular}

Table 11 Comparison of the benefits of the sustained use of the eCook concept with the most common clean cooking interventions

\subsubsection{Existing access to energy and socio-economic status}

The literature suggests that high income, well educated, urban households with unreliable grid or mini-grid connections in countries with low unit costs of electricity (and high prices for alternative fuels) who currently cook on ICS and purchase increasingly costly charcoal/fuelwood (Ghana Energy Commission 2014; EEP 2013) are likely to be the early adopters of B-eCook. Here, the awareness of and desire for access to modern energy services is likely to be higher than all other segments of society. Indeed, charcoal users in countries such as Kenya, where charcoal prices are increasing by as much as $100 \%$ per year ${ }^{4}$ would have the strongest motivation to change (EEP 2013). What is more, their ability to pay for them is also likely to be high, as they are most probably in salaried employment and can also offset their savings on fuelwood/charcoal. Likewise, uptake of PV-eCook is expected to be most rapid amongst rural households without grid connections (or likelihood of grid connection in the short to mid-term) who currently pay for fuelwood/charcoal. However, by building in locally appropriate productive uses of energy and coupling with locally appropriate financing models, eCook could be extended to those who are collecting solid fuel. Naturally, this additional functionality would provide even greater incentive for adoption in general.

By targeting regions where SHS have already had success, PV-eCook can take advantage of the technical knowledge transfer and consumer awareness of electricity and off-grid PV systems and can focus on new cooking practices. What is more, supportive policy measures and the social infrastructure required to install and maintain PV systems is more likely to be in place. By offering PV-eCook upgrades to homes with SHS (i.e. on a part-exchange basis), savings on kerosene, disposable batteries etc. can also be used to offset the PV-eCook payments, alongside firewood/charcoal savings, as lighting and 'connective' applications would add minimal additional load to a PV-eCook system. B-eCook is also potentially a

3 Due to limited displacement of solid fuels

$4 \quad 0.3 \mathrm{USD} / \mathrm{kg}$ in 2010 rising to $0.6 \mathrm{USD} / \mathrm{kg}$ in 2011 (EEP 2013). 
synergistic precursor to PV-eCook, as the urban market could potentially be leveraged to set up local service networks and create awareness before reaching the harder rural markets.

compares the level of electricity access with the level of cooking energy access in an effort to discretise the continuous population and identify which households are most likely to transition to eCook. Of course, this is a gross over-simplification of reality that does not take into account fuel-stacking, or people who have adopted a particular technology, but are unable to keep up with its ongoing costs and are therefore unable to benefit from it. However, the table is merely meant to provide a way of grouping people who have something in common so that we can focus on their behaviour momentarily, before returning to the chaotic textured reality.

Batchelor (Batchelor 2015a) tested the generalisability of these findings by comparing the South African electricity price to that in other African countries. Figure 2 shows that South Africa does have significantly cheaper electricity than many other countries. For example, assuming the price of the other fuels remains constant in all countries, B-eCook seems reasonably competitive in countries such as Egypt and Zambia due to the low cost of electricity (even given the likely cost of the battery with the eCook concept), however elsewhere, for example in Uganda, Namibia and Ghana, the cost of electricity would make it one of the most expensive energy choices ${ }^{5}$.

Figure 2 Residential electricity tariffs in selected African countries 2014, in USD cents per kWh (Batchelor et al, 2015)

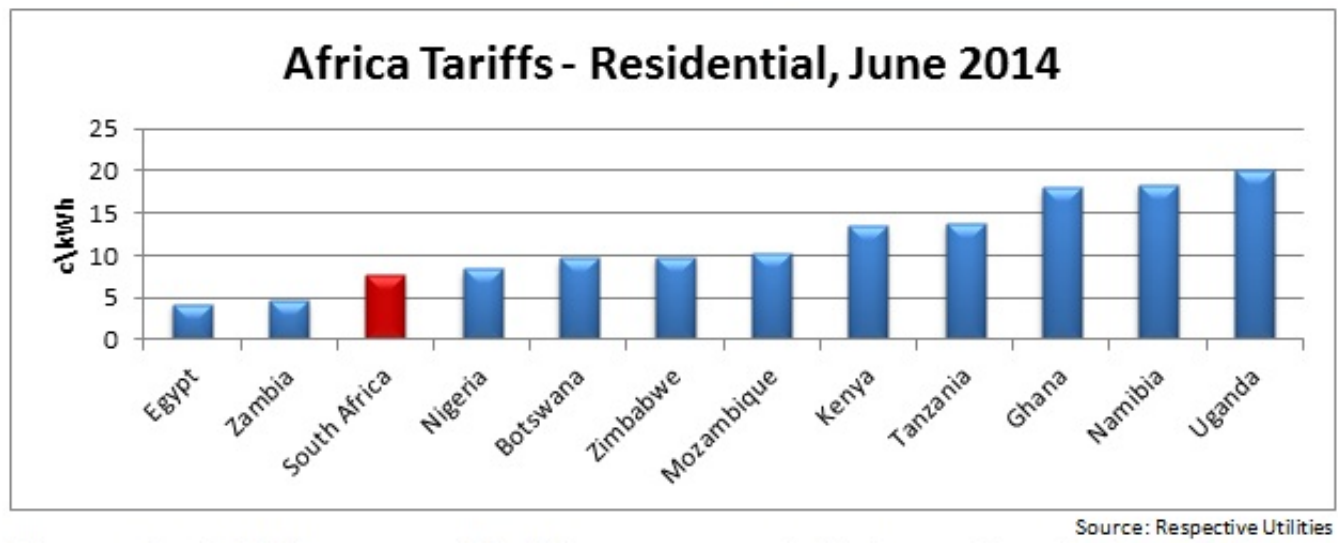


Transition to eCook very unlikely

Transition to eCook challenging as many barriers to address

Transition to eCook possible if several barriers are addressed

Transition to eCook likely if several barriers are addressed

Transition to eCook likely if key barrier addressed

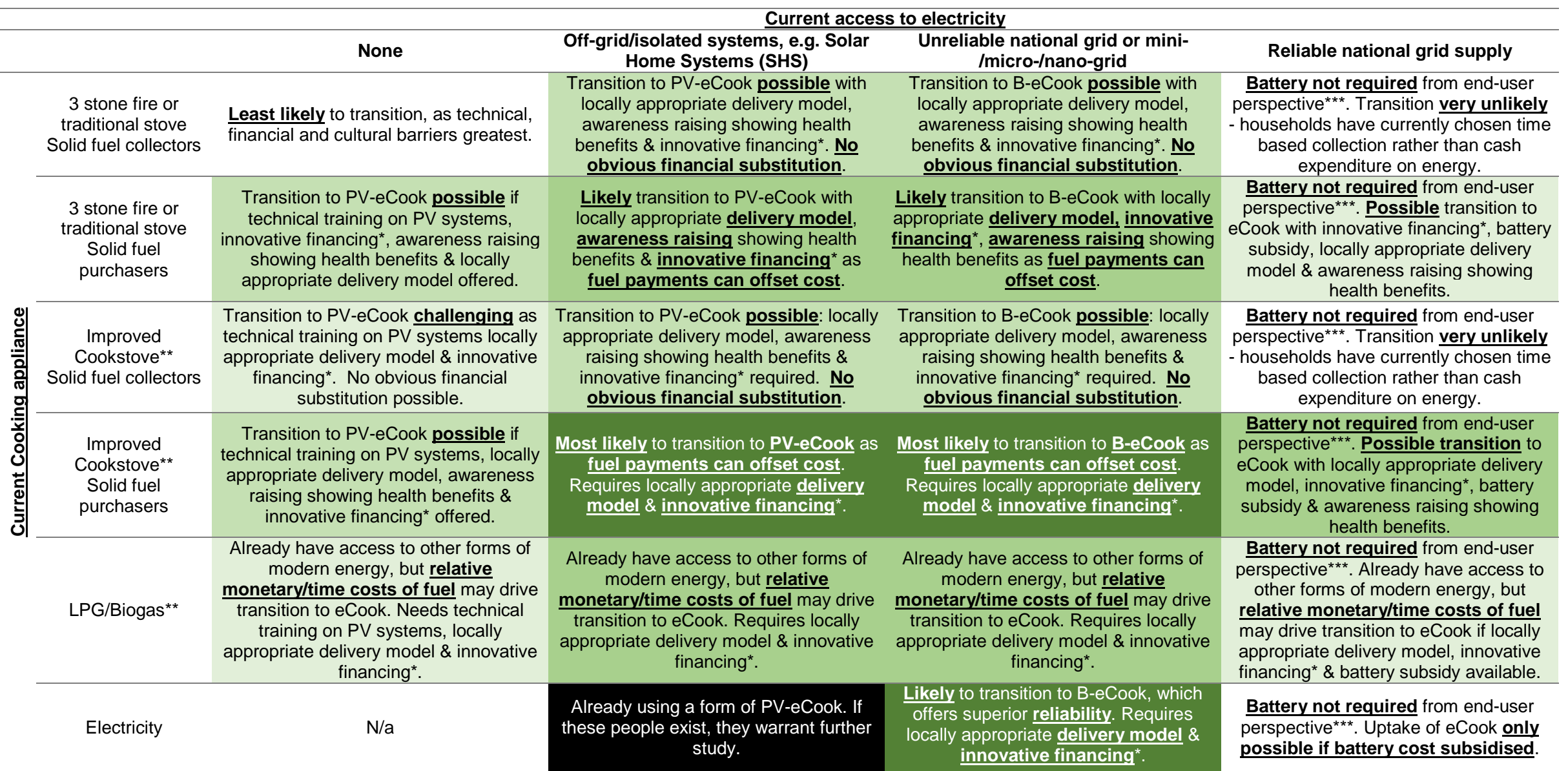

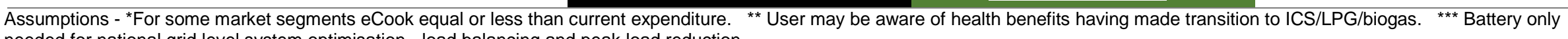
needed for national grid level system optimisation - load balancing and peak load reduction.

Table 12 Categorisation of potential eCook adopters according to existing levels of energy access and assessment of each sector's likelihood of adoption 


\subsubsection{Climate}

Places with a high solar resource throughout the year are obvious choices for PV-eCook, however locations with seasons where the solar resource is significantly reduced (e.g. during monsoon of high latitude winter) may also be viable. In such places, systems could be developed in two ways. Firstly, systems could be sized for the sunny season if users are made aware that they would need to supplement PV-eCook with their traditional fuel source during the rainy season/winter. Observations of fuel stacking in households that have recently transitioned to a cleaner cooking technology suggest that this may not necessarily be problematic (Treiber et al. 2015). Secondly, additional PV panels could be offered to households with higher incomes, both at the time of initial purchase and as an optional upgrade at a later date, once households have had an opportunity to experience the benefits that the system can offer. These higher capacity systems could also be paired with appliances that facilitate productive uses of the additional energy produced during the season of high solar resource availability, such as irrigation pumps.

Although PV panels operate more efficiently in cold conditions, uptake is expected to be slower in regions with cold climates, as traditional stoves often serve the dual purpose of cooking and space heating 6 . In such places, an assessment should be conducted of households' typical thermal energy needs and eCook should be promoted alongside suitable technologies for meeting domestic space heating requirements

\subsubsection{Local cooking practices}

Cowan (2008) noted that the poorer sectors of South African society often tend to eat lower quality cuts of meat, which tend to require longer periods of simmering (e.g. stews) or in the worst case scenario, boiling (e.g. tripe). What is more, in their global review of meat consumption patterns during the last 50 years, Sans \& Combris (2015) found that poorer households generally cook with meat less frequently than households with higher income levels. They also noted that meat consumption varies significantly between cultures, as for example, in Argentina, the average meat consumption is 20 times higher than in India.

Batchelor (2015a) further tested the geographical generalisability of Cowan's (2008) findings by conducting a similar analysis of typical dishes from other African countries. Figure 3 shows that there is a wide range of energy requirements (which would be reflected in the greater initial purchase cost of an eCook system sized accordingly), which suggests that a more detailed country by country analysis of the energy requirements of typical dishes should be conducted in order to determine where the eCook concept is likely to be most viable. Such an analysis would also need to reflect the difference in diet between the poorer and richer members of society and take into account local needs for water boiling for hot drinks and safe drinking water, washing and bathing. Naturally, because of the energy limitations of operating on economically dimensioned battery storage, eCook is expected to be most viable in cultures where the local cuisine is based upon foods that require lower energy inputs. However, it should be noted that solid fuel purchasers with higher energy diets are likely to will be spending more on fuel than those on lower energy diets and would therefore have more income to offset against the costs of an eCook system.

$6 \quad$ Practical Action highlight the correlation of increasing biomass use with altitude in Garwal Kingdom, India, specifically discussing ICS designs that allow space heating whilst still extracting smoke (Practical Action 2014) 


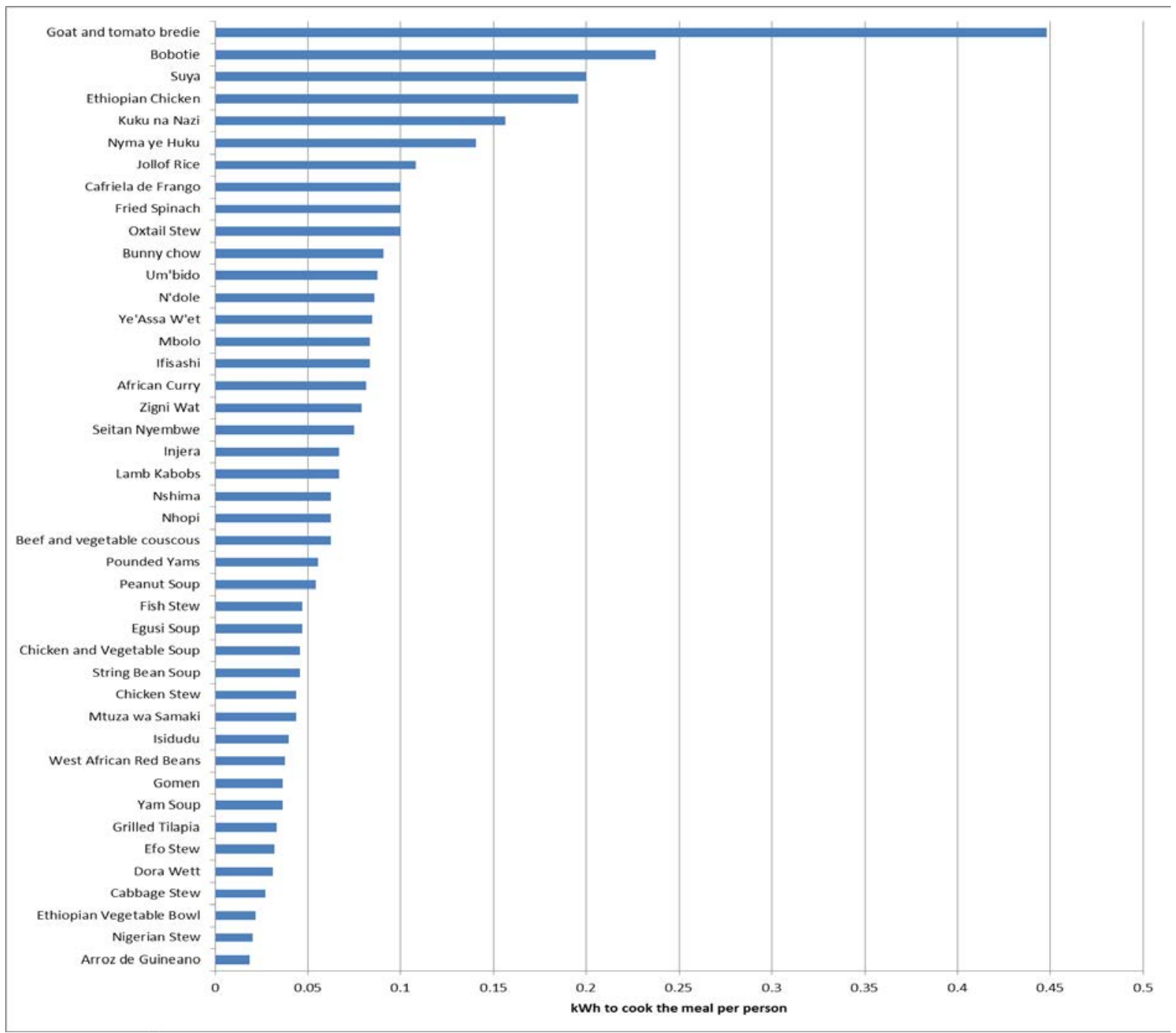

The cultural barriers to the adoption of eCook are expected to be lowest in cultures where cooking practices revolve around the preparation of single pot meals, as this is the most directly compatible with the proposed single $500 \mathrm{~W}$ hot plate. However, it is likely that the concept will continue to evolve in each market depending on the predominant local cuisine. For example, rice cookers have become prevalent amongst newly electrified households in South East Asia (Tomei et al. 2014). The power rating of such appliances is equally as important as their energy consumption, as higher power appliances require higher capacity battery banks and cabling to operate safely. For example, the electric stoves designed specifically to produce Ethiopia's staple, injera, are rated at $4 \mathrm{~kW}$ due to the large area of the hot plate (Alem et al. 2013). Whilst they can operate safely with good quality grid connections, they would require an eCook system costing many times more than the proposed 500W model. Table 13 shows that cultures where both power and energy requirements for cooking are low are most likely to transition to eCook first. 
Appliances required to prepare staple foods

\begin{tabular}{|c|c|c|c|c|}
\hline & & $\begin{array}{l}\text { Low power appliances } \\
\text { e.g. single } 500 \mathrm{~W} \text { hob }\end{array}$ & $\begin{array}{l}\text { Medium power } \\
\text { appliances } \\
\text { e.g. } 500 \mathrm{~W} \text { hob \& } 500 \mathrm{~W} \\
\text { rice cooker }\end{array}$ & $\begin{array}{l}\text { High power appliances } \\
\text { e.g. } 4 \mathrm{~kW} \text { injera stove }\end{array}$ \\
\hline \multirow{3}{*}{ 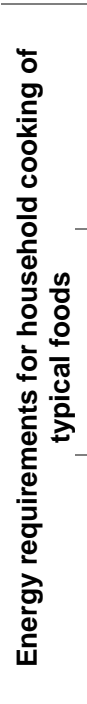 } & $\begin{array}{l}\text { Lowest energy diet } \\
1 \text { meal per day } \\
\text { Low thermal energy } \\
\text { foods (vegetables, } \\
\text { couscous etc.) } \\
\text { No water boiling }\end{array}$ & 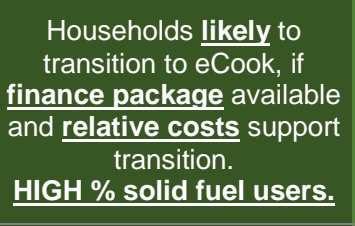 & $\begin{array}{l}\text { Higher income } \\
\text { households may transition } \\
\text { to eCook if finance } \\
\text { package available and } \\
\frac{\text { relative costs support }}{\text { transition. }} \\
\text { Avg. } \% \text { solid fuel users. }\end{array}$ & 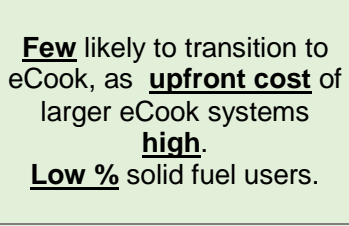 \\
\hline & $\begin{array}{c}\text { Medium energy diet } \\
2 \text { meals per day } \\
\text { Medium thermal energy } \\
\text { foods (liver, chicken, } \\
\text { potatoes etc.) } \\
\text { Water boiling for some } \\
\text { applications } \\
\end{array}$ & $\begin{array}{l}\text { Households likely to } \\
\text { transition to eCook, if } \\
\text { finance package available } \\
\text { and relative costs support } \\
\text { transition. } \\
\text { HIGH \% solid fuel users. }\end{array}$ & $\begin{array}{l}\text { Higher income } \\
\text { households may transition } \\
\text { to eCook if finance } \\
\text { package available and } \\
\text { relative costs support } \\
\text { transition. } \\
\text { Avg. \% solid fuel users. }\end{array}$ & $\begin{array}{l}\text { Few likely to transition to } \\
\text { eCook, as upfront cost of } \\
\text { larger eCook systems } \\
\text { high. } \\
\text { Low \% solid fuel users. }\end{array}$ \\
\hline & $\begin{array}{l}\text { Highest energy diet } \\
3 \text { meals per day } \\
\text { High thermal energy } \\
\text { foods (tripe, dried beans } \\
\text { etc.) } \\
\text { Water boiling for many } \\
\text { applications }\end{array}$ & $\begin{array}{c}\text { Higher income } \\
\text { households may transition } \\
\text { to eCook, but financing } \\
\text { package and relative } \\
\text { costs critical, as upfront } \\
\text { cost of larger eCook } \\
\text { systems high. } \\
\text { Avg. } \% \text { solid fuel users. }\end{array}$ & $\begin{array}{l}\text { Few likely to transition to } \\
\text { eCook, as upfront cost of } \\
\text { larger eCook systems } \\
\text { high. } \\
\text { Low \% solid fuel users. }\end{array}$ & $\begin{array}{l}\text { Very few likely to transition } \\
\text { to eCook, as upfront cost } \\
\text { of larger eCook systems } \\
\text { high. } \\
\text { Low } \% \text { solid fuel users. }\end{array}$ \\
\hline
\end{tabular}

Table 13 Effect of power and energy requirements for preparing local foods on the viability of the eCook concept

\subsubsection{National policy}

Although the potential for local manufacture of eCook is limited in comparison to ICS, efforts could still be made to link into existing distribution channels and use locally available products wherever possible in order to create local jobs, build local capacity and feed money back into the local economy. It is already possible to produce charge controllers, cabling and mounting systems in many Southern countries. PV panels generally require very specialist manufacturing facilities, however, the assembly of PV modules from imported cells is already taking place in a number of Southern countries, such as Ghana, Kenya and Ethiopia.

Naturally, uptake of eCook is expected to be higher in these countries due to both availability and affordability. With regard to batteries, lead-acid has been the standard for many years now and can already be manufactured in urban centres around the world (Aziz \& Chowdhury 2012). New possibilities are also opening up with salt batteries that are non-toxic and locally assemblable, although whether they are able to cope with the rapid discharge needed for eCook remains to be seen (Bullis 2014). Whilst this does not compare to the manufacture of ICS by local artisans, every effort should be made to ensure that as much of the value chain as possible is shifted into the country in question, as the replacement of local ICS industries may be a concern for policy makers, grass-roots advocators and potentially a source of opposition to policy support for the electric cooking concept. Of course, significant thought would need to be put into ensuring that the quality of the final eCook product remains high.

In places such as South Africa (Cowan 2008) and Southern African more generally (Ray et al. 2014), where electrification is given more focus in national policy, there is a clear advantage for the eCook concept. Countries with national policies designed to enable SHS, 
or PV in general are also likely to benefit eCook. Kenya is a good example, as conducive enabling frameworks comprising innovative financing schemes, exemptions from VAT and import taxes, standardised power-purchasing agreements and feed-in tariffs have enabled the widespread diffusion of PV through market-based methods (Hansen 2014). As part of the broader global market assessment, a detailed analysis of national energy policies should be conducted across African nations in order to determine where eCook is most likely to gain high level support.

\subsubsection{Electricity generating infrastructure}

Political support for B-eCook is likely to depend on the state of the national generating infrastructure. For example, if it were introduced in South Africa, where a significant proportion of the population is already cooking with electricity and peak demand is much higher than the base load (Howells et al. 2006), B-eCook is likely to have a positive effect on the load balancing of the grid, by shifting electricity demand for cooking from peak times in the evening and spreading it out during the day when the battery is charging. Batchelor (2015b) adds that in countries such as Kenya, where very few people are currently cooking with electricity, but peak load remains above base load (Barasa \& Aganda 2016), B-eCook would enable many households to transition without adding to peak demand, which would require costly new generation capacity (assuming that batteries were charged during offpeak times). However, in other countries, such as Nigeria or Nepal, demand exceeds supply throughout the day and new generation capacity is desperately needed. In these countries, whilst B-eCook may be beneficial from an individual point of view, from a system-level perspective, it will only make a marginal contribution to load management, as the problem of insufficient generating capacity will still have to be addressed by load shedding (rolling blackouts). In these countries, PV-eCook will provide a means of enabling people to access modern energy without causing further deterioration of inadequate grids. B-eCook will enable users to make use of intermittent electricity supplies, although the effect of connecting more users and increasing demand on the grid will not address the supply/demand gap.

Table 14 shows that countries where electric cooking has not yet been adopted and the national grid is able to keep up with growing demand are likely to offer the strongest political support for B-eCook, as in addition to offering citizens the ability to cook using modern energy, it can perform a load balancing functionality by creating additional demand for electricity outside of peak times. Conducting a Life Cycle Assessment (LCA) of both eCook concepts can help determine the systemic consequences of promoting the technology in different contexts (NREL 2015). What is more, an LCA would also be able to quantify eCook's environmental impact (and its sensitivity to key parameters), which may open up the possibility of further political support by contributing towards national and international climate change targets and attracting carbon finance. 
Transition to eCook very unlikely

Transition to eCook challenging as many barriers to address

Transition to eCook possible if several barriers are addressed

Transition to eCook likely if several barriers are addressed

Transition to eCook likely if key barrier addressed

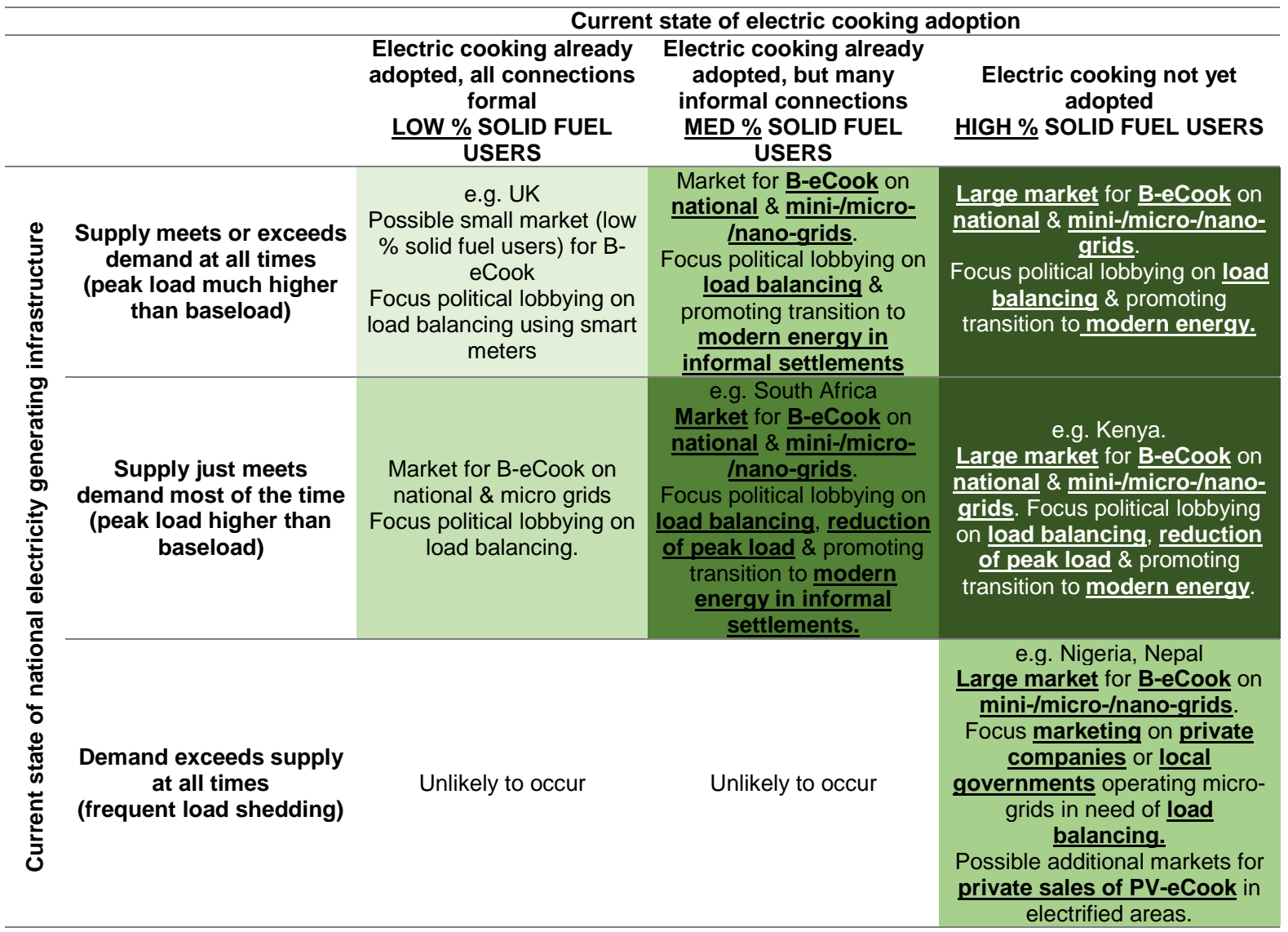

Table 14 Classification of different power generation grids according to their compatibility with the eCook concept

\subsubsection{Conclusion}

Table 15 summarises the key learning points from this section.

\begin{tabular}{|l|c|}
\hline \multicolumn{1}{|c|}{ Recommendation } & \multicolumn{1}{c|}{ Sources } \\
\hline $\begin{array}{l}\text { Low income, rural households unlikely to transition to PV- } \\
\text { eCook if relying on freely collected firewood. Focus on } \\
\text { biomass purchasers, especially charcoal purchasers, as } \\
\text { this cost can be offset against eCook payments. }\end{array}$ & $\begin{array}{c}\text { (Republic of South Africa } \\
\text { 2012; Heltberg 2004) }\end{array}$ \\
\hline $\begin{array}{l}\text { Ensure that any subsidies for eCook are well targeted } \\
\text { towards the poorest and ring fenced from capture by other } \\
\text { types of users (e.g. electric vehicles). }\end{array}$ & (Heltberg 2004; STEPs 2014) \\
\hline $\begin{array}{l}\text { Use B-eCook to set up service network and create } \\
\text { consumer awareness in urban centres before targeting } \\
\text { rural areas, as urban households with higher levels of } \\
\text { income and education are likely to transition first. They're } \\
\begin{array}{l}\text { also most likely to transition to B-eCook as they will } \\
\text { probably be grid connected. }\end{array}\end{array}$ & $\begin{array}{c}\text { (Republic of South Africa } \\
\text { 2012; Heltberg 2004) }\end{array}$ \\
\hline $\begin{array}{l}\text { Fuel stacking likely during first few years of transition, } \\
\text { especially for poorer and rural households. Create }\end{array}$ & $\begin{array}{l}\text { (Balmer 2007; Cowan 2008; } \\
\text { Republic of South Africa }\end{array}$ \\
\hline
\end{tabular}




\begin{tabular}{|l|c|}
\hline \multicolumn{1}{|c|}{ Recommendation } & \multicolumn{1}{|c|}{ Sources } \\
\hline $\begin{array}{l}\text { awareness that fuel stacking is 'ok', and help households } \\
\text { manage it rather than pretend it doesn't exist. }\end{array}$ & $\begin{array}{c}\text { 2012; Bekker et al. 2008; } \\
\text { Sebitosi \& Pillay 2005; Treiber } \\
\text { et al. 2015) }\end{array}$ \\
\hline $\begin{array}{l}\text { Reduction of peak demand by B-eCook likely to be popular } \\
\text { with policy makers and utilities in countries with electricity } \\
\text { grids that could benefit from load smoothing (and peak } \\
\text { load reduction if significant \% already cooking directly with } \\
\text { electricity). Explain implications to policy actors and create } \\
\text { dialogue around the subject. }\end{array}$ & \begin{tabular}{l} 
(Howells et al. 2006) \\
\hline $\begin{array}{l}\text { B-eCook should first be targeted in regions with low unit } \\
\text { costs for electricity. }\end{array}$
\end{tabular} \\
\hline $\begin{array}{l}\text { Target regions where SHS have already had success } \\
\text { - Technical knowledge transfer and consumer } \\
\text { awareness can focus on cooking. }\end{array}$ & $\begin{array}{c}\text { (Sovacool \& D'Agostino 2012; } \\
\text { Sumanik-Leary et al. 2013; } \\
\text { Scott \& Batchelor 1999; } \\
\text { - Social infrastructure required to install and maintain PV- } \\
\text { eCook systems already in place. }\end{array}$ \\
$\begin{array}{l}\text { Laufer \& Schäfer 2011; To et } \\
\text { al. 2012) }\end{array}$ \\
$\begin{array}{l}\text { evolly appropriate financing mechanisms have already } \\
\text { Supportive policy measures will already be in place. }\end{array}$ & \\
\hline
\end{tabular}

Table 15 Key market segmentation recommendations for eCook

\subsubsection{Further research}

\subsubsection{Transition to electric cooking in India}

Studying the transition to electric cooking in South Africa has been extremely beneficial. India is also currently undergoing a similar transition and therefore, reviewing this literature may also provide further insight.

\subsubsection{Market assessments}

This study has identified particular characteristics that may make specific market segments more likely to transition to eCook. A natural progression of this would be to develop a coordinated research programme identifying more precisely the people and places that fall into these segments using a structured methodology building upon the findings of this study. This would enable future eCook programmes to be carefully targeted where they are most likely to have an impact. Appendix D describes a potential outline methodology for such a global market assessment. One of the most important lessons derived from the experiences reviewed over the preceding pages is, however, that there will be no substitute for specific market assessments within particular national/regional contexts. As such, our second recommendation for further research is the development and trailing of a framework for conducting detailed contextual research into the delivery of eCook within specific regions that will have been identified by the global market assessment as showing particularly high potential by the global market assessment described above (again, see Appendix D for a detailed description of how this could be carried out).

\subsubsection{Building strategic alliances}

It would be worth considering new alliances that would broaden awareness of and engagement in eCook as a viable clean cooking solution. This could include GACC (the Global Alliance for Clean Cookstoves), which has been successful in coordinating major international and national stakeholders to address the clean cooking challenge, as well as ISO (International Organisation for Standardisation), Lighting Africa and WHO (World Health Organisation). It may depend on whether such agencies see this as a 'clean cooking solution' or as an 'extension of Solar Home Systems'. While DfID could lead the way, new players may be drawn into such a role, who may see it as an 'innovation led' intervention. 
Whoever coordinates the networking and alliances, it will be important to learn lessons from these organisations on how issues of local manufacture, product quality and international/national standards and certification have been dealt with in the ICS and lighting sectors and use this learning to inform the evolution of the eCook concept.

\subsubsection{Local manufacture}

The replacement of locally manufactured ICS with eCook systems built primarily on imported components may be an issue of concern, as it can increase the need for foreign exchange and eliminate local industries. Fortunately, both PV and battery manufacturing capabilities are gradually spreading across the Global South, with PV module assembly now taking place in Ghana, Kenya and Ethiopia and battery manufacturing already taking place in a much greater selection of countries. There is a need, though, for detailed research into what can realistically be locally produced in each potential market. This should initially be investigated as part of a wider market assessment and continually revisited as local industrial capacity grows. Of course, local manufacturing does not come without risks, such as the sale of poor quality products that can undermine the reputation of the technology as a whole (Kamp \& Vanheule 2015); although of course there is also a considerable risk of low quality imports that do not meet international/national standards (Lindner 2011) as has happened in solar lighting. eCook products are likely to suffer from both imitation (assembly of poor quality, inappropriately sized PV panels, batteries and electric hobs by local suppliers) and counterfeiting (manufacture of falsely branded equipment, often with disappointing performance) issues. Customers may not be able to tell the difference between imitation/counterfeit and genuine articles and as a result, the development of national standards and certification programs, coupled with support for local businesses to meet these requirements is recommended to ensure the local production of components of sufficient quality (Karakaya \& Sriwannawit 2015; Palit 2013).

\subsubsection{Adaptability and fuel stacking}

There are several themes explored in the preceding discussion which highlight the need for further research into specific themes highlighted. One of the most important of these concerns the state of our knowledge of what proportion of cooking operations are actually replaced by an electric appliance and therefore, what proportion of fuelwood/charcoal payments can households realistically be expected to use to offset eCook repayments? These estimates should then be fed into the economic modelling developed by Leach \& Oduro (2015).

We suggest the following approach to investigating this issue further:

- $\quad$ Literature review: conduct a deeper analysis of the literature on LPG and electric cooking in South Africa and elsewhere.

- $\quad$ Theory: map each cooking operation onto an electrical appliance that is specially designed to perform this function. Consider which cooking operations could be performed by a simple electric hob and make a judgement of the adequacy of this replacement.

- $\quad$ Practice: field measurements using field diaries and observation after pilot programme launched to record the actual cooking operations that are performed using the electrical system (as well as the traditional stove) and measure the actual daily time and cost savings for each family. 


\subsection{Marketing strategies}

\subsubsection{Innovative financing mechanisms}

One of the key lessons derived from our review of literature on other transitions (Pampallona \& Bollini 2014; Solar Energy East Africa 2015) suggests that direct subsidies are unlikely to be successful in promoting new energy technology interventions unless they are very carefully targeted. Instead, support for business development and removing market barriers in a similar vein to Lighting Africa's successful strategy with small-scale solar products are more likely to enable a sustainable transition to eCook. Participatory market mapping workshops (Practical Action 2014) can offer an inclusive method for identifying these barriers and producing a joint action plan that has the commitment of key stakeholders. At the same time, the potential support for eCook from governments that favour electrification over the provision of thermal energy sources could leverage support for business development activity, whilst, as suggested above, conducting an LCA of eCook could not only unlock the potential for carbon finance support, but go much further by making the influence of particular delivery models on the social, economic, energy and environmental impacts of eCook (NREL 2015).

Business models developed in different contexts, e.g. micro-finance and fee-for-service models in successful SHS initiatives, have shown particular promise and when combined with mobile payment systems, the latter of which has been shown to be particularly appropriate for reaching poorer households. Mobile enabled fee-for-service business models are much more compatible with eCook than ICS, as the electronic payment controllers needed to facilitate such a model have already been developed for SHS. It is certainly not the case that there is a 'one-size-fits-all' business model that is guaranteed to work in every local context, more that certain models can be more or less appropriate for different contexts and even fine tuning a specific model to meet local nuances can take many years (STEPs 2014; Shell Foundation 2013). As a result, following in the footsteps of tried and tested SHS business models is highly recommended.

However, the key difference between SHS and PV-eCook with regards to ownership is the overall cost of the system. Whilst SHS currently sit in the $\$ 100$ (USD) range, even the most optimistic predictions for PV-eCook state that it will still cost at least $\$ 800$ in 2020 (Leach \& Oduro 2015). There are few examples of poor households owning such high value items and therefore a utility model that focusses on service provision rather than end-user ownership may be more appropriate. In such a model, the equipment would be owned by a utility and leased to the end-user in exchange for a monthly or per-kWh fee. The major difference between this model and the micro-credit and fee-for-service models employed by most SHS initiatives is that after the initial capital cost is paid off by the end-user, they become the owner of the system and the financing mechanism is no longer needed. This is a viable option for equipment with a 2 year investment horizon, such as SHS, however according to the economic modelling conducted by Leach \& Oduro (2015), PV-eCook has been shown to be economically viable for a significant portion of potential users in 2020 with a much longer investment horizon. For poor households, such a long repayment horizon is unlikely to be attractive, consequently the involvement of a utility, who takes on the financial risk of such a long-term investment is highly recommended. In urban centres, locally appropriate business models that have proven successful for water or grid-electricity supply could be adapted for B-eCook. Whilst in the surrounding rural areas, these utility models could be adapted to build upon the successful elements of SHS business models (such as mobile enabled pay-as-yougo payment systems) in order to create a locally appropriate and attractive proposition for rural households. 


\subsubsection{Effective social marketing}

Participatory design approaches can also be used as a tool for engaging communities and encouraging participation in the development of locally appropriate solutions, thus increasing the likelihood of their adoption. The development of local cookbooks clearly stating typical cost and time savings of electric stoves has also been trialled as a promising means of both conducting research and engaging local communities. In fact, both of these techniques could be ideal vehicles for the promotion of energy efficient cooking practices, which could allow those who have already purchased an eCook product to further increase the potential of the product. Incorporating a simple battery charge indicator into the eCook product would enable the user to prioritise when they carry out these energy saving measures.

Shell Foundation (2013) share their experiences with trialling various social marketing approaches, noting that the most effective strategies know their market, match their message to context-specific purchasing triggers and barriers, get the mix right and offer a surge of social marketing activities to raise awareness of the benefits of cleaner cooking before any particular product is even mentioned.

The uptake of SHS has been limited in some locations by the fact or perception that communities are taken off the list for grid electrification if they choose to adopt SHS (Lemaire 2011). Designing PV-eCook systems in such a way that they can easily be converted into BeCook when the grid arrives and organising a resale scheme for the PV panels can help mitigate the effect of 'technological lock-in', as communities are less likely to feel 'locked-in' to PV. However, it is also true to say that in other instances SHS users have kept their panels even after the arrival of the grid due to the unreliability of the latter. From the other experiences reviewed, the expectation would be that it would be younger, better educated and richer households that would be likely to transition to eCook first, however, in order to ensure that other members of society are also able to benefit, longer term awareness raising campaigns should specifically target older, less well educated and poorer households (Urpelainen \& Yoon 2015; Samad et al. 2013; Sovacool et al. 2011).

The role of local leaders as facilitators of community decision making and promoters of the technology should also not be underestimated. In some cases, installing trial systems in their homes first has proved to be a successful means of engaging new communities in SHS (Siegel \& Rahman 2011) and a similar promotional strategy could work for eCook. Whilst these early adopters may not be the poorest in their community, they can facilitate word of mouth dissemination in places that other marketing messages simply could not reach (Shell Foundation 2013).

Batchelor (2015a) suggests that promoting eCook first and then following up with specific training programmes designed to raise awareness of simple energy saving techniques that reduce the energy needed for particular cooking activities could facilitate uptake, as immediately combining transitioning to a new fuel, with a whole series of new behaviours, could be a significant barrier to uptake for many households.

\subsubsection{Gender}

Another key theme that emerges from the discussions in Section 2 is that effective system design, distribution channels and marketing approaches for eCook should be based on a detailed analysis of the specific gender context and should ensure inclusiveness in genderappropriate ways for both men and women. For example, whilst ICS clearly offers both cost/time savings and health benefits to users, a significant barrier identified in some contexts has been the fact that in many cultures it is men who decide on capital expenditures, whilst it is women who would gain most of the benefit. As a result, engaging 
men is seen as of critical importance to the success of the proposed eCook concept. In many cases, not only is it them who must be persuaded to make the initial purchase, but they must also continue to see the value that the technology offers them so that any further repayments or additional expenditures required to maintain the system can also be justified. Electricity is the most versatile energy vector and the higher capacity of eCook makes the scope for incorporating additional appliances for both entertainment and productive uses broad.

Including women throughout the eCook value chain should clearly be a general goal for the evolution of the concept, but this is especially so in relation to marketing and after-sales service, as their likely role as the primary end-users of the technology offers far greater credibility when describing the benefits to potential customers and their motivation to perform repairs for other women in their community will be highest. In order to achieve this, it may make sense for training programmes for both entrepreneurial and technical skills to be designed specifically for women. Programmes such as the Barefoot College in India have shown that practically focussed programmes can successfully transfer the knowledge required to run an SHS business to poor women from across the Global South, who may well have lower levels of education than their male peers (Sharma 2007).

Evidence from the ICS transition shows that whilst health benefits may be a primary motivating factor for clean cooking programme designers due to reduced smoke inhalation, it is often given little importance at the household level, even by women who are at greatest risk (Mobarak et al. 2012). Consequently, marketing messages and awareness raising campaigns may be more effective if they focus on the cleanliness of the kitchen environment and the cost/time savings. Again, however, the approach taken should be tailored based on detailed assessment of what particular factors are prioritised by the specific target market and who is making purchasing decisions.

\subsubsection{Conclusion}

Table 16 summarises the key learning points from this section. 


\begin{tabular}{|c|c|}
\hline Recommendation & Sources \\
\hline Leverage policy preference for electrification where it exists. & (Ray et al. 2014) \\
\hline $\begin{array}{l}\text { International carbon finance should be investigated, ideally for } \\
\text { targeted interventions to strengthen market based systems rather } \\
\text { than direct subsidies. }\end{array}$ & $\begin{array}{l}\text { (Pampallona \& Bollini } \\
\text { 2014; Lewis \& } \\
\text { Pattanayak 2012) }\end{array}$ \\
\hline Successful local micro-finance schemes should be leveraged. & $\begin{array}{l}\text { (Pampallona \& Bollini } \\
\text { 2014; Lewis \& } \\
\text { Pattanayak 2012) }\end{array}$ \\
\hline $\begin{array}{l}\text { Well-regulated market based approaches with effective social } \\
\text { marketing strategies can be very powerful. Successful strategies } \\
\text { know the market, match message to context-specific purchasing } \\
\text { triggers \& barriers, get the mix right \& begin with a surge of social } \\
\text { marketing activities. }\end{array}$ & $\begin{array}{l}\text { (Jeuland \& Pattanayak } \\
\text { 2012; Shell } \\
\text { Foundation 2013) }\end{array}$ \\
\hline $\begin{array}{l}\text { Engage women: } \\
\text { - Include women throughout the value chain, especially in } \\
\text { product/programme design, marketing and after-sales service but } \\
\text { consider the role of men within the decision-making process in } \\
\text { different cultural contexts and ways in which the use of electricity } \\
\text { opens up potential to include benefits for men, especially when } \\
\text { they are the primary household decision makers. } \\
\text { Design training programmes specifically for women, as their } \\
\text { motivation to perform repairs will be highest, as they are the } \\
\text { primary beneficiaries }\end{array}$ & $\begin{array}{l}\text { (Hart \& Smith 2014; } \\
\text { Gill et al. 2015; To et } \\
\quad \text { al. 2012) }\end{array}$ \\
\hline $\begin{array}{l}\text { Ensure a poverty focus for market-based approaches, which have the } \\
\text { potential to reach scale, but must be carefully monitored to ensure } \\
\text { that the poor, not the profit-makers, benefit most. }\end{array}$ & $\begin{array}{l}\text { (Sesan et al. 2013; } \\
\text { Practical Action 2014; } \\
\text { Venkataraman et al. } \\
\text { 2010) }\end{array}$ \\
\hline $\begin{array}{l}\text { Assess the potential for local manufacture, whilst remaining wary of } \\
\text { the potential for counterfeit/imitation systems to damage the } \\
\text { reputation of the technology. }\end{array}$ & $\begin{array}{l}\text { (Ray et al. 2014; } \\
\text { Kamp \& Vanheule } \\
\text { 2015) }\end{array}$ \\
\hline $\begin{array}{l}\text { Identify the financing requirements and the country specific policies } \\
\text { that may affect fee-for-service business models. }\end{array}$ & (STEPs 2014) \\
\hline $\begin{array}{l}\text { Promote energy efficiency measures in follow-up training sessions } \\
\text { (instead of at initial purchase) may facilitate uptake, as it would } \\
\text { minimise the behaviour change required for initial adoption. }\end{array}$ & (Batchelor 2015) \\
\hline $\begin{array}{l}\text { Build in community engagement and participation measures that } \\
\text { may facilitate interest and uptake, e.g.: } \\
\text { - Producing and distributing marketing material that advertises the } \\
\text { low cost of eCook (in contexts where this is the case) compared } \\
\text { to other options e.g. development of local cookbooks clearly } \\
\text { stating typical cost and time savings of electric stoves } \\
\text { - Local leaders/institutions should be targeted as facilitators of } \\
\text { community decision making and promoters of the technology. } \\
\text { Public cooking competitions can be effective for engaging the } \\
\text { local population in making smarter energy choices, raising } \\
\text { awareness of eCook and measuring actual cooking times and } \\
\text { energy consumptions for local meals. }\end{array}$ & $\begin{array}{l}\text { (Cowan 2008; } \\
\text { Pampallona \& Bollini } \\
\text { 2014) }\end{array}$ \\
\hline $\begin{array}{l}\text { Offer PV-eCook upgrades to homes with SHS so that expenditure } \\
\text { savings on kerosene, disposable batteries etc. can also be used to } \\
\text { offset the PV-eCook payments. }\end{array}$ & $\begin{array}{l}\text { (Jacobson 2007; } \\
\text { Laufer \& Schäfer } \\
\text { 2011; Komatsu et al. } \\
\text { 2011; Mondal \& Klein } \\
\text { 2011) }\end{array}$ \\
\hline $\begin{array}{l}\text { Initially, target younger, better educated and richer households, but } \\
\text { focus longer term awareness raising campaigns on older, less well } \\
\text { educated and poorer households. }\end{array}$ & $\begin{array}{l}\text { (Samad et al., 2013; } \\
\text { Urpelainen \& Yoon, } \\
\text { 2015) }\end{array}$ \\
\hline
\end{tabular}

Table 16 Key marketing strategy recommendations for eCook 


\subsubsection{Further research}

\subsubsection{Thinking beyond the household}

A number of additional market segments have been identified during the course of this research that could generate additional demand for eCook. Further research is needed to investigate each of the following options:

- $\quad$ Larger systems for community services, e.g. schools, and small businesses. If distributed free of charge as a marketing strategy to these places, they could also provide a way of raising awareness of eCook.

- $\quad$ Portable systems for nomadic and semi-nomadic people.

- Specialist systems designed for rapid deployment in disaster relief scenarios.

\subsubsection{Marketing strategies}

Some of the focus in the preceding discussion has been upon the development of participatory female focussed marketing strategies and training programmes. There is a need for further work to be done on the successes and challenges faced by existing examples of such initiatives in the solar and ICS contexts, as well as the degree to which they have been accepted and/or challenged by men. During the early stages of market development, it will be important to explore a range of different female-led marketing techniques, measure uptake and explore the experiences of the entrepreneurs and their male partners/family members using a range of qualitative research techniques.

\subsubsection{Theft}

One further research question which arose whilst conducting the research for this paper was the degree to which the increasing number of PV panels on household roofs required for the PV-eCook concept might result in increased incidences of theft. This is a potentially significant issue and will require further exploration into both the incidence of panel theft in existing SHS and solar mini-/micro-/nano-grid programmes in a range of different contexts, as well as careful observational research during eCook pilot programmes.

\subsubsection{Utility business models and leasing of high value products by poor households}

This paper has focussed on the micro-credit and fee-for-service business models commonly employed by SHS initiatives, however as discussed earlier in this section, the higher cost of eCook systems (and therefore much longer investment horizon) suggests that a utility model may be more appropriate. Further research is needed into both the generic aspects of utility models and their compatibility with the eCook concept, as well as context-specific research into locally appropriate variants, the latter of which will most likely be conducted as part of a series of local market assessments. In addition to this, studying the financial mechanisms that have allowed poor households to gain access to other high value items such as motorbikes or biogas digesters would also be beneficial.

\subsection{User-focussed system design}

This final sub-section of the recommendations starts from the premise that whilst a generic eCook prototype may serve as a starting point in each new place, each context will present its own challenges and opportunities and the value of ensuring that eCook continues to evolve in tune with these cannot be overstated. As outlined above, a local market assessment (see Appendix D) should be conducted in order to determine if a significant market for eCook exists and if so, to determine how the technology should be delivered in order to achieve maximum impact for the poor. The continual evolution of eCook into a 
locally appropriate solution for meeting cooking energy demand in any potential location could be achieved using participatory design and extensive iterative field testing, an example of which is given in Appendix D.

What is more, Table 17 also lists a series of generic design modifications that could universally improve the uptake of eCook. For example, incorporating a simple battery charge indicator into the eCook concept would enable the user to prioritise when they wanted to carry out these energy saving measures, i.e. putting a lid on the pan when there's a long simmer ahead and the battery is already low. Pairing PV-eCook with locally productive applications that exploit the additional energy available during the sunniest seasons, such as irrigation pumps, also offers particular promise. However, further research is needed to determine whether these alternative applications will actually take away from the energy required for cooking as opposed to utilising the excess power. One way of addressing this would be to install electronic dataloggers on all eCook prototypes and ask participants to fill out field diaries on appliance use.

\begin{tabular}{|c|c|}
\hline Recommendation & Sources \\
\hline $\begin{array}{l}\text { Ensure early eCook devices meet the user expectations. } \\
\text { Adaptability (the ability to handle pots/pans of different } \\
\text { sizes/shapes) is particularly important. }\end{array}$ & (Pampallona \& Bollini 2014) \\
\hline $\begin{array}{l}\text { Facilitate the local evolution of PV-eCook concept through } \\
\text { participatory design/ongoing feedback from end-users. }\end{array}$ & $\begin{array}{l}\text { (Solar Energy East Africa } \\
\text { 2015; Pampallona \& Bollini } \\
\text { 2014; Sovacool \& D'Agostino } \\
\text { 2012; Sovacool et al. 2011) }\end{array}$ \\
\hline \multicolumn{2}{|l|}{$\begin{array}{l}\text { Ensure early eCook devices are sold with battery charge } \\
\text { indicators and are accompanied by training/awareness raising } \\
\text { on how to respond to indicator to ensure that users are able to } \\
\text { prioritise energy saving measures at their discretion. }\end{array}$} \\
\hline $\begin{array}{l}\text { Assess local needs for water boiling for hot drinks, washing } \\
\text { and bathing in local eCook system design evolution. }\end{array}$ & $\begin{array}{l}\text { (Cowan 2008) (Pampallona } \\
\text { \& Bollini 2014) }\end{array}$ \\
\hline $\begin{array}{l}\text { Offer additional appliances that are relevant to local lifestyles } \\
\text { and incentivise men to purchase. }\end{array}$ & (Sovacool et al. 2011) \\
\hline $\begin{array}{l}\text { Offer a portable equivalent for nomadic and semi-nomadic } \\
\text { people. }\end{array}$ & $\begin{array}{c}\text { (Sovacool \& D'Agostino } \\
\text { 2012; Batchelor et al. 1999) }\end{array}$ \\
\hline $\begin{array}{l}\text { Design PV-eCook systems to be easily converted into B-eCook } \\
\text { when the grid arrives. }\end{array}$ & $\begin{array}{l}\text { (Prasad 2007; Lemaire 2011; } \\
\quad \text { Ray et al. 2015) }\end{array}$ \\
\hline $\begin{array}{l}\text { Pair PV-eCook with productive applications, such as irrigation } \\
\text { pumps, so as to avoid trapping the poorest of the poor further } \\
\text { into poverty. }\end{array}$ & $\begin{array}{c}\text { (Sovacool \& D'Agostino, } \\
\text { 2012) }\end{array}$ \\
\hline $\begin{array}{l}\text { Offer a range of sizes (500W, } 750 \mathrm{~W}, 1 \mathrm{~kW} \text { etc.) to cater for } \\
\text { different income levels and growing demand. }\end{array}$ & (Komatsu et al. 2011) \\
\hline
\end{tabular}

Table 17 Key recommendations for the eCook concept relating to user-focused design 


\section{SECTION 4 \\ Conclusion}

This paper has assessed the behavioural change aspects of the proposed eCook concept, a device that utilises a battery to enable electric cooking in households with unreliable electricity grids ${ }^{7}$ (B-eCook) or household generation such as PV panels (PV-eCook) ${ }^{8}$. If households were to adopt the concept, it offers the potential for emission free cooking, a high potential for time/money saving and broader environmental benefits from offset fuelwood collection/purchase of charcoal purchase. However, the high upfront cost could present a potentially significant barrier to realising this potential.

\subsection{Where is this transition likely to take place first?}

Uptake of the eCook concept is predicted to be most rapid in hot climates, where there is no need for heating from a traditional stove; contexts where fuelwood/charcoal is purchased and prices are increasing most rapidly; cultures where low energy diets (fewer meals that require lower thermal input during the cooking process per meal) and low power cooking devices are the standard; and in higher income, better educated, younger households. The transition to PV-eCook is expected to take place first in rural areas without potential for grid connection in the short- or medium-term, where SHS programmes have already reached scale in a sustainable manner, developing locally appropriate delivery models and paving the way for PV-eCook. Naturally, places with high solar resource throughout the year are seen as especially favourable and high income rural households in remote areas, far away from the grid are expected to be the early adopters. B-eCook is expected to spread most rapidly in urban settlements with unreliable grid or mini-grid connections in countries with a low unit cost for electricity and would find favourable political support in countries where load balancing would be beneficial to national grid infrastructure. Of course, the relative price points of other cooking fuels is also a critical factor, which varies both geographically and temporally.

Countries with strong policy support for electrification and/or SHS (PV-eCook only) are likely to provide more favourable enabling environments for eCook initiatives and the value that load balancing (and if possible, also peak load reduction) can offer to the national electricity generation network is expected to be crucial for obtaining high level support for the concept.

\subsection{How can this transition be supported?}

eCook should be launched on the open market with a suitable service network (most likely to be created by strengthening the existing SHS infrastructure in rural areas) that is also capable of collecting feedback from end users and delivering this to relevant stakeholders. Establishing service networks for B-eCook in urban areas first would greatly facilitate the development of similar networks in the surrounding rural areas that are harder to reach. Due to the relatively high value of the eCook equipment (and therefore longer investment horizon for poor households), a utility business model (as opposed to household system ownership) is seen as the most attractive for poor households, as the utility would take on the financial

7 Unreliable national grids or fossil/renewable mini-/micro-/nano-grids.

$8 \quad$ Small wind turbines, pico-hydro turbines or other household generation systems could substitute for PV panels where appropriate. 
risk of owning the system. Training programmes should consider focussing on women, as they are the primary beneficiaries and will therefore have the greatest motivation to see the technology succeed. Bundling eCook with locally appropriate appliances can increase the value of the electrical infrastructure embedded within households. In cultural contexts where men make major household decisions, this can incentivise them both to purchase and keep up with repayments. Productive appliances that match with the availability of the solar resource such as irrigation pumps are particularly appropriate for PV-eCook, as uptake is most likely in rural areas, where few opportunities for paid work exist that could take advantage of the time saved on food preparation and/or fuel collection. Awareness raising campaigns on the benefits of clean cooking that are tailored to the market, match message to context-specific purchasing triggers/barriers and get the mix right should pave the way for eCook in new places by beginning with a surge of social marketing activities. However, in order to ensure maximum impact throughout society, longer term awareness raising campaigns should be targeted at older, less well educated and poorer households. Finally, in order to overcome the perception of PV as an inferior technology that communities can be 'locked-in' to, PV-eCook should be designed to enable quick and easy conversion to BeCook if/when the grid arrives.

This paper has sought to identify the possible intra and inter household dynamics among African households (including the very poor) that may affect the uptake of the eCook concept. In order to better understand the behavioural change challenges that may affect the outworking of the concept, longer term research is proposed, beginning with a global market assessment to identify actual places that most closely resemble the ideal context described above. In each of these places, a more detailed local market assessment can determine in what form eCook should be delivered in order to achieve maximum impact for the poorest members of society. If the results of the local market assessment are favourable, a participatory process should ensue, whereby local people can determine how eCook can best evolve to meet their needs, engaging local leaders, particularly women as champions.

Significant effort should be put into an initial social marketing campaign to raise awareness of the potential benefits of cleaner cooking, as well as the eCook concept itself. eCook can then be trialled in a significant number of households, collecting valuable data on actual energy consumption, consumer satisfaction and suggestions for further design modifications to both the generic and local variant of the concept. Finally, developing a strong working relationship with organisations that can support the eCook concept locally, nationally and internationally is seen as key and investigating the dynamics of the $2 \%$ of South Africans already reportedly cooking on solar electric systems (e.g. system design, target market segments, end-user feedback, drivers of uptake) could provide valuable further learning opportunities for eCook. 


\section{References}

Alem, Y., Hassen, S. \& Kohlin, G., 2013. The Dynamics of electric cookstove adoption: panel data evidence from Ethiopia. , 2473(557), p.26.

Allen, S., 2012. The materiality of knowledge production. Journal of Comparative Research in Anthropology and Sociology, 3(1), pp.31-51.

Aziz, S. \& Chowdhury, S.A., 2012. A description of human resource development in the Solar Home System industry in Bangladesh. In 2nd International Conference on the Developments in Renewable Energy Technology (ICDRET 2012).

Bailis, R. et al., 2009. Arresting the Killer in the Kitchen: The Promises and Pitfalls of Commercializing Improved Cookstoves. World Development, 37(10), pp.1694-1705. Available at: http://dx.doi.org/10.1016/j.worlddev.2009.03.004.

Baker, L., Newell, P. \& Phillips, J., 2014. The Political Economy of Energy Transitions: The Case of South Africa. New Political Economy, 19(6), pp.791-818.

Balmer, M., 2007. Energy poverty and cooking energy requirements: The forgotten issue in South African energy policy? Journal of Energy in Southern Africa, 18(3), pp.4-9.

Barasa, M. \& Aganda, A., 2016. Wind power variability of selected sites in Kenya and the impact to system operating reserve. Renewable Energy, 85, pp.464-471. Available at: http://linkinghub.elsevier.com/retrieve/pii/S0960148115300057.

Barstow, C.K. et al., 2014. Designing and piloting a program to provide water filters and improved cookstoves in Rwanda. PloS one, 9(3).

Baruah, B., 2015. Creating Opportunities for Women in the Renewable Energy Sector: Findings from India. Feminist Economics, 21(2), pp.53-76.

Batchelor, S., 2015a. Africa cooking with electricity (ACE), Gamos Working Paper (Draft as at August 2015). Reading, UK.

Batchelor, S., 2015b. Cooking with electricity in Africa in 2020. A transformational shift? In Royal Geographical Society Annual International Conference 2015. Exeter University, UK.

Batchelor, S. et al., 1999. Evaluating the Impact of Wind Generators in Inner Mongolia Project Technical Report, Reading, UK: DfID, Gamos Ltd. Available at: http://www.gamos.org/research-and-publications-mainmenu-26/projectdocuments/evaluating-the-impact-of-wind-generators-in-inner-mongolia-technicalreport/download.

Batchelor, S., 2014. Going Beyond Solar Electric Cooking, Gamos Concept Note, May 2014.

Batchelor, S., 2013. Is it time for Solar electric cooking for Africa?, Gamos Concept Note, May 2013, Reading, UK. Available at: http://www.gamos.org/images/documents/ls it time for Solar electric cooking for Africa 18062013.pdf accessed October 2015.

Batchelor, S. \& Scott, N., 2013. Moving Forward with Solar Electric Cooking - Phase 1, Gamos Concept Paper, June 2013. Available on request.

Bekker, B. et al., 2008. South Africa's rapid electrification programme: Policy, institutional, planning, financing and technical innovations. Energy Policy, 36(8), pp.3125-3137. Available at: http://linkinghub.elsevier.com/retrieve/pii/S0301421508001961.

Beute, N., 2012. Electrification in South Africa over the last 20 years. In Domestic Use of Energy Conference (DUE), Proceedings of the 20th Conference, pp. 55-63.

Bhattacharyya, S.C., 2012. Energy access programmes and sustainable development: A critical review and analysis. Energy for Sustainable Development, 16(3), pp.260-271. Available at: http://linkinghub.elsevier.com/retrieve/pii/S0973082612000245.

Bond, M., Fuller, R.J. \& Aye, L., 2012. Sizing solar home systems for optimal development impact. Energy Policy, 42, pp.699-709.

Bullis, K., 2014. How to Make a Cheap Battery for Storing Solar Power | MIT Technology Review. TechnologyReview.com. Available at:

http://www.technologyreview.com/demo/524466/storing-the-sun/ [Accessed October 9, 
2015].

Burwen, J. \& Levine, D.I., 2012. A rapid assessment randomized controlled trial of improved cookstoves in rural Ghana.pdf. Energy for Sustainable Development, 16, pp.328-338.

Carvalho Neves, P. et al., 2015. Assessment of locally manufactured small wind turbines as an appropriate technology for the electrification of the Caribbean Coast of Nicaragua. AIMS Energy, 3(1), pp.41-74. Available at: http://www.aimspress.com/aimse/ch/reader/view_abstract.aspx?doi=10.3934/energy.20 15.1.41 [Accessed May 14, 2015].

Cowan, B., 2008. Identification and demonstration of selected energy best practices for lowincome urban communities in South Africa, Alleviation of Poverty through the Provision of Local Energy Services.

Dinkelman, T., 2011. The effects of rural electrification on employment: New evidence from South Africa. The American Economic Review, 101(7), pp.3078-3108.

EEP, 2013. Analysing briquette markets in Tanzania, Kenya \& Uganda, Gauten, South Africa.

Ellegård, A. et al., 2004. Rural people pay for solar: experiences from the Zambia PV-ESCO project. Renewable Energy, 29(8), pp.1251-1263. Available at: http://linkinghub.elsevier.com/retrieve/pii/S0960148103003823.

Friebe, C.A., Flotow, P. von \& Täube, F.A., 2013. Exploring the link between products and services in low-income markets-Evidence from solar home systems. Energy Policy, 52, pp.760-769.

Gamos, 2015. Cooking with Electricity in Africa and Asia, Infographic attached to TOR, August 2015.

George, E., 2002. A Comparison of Wood- Burning Cookstoves for Uganda: Testing and Development. , (June), pp.1-51. Available at: http://www.repp.org/discussiongroups/resources/stoves/George/A Comparison of Woodburning.pdf\#search="fuelwood myth stoves"InC:IDocuments and SettingslivnylMy Documentslitteraturltest of improved woodstoves.pdf.

Ghana Energy Commission, 2014. Charcoal Price Tracking in Major Urban Centres of Ghana, Accra, Ghana.

Gill, B. et al., 2015. The Value of Engaging Women in the Energy Provisioning Process: $A$ Case Study on the Shramik Bharti Experience Authors, New Delhi, India.

Goodwin, N.J. et al., 2014. The Use of Behaviour Change Techniques in Clean Cooking Interventions to Achieve Health, Economic and Environmental Impact: A review of the evidence and scorecard of effectiveness, London.

GVEP, 2015. Powering households | GVEP International. Available at: http://www.gvepinternational.org/en/business/powering-households [Accessed October 8, 2015].

Hancock, K.J., 2015. The expanding horizon of renewable energy in sub-Saharan Africa: Leading research in the social sciences. Energy Research \& Social Science, 5, pp.1-8. Available at: http://www.sciencedirect.com/science/article/pii/S2214629614001558.

Hanna, R., Duflo, E. \& Greenstone, M., 2012. Up in Smoke: The Influence of Household Behavior on the Long-Run Impact of Improved Cooking Stoves,

Hansen, U.E., 2014. Review of Solar PV market development in East Africa. UNEP Ris $\varnothing$ Centre Technical University of Denmark.

Harish, S.M. et al., 2013. Adoption of solar home lighting systems in India: What might we learn from Karnataka? Energy Policy, 62, pp.697-706.

Harris, D. \& Kor, Y., 2013. The Role of Human Capital in Scaling Social Entrepreneurship. Journal of Management for Global Sustainability, 1(2), pp.163-172.

Hart, C. \& Smith, G.M., 2014. Overcoming Barriers to Clean Cookstove and Fuel Adoption: Why and How Women Must be Integrated Throughout the Value Chain. HEDON Boiling Point, (64: Barriers to Cookstoves).

Heltberg, R., 2004. Fuel switching: evidence from eight developing countries. Energy Economics, 26(5), pp.869-887. Available at: http://linkinghub.elsevier.com/retrieve/pii/S0140988304000258. 
Howells, M. et al., 2006. Beyond free electricity: The costs of electric cooking in poor households and a market-friendly alternative. Energy Policy, 34(17), pp.3351-3358. Available at: http://linkinghub.elsevier.com/retrieve/pii/S0301421505001898.

IEA, 2014. Africa Energy Outlook. A focus on the energy prospects in sub-Saharan Africa, World Energy Outlook Special Report, International Energy Agency Publication.

IED, 2012. Final Report - Support Study on Green Mini-Grid Development, Francheville. Available at:

https://www.gov.uk/government/uploads/system/uploads/attachment_data/file/278021// ED-green-min-grids-support-study1.pdf [Accessed January 8, 2015].

Jacobson, A., 2007. Connective Power: Solar Electrification and Social Change in Kenya. World Development, 35(1), pp.144-162.

Jeuland, M. a. \& Pattanayak, S.K., 2012. Benefits and costs of improved cookstoves: Assessing the implications of variability in health, forest and climate impacts. PLoS ONE, 7(2).

Kamp, L.M. \& Vanheule, L.F.I., 2015. Review of the small wind turbine sector in Kenya: Status and bottlenecks for growth. Renewable and Sustainable Energy Reviews, 49, pp.470-480. Available at: http://linkinghub.elsevier.com/retrieve/pii/S1364032115003524.

Karakaya, E. \& Sriwannawit, P., 2015. Barriers to the adoption of photovoltaic systems: The state of the art. Renewable and Sustainable Energy Reviews, 49, pp.60-66.

Karekezi, S. \& Kithyoma, W., 2002. Renewable energy strategies for rural Africa: Is a PV-led renewable energy strategy the right approach for providing modern energy to the rural poor to sub-Saharan Africa? Energy Policy, 30(11-12), pp.1071-1086.

Kebede, K., Mitsufuji, T. \& Choi, E., 2014. After-sales service and local presence: Key factors for solar energy innovations diffusion in developing countries. In PICMET conference, 28th July, 2014, Kanzawa, Japan.

Komatsu, S., Kaneko, S. \& Ghosh, P.P., 2011. Are micro-benefits negligible? The implications of the rapid expansion of Solar Home Systems (SHS) in rural Bangladesh for sustainable development. Energy Policy.

Krupa, J. \& Burch, S., 2011. A new energy future for South Africa: The political ecology of South African renewable energy. Energy Policy, 39(10), pp.6254-6261.

Laufer, D. \& Schäfer, M., 2011. The implementation of Solar Home Systems as a poverty reduction strategy -A case study in Sri Lanka. Energy for Sustainable Development.

Leach, M. \& Oduro, R., 2015. Preliminary design and analysis of a proposed solar and battery electric cooking concept : costs and pricing,

Lemaire, X., 2011. Off-grid electrification with solar home systems: The experience of a feefor-service concession in South Africa. Energy for Sustainable Development, 15(3), pp.277-283.

Lemaire, X. \& Kerr, D., 2015. Business Models for Rural Energy Services in Developing Countries: List of references and examples focusing on rural electrification, UCL Energy Institute.

Lewis, J.J. \& Pattanayak, S.K., 2012. Who adopts improved fuels and cookstoves? A systematic review. Environmental health perspectives, 120(5), pp.637-45. Available at: http://www.pubmedcentral.nih.gov/articlerender.fcgi?artid=3346782\&tool=pmcentrez\&re ndertype=abstract.

Lindner, K., 2011. Quality Issues in the market based dissemination of solar home systems. In Proceedings of the International Conference, Technische Universität Berlin, Berlin, Germany (2011).

Martinot, E., Cabraal, a. \& Mathur, S., 2001. World Bank/GEF solar home system projects: experiences and lessons learned 1993-2000. Renewable \& sustainable energy reviews, 5(1), pp.39-57.

Miller, G. \& Mobarak, A.M., 2013. Gender Differences in Preferences, Intra-household Externalities and Low Demand for Improved Cookstoves, NBER Working Paper Series.

Mobarak, A.M. et al., 2012. Low demand for nontraditional cookstove technologies. Proceedings of the National Academy of Sciences of the United States of America, 
109(27), pp.10815-20.

Mondal, A.H. \& Klein, D., 2011. Impacts of solar home systems on social development in rural Bangladesh. Energy for Sustainable Development, 15(1), pp.17-20. Available at: http://linkinghub.elsevier.com/retrieve/pii/S0973082610000724.

Nautiyal, S., 2013. A transition from wood fuel to LPG and its impact on energy conservation and health in the Central Himalayas, India. Journal of Mountain Science, 10(5), pp.898912. Available at: http://link.springer.com/10.1007/s11629-013-2698-1.

NREL, 2015. Energy Analysis - Life Cycle Assessments of Energy Technologies. Available at: http://www.nrel.gov/analysis/sustain_Ica_about.html [Accessed November 4, 2015].

Palit, D., 2013. Solar energy programs for rural electrification: Experiences and lessons from South Asia. Energy for Sustainable Development, 17(3), pp.270-279.

Pampallona, S. \& Bollini, P., 2014. A participative approach: A rural community develops, tests and adopts an improved cooking stove in India. HEDON Boiling Point, (64: Barriers to Cookstoves).

Practical Action, 2014. Poor People's Energy Outlook 2014: Key messages on energy for poverty alleviation, Rugby, UK.

Prasad, G., 2007. Electricity from solar home systems in South Africa, Rondebosch, South Africa.

Preston, K.M., 2012. Fuelwood Collection and Consumption: A Case Study in Lupeta, Tanzania. MICHIGAN TECHNOLOGICAL UNIVERSITY.

Pueyo, A., 2013. Real Time Monitoring Technologies for Pro-Poor Access to Electricity, Institute of Development Studies (IDS).

Puzzolo, E. et al., 2013. Systematic review Factors influencing the large-scale uptake by households of cleaner and more efficient household energy technologies, London: EPPI-Centre, Social Science Research Unit, Institute of Education, University of London.

Ray, C. et al., 2015. Understanding the Barriers to the Introduction and Uptake of Clean/Improved Cookstoves in Southern Africa. In Royal Geographical Society Annual Conference, University of Exeter.

Ray, C., Clifford, M. \& Jewitt, S., 2014. The introduction and uptake of improved cookstoves: Making sense of engineers, social scientists, barriers, markets and participation. HEDON, (64: Barriers to Cookstoves).

Rebane, K.L. \& Barham, B.L., 2011. Knowledge and adoption of solar home systems in rural Nicaragua. Energy Policy, 39(6), pp.3064-3075.

Republic of South Africa, 2012. A survey of energy-related behaviour and perceptions in South Africa. Available at: http://www.energy.gov.za/files/media/Pub/Survey of Energy related behaviour and perception in SA - Residential Sector - 2012.pdf.

Samad, H. a. et al., 2013. The Benefits of Solar Home Systems: An Analysis from Bangladesh. , (December), pp.1-39.

Sans, P. \& Combris, P., 2015. World meat consumption patterns: An overview of the last fifty years (1961-2011). Meat Science, 109, pp.106-111. Available at: http://www.sciencedirect.com/science/article/pii/S0309174015300115.

Scott, N. \& Batchelor, S., 1999. Small wind generators - Their impact on people. Boiling Point, (43). Available at: http://www.hedon.info/SmallWindGenerators?bl=y.

Sebitosi, a. B. \& Pillay, P., 2005. Energy services in sub-Saharan Africa: how conducive is the environment? Energy Policy, 33(16), pp.2044-2051. Available at: http://linkinghub.elsevier.com/retrieve/pii/S0301421504001004.

Sesan, T. et al., 2013. Corporate-Led Sustainable Development and Energy Poverty Alleviation at the Bottom of the Pyramid: The Case of the CleanCook in Nigeria. World Development, 45, pp.137-146. Available at: http://dx.doi.org/10.1016/j.worlddev.2012.10.009.

Sharma, D.C., 2007. Transforming rural lives through decentralized green power. Futures, 39(5), pp.583-596.

Shell Foundation, 2013. Social Marketing in India: Lessons learned from efforts to foster demand for cleaner cookstoves, 
Siegel, J.R. \& Rahman, A., 2011. The Diffusion of Off-Grid Solar Photovoltaic Technology in Rural Bangladesh. Energy, Climate, and Innovation Program (ECl) Center for International Environment and Resource Policy (CIERP), (September).

Solar Energy East Africa, 2015. Solar Energy Opportunities in East Africa. In Solar Energy East Africa. Intercontinental, Nairobi, Kenya.

Sovacool, B.K. \& D'Agostino, A.L., 2012. A comparative analysis of solar home system programmes in China, Laos, Mongolia and Papua New Guinea. Progress in Development Studies, 12(4), pp.315-335. Available at: http://pdj.sagepub.com/cgi/content/abstract/12/4/315.

Sovacool, B.K., D'Agostino, A.L. \& Jain Bambawale, M., 2011. The socio-technical barriers to Solar Home Systems (SHS) in Papua New Guinea: "Choosing pigs, prostitutes, and poker chips over panels." Energy Policy, 39(3), pp.1532-1542. Available at: http://linkinghub.elsevier.com/retrieve/pii/S0301421510009274.

STEPs, 2014. Business Models for the Delivery of Modern Thermal Energy Services: The Cases of Ghana and Tunisia, Sustainable Thermal Energy Service Partnerships.

Sumanik-Leary, J. et al., 2014. Engineering in Development: Energy, London, UK: Engineers Without Borders UK.

Sumanik-Leary, J., While, A. \& Howell, R., 2013. Small wind turbines for decentralised rural electrification: case studies in Peru, Nicaragua and Scotland. PhD Thesis, University of Sheffield.

To, L.S., Zahnd, A. \& Riek, R., 2012. Enhancing capacity for solar photovoltaics in rural Nepal. In World Renewable Energy Forum , WREF 2012 , Including World Renewable Energy Congress XII and Colorado Renewable Energy Society (CRES ).

Tomei, J. et al., 2014. New Modern Energy Consumers: Challenges for efficient cooking fuels in the Greater Mekong Subregion. HEDON Boiling Point, (64: Barriers to Cookstoves).

Treiber, M.U., Grimsby, L.K. \& Aune, J.B., 2015. Reducing energy poverty through increasing choice of fuels and stoves in Kenya: Complementing the multiple fuel model. Energy for Sustainable Development, 27, pp.54-62. Available at: http://www.scopus.com/inward/record.url?eid=2-s2.084928779376\&partnerID=tZOtx3y1.

Urmee, T. \& Harries, D., 2012. The solar home PV program in Fiji - A successful RESCO approach? Renewable Energy, 48, pp.499-506.

Urpelainen, J. \& Yoon, S., 2015. Solar home systems for rural India: Survey evidence on awareness and willingness to pay from Uttar Pradesh. Energy for Sustainable Development, 24, pp.70-78. Available at: http://linkinghub.elsevier.com/retrieve/pii/S0973082614001045.

Venkataraman, C. et al., 2010. The Indian National Initiative for Advanced Biomass Cookstoves: The benefits of clean combustion. Energy for Sustainable Development, 14(2), pp.63-72. Available at: http://linkinghub.elsevier.com/retrieve/pii/S0973082610000219.

World Bank, 2015. The State of the Global Clean and Improved Cooking Sector. , pp.1-179. 
Appendix A Electricity access and population relying on traditional biomass in sub-Saharan Africa

\begin{tabular}{|c|c|c|c|c|c|c|}
\hline & $\begin{array}{l}\text { Population without } \\
\text { electricity } \\
\text { (millions) }\end{array}$ & $\begin{array}{l}\text { National } \\
\text { electrification } \\
\text { rate(\$) }\end{array}$ & $\begin{array}{l}\text { Urban } \\
\text { electrification } \\
\text { rate (\$) }\end{array}$ & $\begin{array}{l}\text { Rural } \\
\text { eloctrification } \\
\text { rate (\$) }\end{array}$ & $\begin{array}{l}\text { Population relying on } \\
\text { traditional use of } \\
\text { biomass (x) }\end{array}$ & $\begin{array}{l}\text { Population relying on } \\
\text { traditional use of } \\
\text { biomass (millions) }\end{array}$ \\
\hline Sub-Saharan Africa & 621 & 32 & 59 & 16 & $\$ 0$ & 727 \\
\hline Angola & 15 & 30 & 46 & 6 & 56 & 12 \\
\hline Benin & 7 & 28 & 55 & 6 & 94 & 9 \\
\hline Botswana & 1 & 66 & 75 & 51 & 37 & 1 \\
\hline Burkina Faso & 14 & 16 & 54 & 2 & 95 & 16 \\
\hline Burundi & 9 & 10 & 34 & 7 & 98 & 10 \\
\hline Cameroon & 10 & 54 & 88 & 17 & 75 & 16 \\
\hline Cabo Verde & 0 & 94 & 100 & 84 & 31 & 0 \\
\hline Central African Rep. & 4 & 3 & 5 & 1 & 97 & 4 \\
\hline Chad & 12 & 4 & 16 & 0 & 93 & 12 \\
\hline Comoros & 0 & 45 & 72 & 35 & 71 & 1 \\
\hline Congo & 3 & 35 & 52 & 5 & 76 & 3 \\
\hline Cobte d'lvoire & 15 & 26 & 42 & 8 & 79 & 16 \\
\hline Dem, Rep, of Conso & 60 & 9 & 24 & 1 & 93 & 61 \\
\hline Djibouti & 0 & 50 & 61 & 14 & 14 & 0 \\
\hline Equatorial Guinea & 0 & 66 & 93 & 48 & 78 & 1 \\
\hline Eritrea & 4 & 32 & 86 & 17 & 63 & 4 \\
\hline Ethiopia & 70 & 23 & 85 & 10 & 95 & 87 \\
\hline Gabon & 1 & 60 & 64 & 34 & 21 & 0 \\
\hline Gambia & 1 & 35 & 60 & 2 & 95 & 2 \\
\hline Ghana & 7 & 72 & 90 & 52 & 84 & 21 \\
\hline Guiner & 10 & 12 & 28 & 3 & 96 & 11 \\
\hline Guinez-Bissau & 1 & 20 & 37 & 6 & 98 & 2 \\
\hline Kenyz & 35 & 20 & 60 & 7 & 84 & 36 \\
\hline Lesotho & 2 & 28 & 55 & 17 & 62 & 1 \\
\hline Liberia & 4 & 2 & 3 & 0 & 98 & 4 \\
\hline Madagascar & 19 & 15 & 37 & 4 & 98 & 22 \\
\hline Malawi & 15 & 9 & 33 & 5 & 97 & 15 \\
\hline Mali & 11 & 27 & 55 & 12 & 98 & 15 \\
\hline Mauritania & 3 & 21 & 47 & 2 & 56 & 2 \\
\hline Mauritius & 0 & 100 & 100 & 100 & 0 & 0 \\
\hline Mozambique & 15 & 39 & 66 & 27 & 96 & 24 \\
\hline Namibia & 2 & 30 & 50 & 17 & 55 & 1 \\
\hline Niger & 15 & 14 & 62 & 4 & 94 & 16 \\
\hline Nigeria & 93 & 45 & 55 & 35 & 68 & 115 \\
\hline Réunion & 0 & 99 & 100 & 87 & 10 & 0 \\
\hline Rwanda & 10 & 17 & 67 & 5 & 98 & 11 \\
\hline Sao Tome and Principe & 0 & 59 & 70 & 40 & 71 & 0 \\
\hline Senegal & 6 & 55 & 90 & 28 & 56 & 8 \\
\hline Seychelks & 0 & 97 & 97 & 97 & 0 & 0 \\
\hline Sierra Leone & 6 & 5 & 11 & 1 & 98 & 6 \\
\hline Somaliz & 9 & 15 & 33 & 4 & 96 & 10 \\
\hline South Africa & 8 & 85 & 88 & 82 & 13 & 7 \\
\hline South Sudan & 11 & 1 & 4 & 0 & 97 & 11 \\
\hline Sudan & 24 & 35 & 63 & 21 & 72 & 27 \\
\hline Swaziland & 1 & 27 & 40 & 24 & 62 & 1 \\
\hline Tanz aniz & 36 & 24 & 71 & 7 & 96 & 46 \\
\hline Togo & 5 & 27 & 35 & 21 & 95 & 6 \\
\hline Uganda & 31 & 15 & 55 & 7 & 97 & 35 \\
\hline Zambia & 10 & 26 & 45 & 14 & 83 & 12 \\
\hline Zimbabwe & 8 & 40 & 80 & 14 & 70 & 10 \\
\hline
\end{tabular}

Source; IEA, World Energy Outlook (2014)

Table 18 Electricity access and population relying on traditional biomass in sub-Saharan Africa in 2012 (Hancock, 2015) 
Appendix B Statistics from South African electric cooking transition

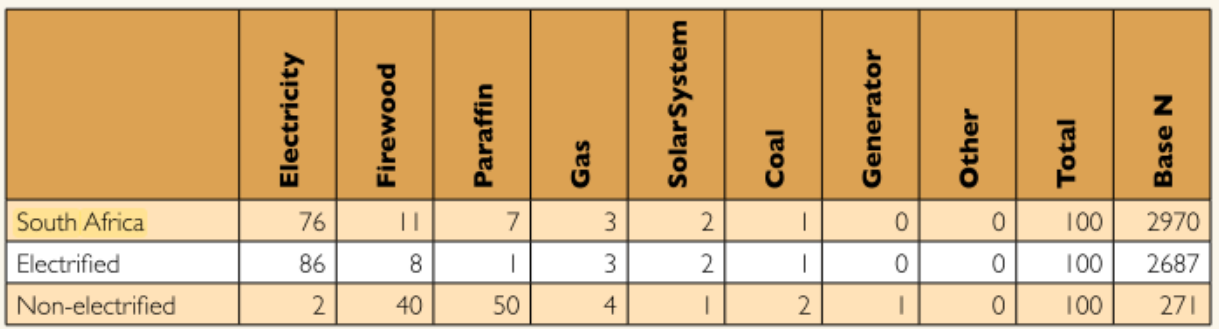

Table 19 Main energy source used for cooking by electrification status (cell percent, multiple response table) (Republic of South Africa, 2012)

Figure 4 Main energy source used for cooking, by living standard level and quintiles of per capita monthly income (percent using) (Republic of South Africa, 2012)

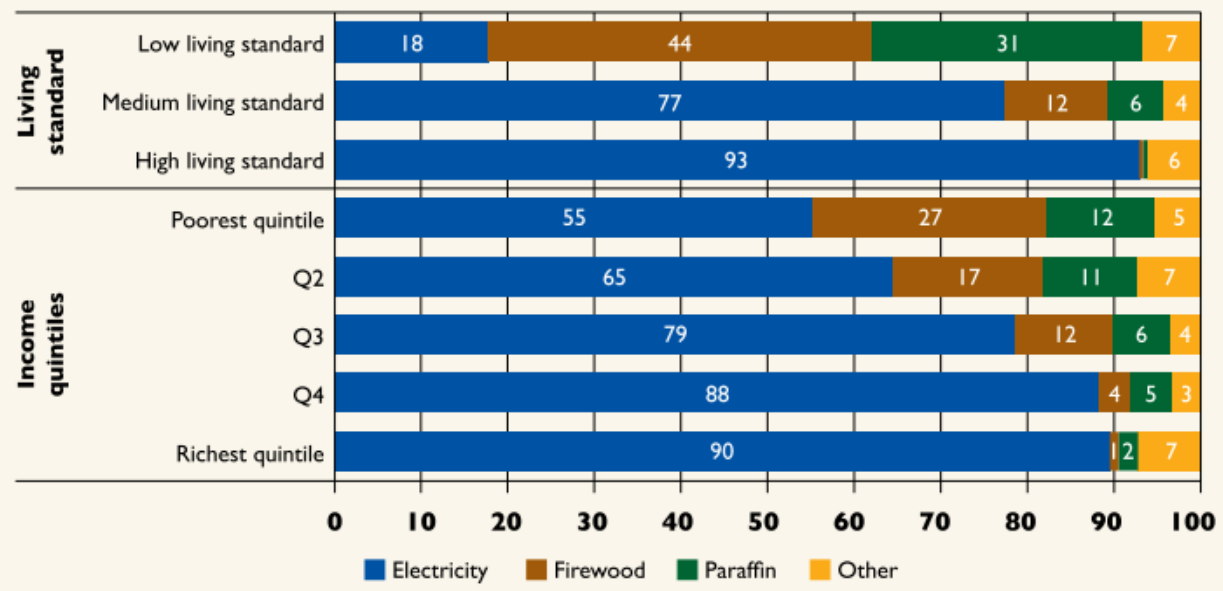

\begin{tabular}{|c|c|c|c|c|c|c|c|c|c|c|}
\hline & 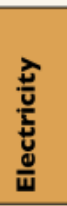 & $\begin{array}{l}\text { ¿ू } \\
\vdots \\
\vdots \\
\vdots\end{array}$ & 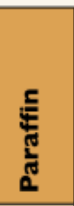 & है & 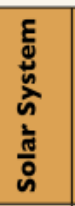 & ฮु & 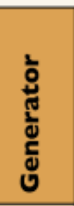 & 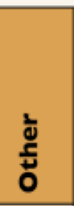 & $\begin{array}{l}\bar{J} \\
\stackrel{\text { J }}{\vdash}\end{array}$ & $\begin{array}{l}\mathbf{z} \\
\mathbf{y} \\
\tilde{y} \\
\end{array}$ \\
\hline South Africa & 76 & 11 & 7 & 3 & 2 & 1 & 0 & 0 & 100 & 2970 \\
\hline \multicolumn{11}{|c|}{ Geographic location } \\
\hline Urban formal & 91 & 1 & 2 & 3 & 2 & 0 & 0 & 0 & 100 & 1873 \\
\hline Urban informal & 68 & 1 & 27 & 0 & 2 & 1 & 1 & 0 & 100 & 239 \\
\hline Rural, trad. auth. areas & 53 & 36 & 8 & 3 & 0 & 0 & 0 & 0 & 100 & 619 \\
\hline Farms & 62 & 18 & 11 & 3 & 1 & 4 & 0 & 0 & 100 & 239 \\
\hline
\end{tabular}

Table 20 Main energy source used for cooking, by socioeconomic characteristics (cell percent, multiple response table) (Republic of South Africa, 2012) 


\begin{tabular}{|c|c|c|c|c|c|c|}
\hline $\begin{array}{l}\text { Multiple energy sources } \\
\text { for cooking }\end{array}$ & $\begin{array}{l}\text { South } \\
\text { Africa }\end{array}$ & Electrified & $\begin{array}{c}\text { Non- } \\
\text { electrified }\end{array}$ & Low & Medium & High \\
\hline Single energy use & 52 & 52 & 50 & 41 & 47 & 65 \\
\hline Electricity only & 42 & 47 & I & 5 & 37 & 62 \\
\hline Firewood only & 4 & 3 & 16 & 18 & 4 & 0 \\
\hline Paraffin only & 4 & 0 & 31 & 16 & 4 & 0 \\
\hline Gas only & 1 & 0 & 1 & 0 & 0 & 1 \\
\hline Solar system only & 1 & 1 & 1 & 1 & 1 & 0 \\
\hline Coal only & 0 & 0 & 0 & 1 & 0 & 0 \\
\hline Other source only & 0 & 0 & 0 & 0 & 0 & 0 \\
\hline Multiple energy use & 48 & 48 & 50 & 59 & 53 & 35 \\
\hline Firewood \& electricity & 11 & 12 & 0 & 7 & 16 & 4 \\
\hline Gas \& electricity & 8 & 9 & 0 & 0 & 5 & 16 \\
\hline Paraffin \& electricity & 11 & 13 & 0 & 4 & 16 & 6 \\
\hline Paraffin, firewood \& electricity & 4 & 4 & 0 & 4 & 5 & 1 \\
\hline Paraffin \& firewood & 4 & 0 & 33 & 30 & I & 0 \\
\hline Paraffin, gas \& electricity & 2 & 2 & 0 & 0 & 2 & 1 \\
\hline Gas, firewood \& electricity & 1 & 1 & 0 & 0 & 1 & 1 \\
\hline Coal \& electricity & 1 & 1 & 0 & 0 & 2 & 1 \\
\hline Paraffin \& gas & 0 & 0 & 3 & 2 & 0 & 0 \\
\hline Paraffin, gas \& firewood & 1 & 0 & 3 & 1 & 1 & 0 \\
\hline Other energy combinations & 5 & 5 & 11 & 11 & 5 & 4 \\
\hline Total & 100 & 100 & 100 & 100 & 100 & 100 \\
\hline
\end{tabular}

Table 21 Energy Choice for cooking, by electrification status and living standard (column percent) (Republic of South Africa, 2012) 
Appendix C Cooking energy cost comparison for a range of typical South African meals using a range of typical fuels
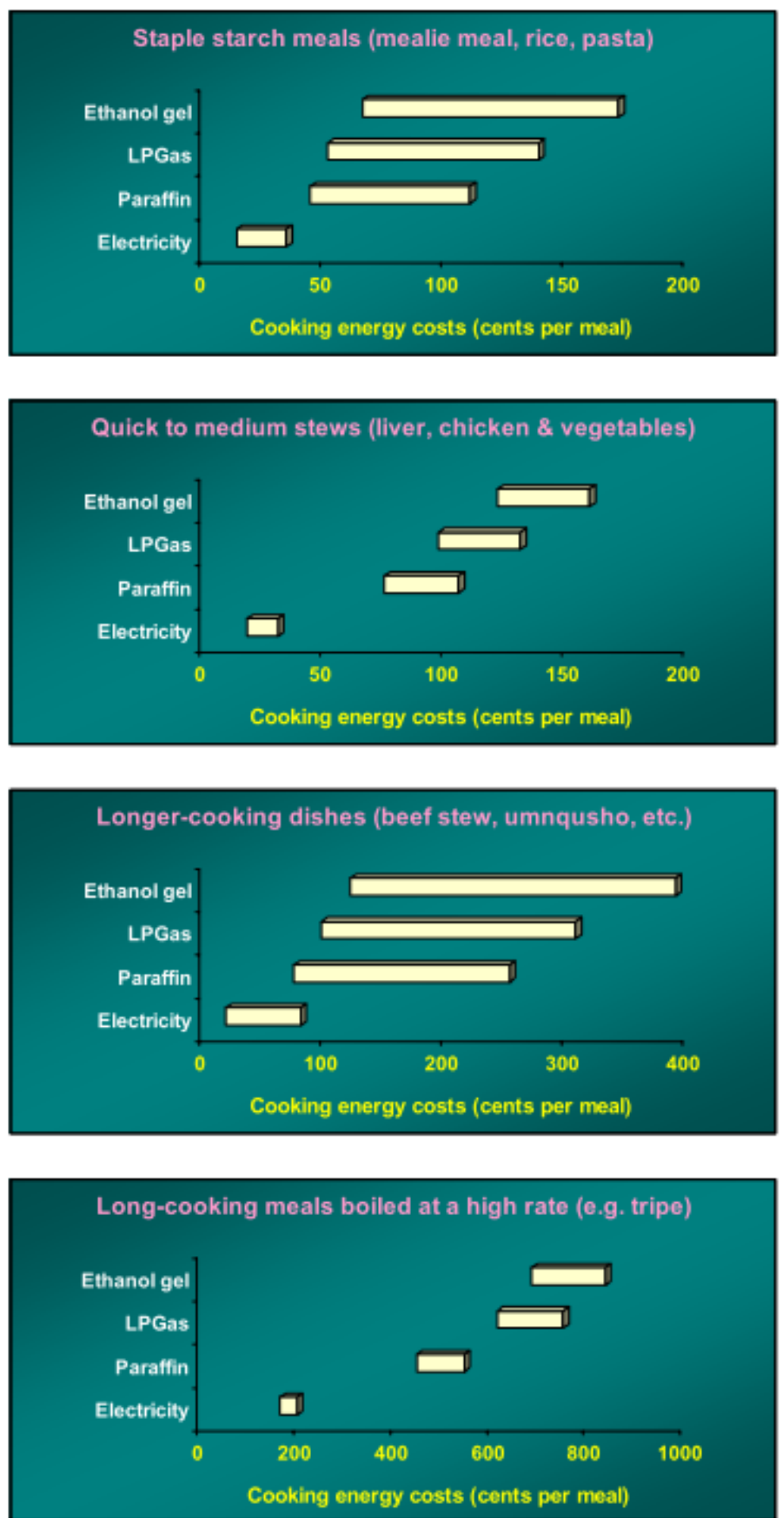

Table 22 Measured energy costs for four different meal types and four different fuels (Cowan 2008) 
Cowan's (2008) recommendations for energy efficient cooking:

- Electric kettles are a faster and more efficient way of boiling water than a pot on the stove

- Bring water to the boil as quickly as possible to minimise heat loss during the boiling process

- Avoid heat escaping round the sides of the pot by avoiding the use of small pots on big burners

- Heat food/water when needed, i.e. don't leave it to stand around

- $\quad$ Do not boil more water than needed

- $\quad$ Choose a stove with an accurate low power setting to avoid wasting energy during simmering

- $\quad$ Use a tight fitting lid and avoid stirring as much as possible

- $\quad$ Flat bottomed pots are most efficient on electric stoves

- Insulate pots if possible

- $\quad$ Cover the lid of the pot (where most heat escapes) with insulating material such as a dish cloth

- $\quad$ There may be a market for a cheap fireproof insulating shroud that fits around pots of various sizes 


\section{Appendix D Market assessment outlines}

This document presents a collection of ideas relating to how to design and carry out both a global and local market assessment for eCook. The ideas described here are by no means exhaustive and are simply meant to indicate some of the key questions that should be asked, methodologies that should be employed to investigate them and outputs that should result.

Global market assessment outline:

- Research questions:

- Where in the world is eCook a viable technology and how should it be delivered?

- $\quad$ Are there specific niche applications outside of standard household unit viable, e.g. refugee camps, schools, restaurants, hospitals and other institutions and as a mobile unit for nomadic people?

- Is eCook actually a low carbon technology and if so, how much carbon is each unit likely to mitigate?

- Methodology:

- $\quad$ Search for people and places that match the criteria defined in the preceding section as being most likely to adopt eCook.

- $\quad$ Conduct a Life Cycle Analysis (LCA) of eCook in a variety of likely scenarios in order to determine the social, energy, carbon and financial inputs/outputs of the product and their sensitivities to key parameters in order to avoid unintended developmental or environmental impacts

- $\quad$ Key outputs:

- $\quad$ Location and quantification of the key target markets to conduct more detailed national/local market assessments in

- Assessment of the ability to access carbon financing

National/Local market assessment outline:

- Research question: is eCook a viable technology for a particular new context? If so, how and where should it be delivered?

Methodology:

- Assess drivers

- What is the current price of alternative cooking fuels? Are they increasing/decreasing? Who are the main consumers?

- What is the current unit cost of electricity? Are there any subsidies available for poorer households?

- What are the local cooking cultures in each part of the region under study and within each sector of society?

- Is there a local preference (either perceived or real) for food cooked on a traditional stove? If so, is it all foods or just certain dishes or cooking operations (e.g. grilling)?

- Does national policy favour electrification or PV specifically?

- Assess demand:

- $\quad$ Assess local needs for water boiling for hot drinks, washing and bathing

- $\quad$ Conduct an energy analysis of staple foods, paying particular attention to the diet of low income households and which appliances would be most suitable for the preparation of these foods

- $\quad$ Assess barriers

- Host participatory market mapping workshop and produce joint action plan to overcome them 
- Use sales predictions from above to make an assessment of whether local supply chains are likely to be able to supply this demand.

- $\quad$ Estimate component lifetimes and the ability of local service networks to be able to repair/replace broken components

- $\quad$ Conduct an assessment of the local availability of skills and components for E-Cook manufacturing, distribution and service

- For B-eCook, assess the state of the national electricity for the relevance of load smoothing and determine the local unit cost of grid electricity.

- $\quad$ Fuel stacking likely in first few years of transition, especially in rural areas and large households. To what extent this takes place will govern the averted income that solid fuel purchasers are able to put towards eCook repayments, the sizing of the eCook systems (i.e. to meet all cooking needs, or just the everyday) and the benefits obtained.

- $\quad$ Anecdotal evidence from the ICS transitions literature suggests that the lack of 'smokiness' reduces the desirability of food cooked on traditional stoves. This may be a cultural preference and/or may depend of the type of cooking operation (i.e. grilling is more likely to affect the taste than boiling in a pot). This could be tested on a local level by conducting a blind taste test, i.e. cooking a variety of local meals on both a traditional and electric stove, serving in identical bowls (numbered on the bottom for reference) to a representative group and asking them to rate each one and guess which was cooked on the traditional stove.

Key outputs

- Identification and quantification of households most likely to transition in that particular region

- Locally appropriate strategies for facilitating that transitions

- $\quad$ Plan for how to deliver eCook 


\section{Appendix E Participatory iterative design}

The steps outlined below offer one example of the process that could be adopted for a participatory iterative design approach that would enable eCook to evolve into a culturally informed locally variant, that is therefore more likely to be adopted and remain in sustained use.

1. Begin with background research into local domestic cultural practices and evaluation of local ICS programmes.

2. Design a local eCook prototype using participatory design methods, pairing the basic concept with locally appropriate appliances and using locally available skills and materials wherever possible

3. Conduct preliminary field testing in a manner that is appropriate and sensitive to the local context, including consideration of gender

4. Redesign local eCook prototype based on piloting

5. Conduct extended field testing, with local eCook prototypes taken home by a much larger number of local women. Data collected by monitoring using electronic dataloggers, personal field diaries for each user, observation by field researchers in selected homes, interviews with selected homes, evaluative survey for all homes.

6. Redesign local eCook prototype

7. If successful up to this point, consider launching the local eCook product on the open market with a proven local financing scheme. Continue to collect data in a similar way from randomised households.

8. Redesign local eCook product

9. Create a permanent feedback mechanism from end-users to local manufacturers/distributors/installers, e.g. via a service network

10. Continual evolution of local eCook product 